\title{
SECUENCIA CONSTRUCTIVA DE LAS PLAZAS \\ EN EL GRUPO PRINCIPAL DE EL PALMAR, CAMPECHE, MÉXICO
}

\author{
Kenichiro TSUKAmoto \\ School of Anthropology, University of Arizona
}

\author{
HiRokazu Kotegawa \\ Posgrado en Antropología, Facultad de Filosofía y Letras / Instituto \\ de Investigaciones Antropológicas, Universidad Nacional Autónoma de México \\ Facultad de Antropología, Universidad Veracruzana
}

\author{
Luz Evelia Campaña \\ Proyecto Arqueológico El Palmar
}

\begin{abstract}
Resumen: La ubicación y dimensión de los espacios abiertos fueron aspectos considerados al planificar las ciudades de las Tierras Bajas Mayas en el periodo prehispánico. Las plazas eran los espacios políticos donde las élites gobernantes legitimaban a sus autoridades y manifestaban a otros participantes sus capacidades para comunicarse con los ancestros o deidades. Este trabajo se centra en la secuencia constructiva de ocho plazas en el Grupo Principal del sitio arqueológico de El Palmar, Campeche, México. Los resultados obtenidos durante las temporadas de campo en el 2007 y el 2009 indican que las grandes plazas fueron construidas durante la segunda mitad del Clásico Temprano (400-600 d.C.) y que en ellas se celebraron ceremonias públicas inscritas en los monumentos conmemorativos.
\end{abstract}

Palabras clave: plaza, El Palmar, teatro político, secuencia constructiva, antigua sociedad maya del Clásico.

ABSTRACT: The location and dimension of open spaces were important aspects involved in Maya Lowlands planning during the prehispanic period. Plazas were political spaces in which ruling elites legitimated their authorities and manifested to other participants their capacities of communication with ancestors or deities. This paper focuses on the construction sequence of eight plazas at the Main Group of El Palmar, Campeche, Mexico. The results recovered from the 2007 and 2009 fieldwork seasons indicate that large plazas were build during the second part of the Early Classic period (400-600 AD), with the erection of commemorative monuments narrating public ceremonies.

Kerwords: plaza, El Palmar, political theater, construction sequence, Classic Maya society.

ReCEPCIÓn: 31 de agosto del 2010.

ACEPTACIÓN: 24 de marzo del 2011. 


\title{
SECUENCIA CONSTRUCTIVA DE LAS PLAZAS \\ EN EL GRUPO PRINCIPAL DE EL PALMAR, CAMPECHE, MÉXICO
}

\author{
Kenichiro TSUKAmoto \\ School of Anthropology, University of Arizona
}

\author{
HiRokazu Kotegawa \\ Posgrado en Antropología, Facultad de Filosofía y Letras / Instituto \\ de Investigaciones Antropológicas, Universidad Nacional Autónoma de México \\ Facultad de Antropología, Universidad Veracruzana
}

\author{
Luz Evelia Campaña \\ Proyecto Arqueológico El Palmar
}

\begin{abstract}
Resumen: La ubicación y dimensión de los espacios abiertos fueron aspectos considerados al planificar las ciudades de las Tierras Bajas Mayas en el periodo prehispánico. Las plazas eran los espacios políticos donde las élites gobernantes legitimaban a sus autoridades y manifestaban a otros participantes sus capacidades para comunicarse con los ancestros o deidades. Este trabajo se centra en la secuencia constructiva de ocho plazas en el Grupo Principal del sitio arqueológico de El Palmar, Campeche, México. Los resultados obtenidos durante las temporadas de campo en el 2007 y el 2009 indican que las grandes plazas fueron construidas durante la segunda mitad del Clásico Temprano (400-600 d.C.) y que en ellas se celebraron ceremonias públicas inscritas en los monumentos conmemorativos.
\end{abstract}

Palabras clave: plaza, El Palmar, teatro político, secuencia constructiva, antigua sociedad maya del Clásico.

ABSTRACT: The location and dimension of open spaces were important aspects involved in Maya Lowlands planning during the prehispanic period. Plazas were political spaces in which ruling elites legitimated their authorities and manifested to other participants their capacities of communication with ancestors or deities. This paper focuses on the construction sequence of eight plazas at the Main Group of El Palmar, Campeche, Mexico. The results recovered from the 2007 and 2009 fieldwork seasons indicate that large plazas were build during the second part of the Early Classic period (400-600 AD), with the erection of commemorative monuments narrating public ceremonies.

Kerwords: plaza, El Palmar, political theater, construction sequence, Classic Maya society.

ReCEPCIÓn: 31 de agosto del 2010.

ACEPTACIÓN: 24 de marzo del 2011. 


\title{
SECUENCIA CONSTRUCTIVA DE LAS PLAZAS \\ EN EL GRUPO PRINCIPAL DE EL PALMAR, CAMPECHE, MÉXICO
}

\author{
Kenichiro TSUKAmoto \\ School of Anthropology, University of Arizona
}

\author{
HiRokazu Kotegawa \\ Posgrado en Antropología, Facultad de Filosofía y Letras / Instituto \\ de Investigaciones Antropológicas, Universidad Nacional Autónoma de México \\ Facultad de Antropología, Universidad Veracruzana
}

\author{
Luz Evelia Campaña \\ Proyecto Arqueológico El Palmar
}

\begin{abstract}
Resumen: La ubicación y dimensión de los espacios abiertos fueron aspectos considerados al planificar las ciudades de las Tierras Bajas Mayas en el periodo prehispánico. Las plazas eran los espacios políticos donde las élites gobernantes legitimaban a sus autoridades y manifestaban a otros participantes sus capacidades para comunicarse con los ancestros o deidades. Este trabajo se centra en la secuencia constructiva de ocho plazas en el Grupo Principal del sitio arqueológico de El Palmar, Campeche, México. Los resultados obtenidos durante las temporadas de campo en el 2007 y el 2009 indican que las grandes plazas fueron construidas durante la segunda mitad del Clásico Temprano (400-600 d.C.) y que en ellas se celebraron ceremonias públicas inscritas en los monumentos conmemorativos.
\end{abstract}

Palabras clave: plaza, El Palmar, teatro político, secuencia constructiva, antigua sociedad maya del Clásico.

ABSTRACT: The location and dimension of open spaces were important aspects involved in Maya Lowlands planning during the prehispanic period. Plazas were political spaces in which ruling elites legitimated their authorities and manifested to other participants their capacities of communication with ancestors or deities. This paper focuses on the construction sequence of eight plazas at the Main Group of El Palmar, Campeche, Mexico. The results recovered from the 2007 and 2009 fieldwork seasons indicate that large plazas were build during the second part of the Early Classic period (400-600 AD), with the erection of commemorative monuments narrating public ceremonies.

Kerwords: plaza, El Palmar, political theater, construction sequence, Classic Maya society.

ReCEPCIÓn: 31 de agosto del 2010.

ACEPTACIÓN: 24 de marzo del 2011. 



\title{
SECUENCIA CONSTRUCTIVA DE LAS PLAZAS EN EL GRUPO PRINCIPAL DE EL PALMAR, CAMPECHE, MÉXICO
}

\author{
Kenichiro TSUKAmoto \\ School of Anthropology, University of Arizona \\ HiRokAZU Kotegawa \\ Posgrado en Antropología, Facultad de Filosofía y Letras / Instituto de Investi- \\ gaciones Antropológicas, Universidad Nacional Autónoma de México \\ Facultad de Antropología, Universidad Veracruzana \\ LuZ Evelia CAmpaña \\ Proyecto Arqueológico El Palmar
}

\section{Introducción}

En las Tierras Bajas Mayas, la construcción y remodelación de la plaza estaba relacionada con la organización política (Inomata, 2006; Restall, 2001; Ringle y Bey III, 2001; Sharer y Golden, 2004). Recientes estudios arqueológicos, epigráficos e iconográficos han profundizado sobre la organización política, particularmente sobre la institución encabezada por el Ajaw, que se fundó en el periodo Preclásico Tardío (250 a.C.-250 d.C.) (Freidel y Schele, 1988) y floreció durante todo el Clásico (250-900 d.C.). Las élites gobernantes fueron promotoras de la construcción de estructuras monumentales, del desarrollo de guerras, de la erección de monumentos conmemorativos y de la celebración de sacrificios humanos y rituales públicos. Durante periodos de agitación política, ejecutaron esas actividades de manera acelerada para mantener su autoridad política, no siempre estable. Una de las estrategias de la institución Ajaw para la legitimización del poder fue quizás el teatro político, hipótesis originalmente propuesta por Geertz (1980) al estudiar la sociedad de Bali en el siglo xIx (Demarest, 1992; Houston,

Agradecemos al Instituto Nacional de Antropología e Historia (INAH), institución que otorgó los permisos C.A. 401-361/138 y C.A. 401-36/0837 para realizar el proyecto arqueológico El Palmar: Urbanización del espacio social en las tierras bajas mayas. Reconocemos de manera especial al arqueólogo Javier López Camacho, de la Escuela Nacional de Antropología e Historia (ENAH), quien es codirector del proyecto. Asimismo a Octavio Esparza Olguín, Alejandra Salinas, Tatsuya Murakami, Yuki Tanaka, estudiantes de la enAH, y a los trabajadores locales del ejido Kiché las Pailas, por su participación desinteresada. Finalmente, a Takeshi Inomata y Daniela Triadan por su apoyo académico. El proyecto fue financiado por la SBSRI Pre-doctoral Grant de la Universidad de Arizona. 
1998; Sharer y Golden, 2004), quien sugirió que la razón de existir del Estado era mantener el teatro político (Inomata, 2006: 808). Turner (1986) y Schechner (1985) indican que en cualquier sociedad los rituales públicos tienen un carácter teatral; sin duda, estos tuvieron un carácter teatral en la antigua sociedad maya del Clásico, a juzgar por las reiteradas representaciones grabadas en sus monumentos escultóricos. Los personajes que aparecen en estos últimos, por lo regular llevan máscaras, ornamentos, bastones ceremoniales y atavíos espléndidos, los cuales pudieron haber complementado el carácter teatral de rituales públicos. Con el fin de utilizar el teatro político como espectáculo, las plazas públicas fueron el escenario propicio para concentrar y acomodar a la población o a grupos seleccionados de la sociedad, dependiendo de la dimensión y ubicación de los espacios abiertos. En este sentido, su construcción y remodelación revelaría las huellas de una cultura material donde la gente consentía o era coercionada por las decisiones políticas de la élite gobernante, pues la mayor parte de la población debió participar en la erección de obras monumentales, incluidos los espacios públicos. Así, a través del estudio de su secuencia constructiva y de los materiales arqueológicos asociados es factible aproximarse al papel de los rituales públicos en la sociedad maya y al comportamiento de la población ante el teatro político de las élites gobernantes.

El presente trabajo presenta la secuencia constructiva de ocho plazas del Grupo Principal en el sitio arqueológico de El Palmar, ubicado al sureste de Campeche, México, como un caso de estudio.

\section{El Palmar}

El Palmar posee un carácter peculiar en cuanto a su ubicación. Se localiza en el sureste de Campeche, México, relativamente cerca de varios centros mayores: $90 \mathrm{~km}$ al sur se ubica Tikal; $50 \mathrm{~km}$ al oriente, Calakmul; y $70 \mathrm{~km}$ al norte, Becán (figura 1). En sus inmediaciones se encuentran también Mucaancah, Río Azul, Los Alacranes, La Milpa, Río Bec y Altar de los Reyes (Šprajc, 2008). De acuerdo con Adams y Jones (1981), esta área fue ocupada por tres esferas geopolíticas (Tikal, Calakmul y Río Bec) durante el Clásico Tardío y, por su localización, El Palmar pudo haber sido el centro de gravedad limítrofe de las tres regiones. Además de los conflictos políticos entre Tikal y Calakmul, en los sitios de la región Río Bec, como Becán, Río Bec y Hormiguero, se construyeron estructuras monumentales con un estilo arquitectónico propio durante el Clásico Tardío (600-800 d.C.) (Bueno, 1999; Campaña, 2005). Es decir, en términos de las interacciones políticas, los años transcurridos entre el 400 d.C. y el 700 d.C. debieron constituir un periodo dinámico y es probable que la participación de El Palmar fuera inevitable en los asuntos políticos.

Los recorridos de superficie y el levantamiento topográfico han detectado que

El Palmar tiene al menos otros ocho grupos arquitectónicos agrupados dentro de 


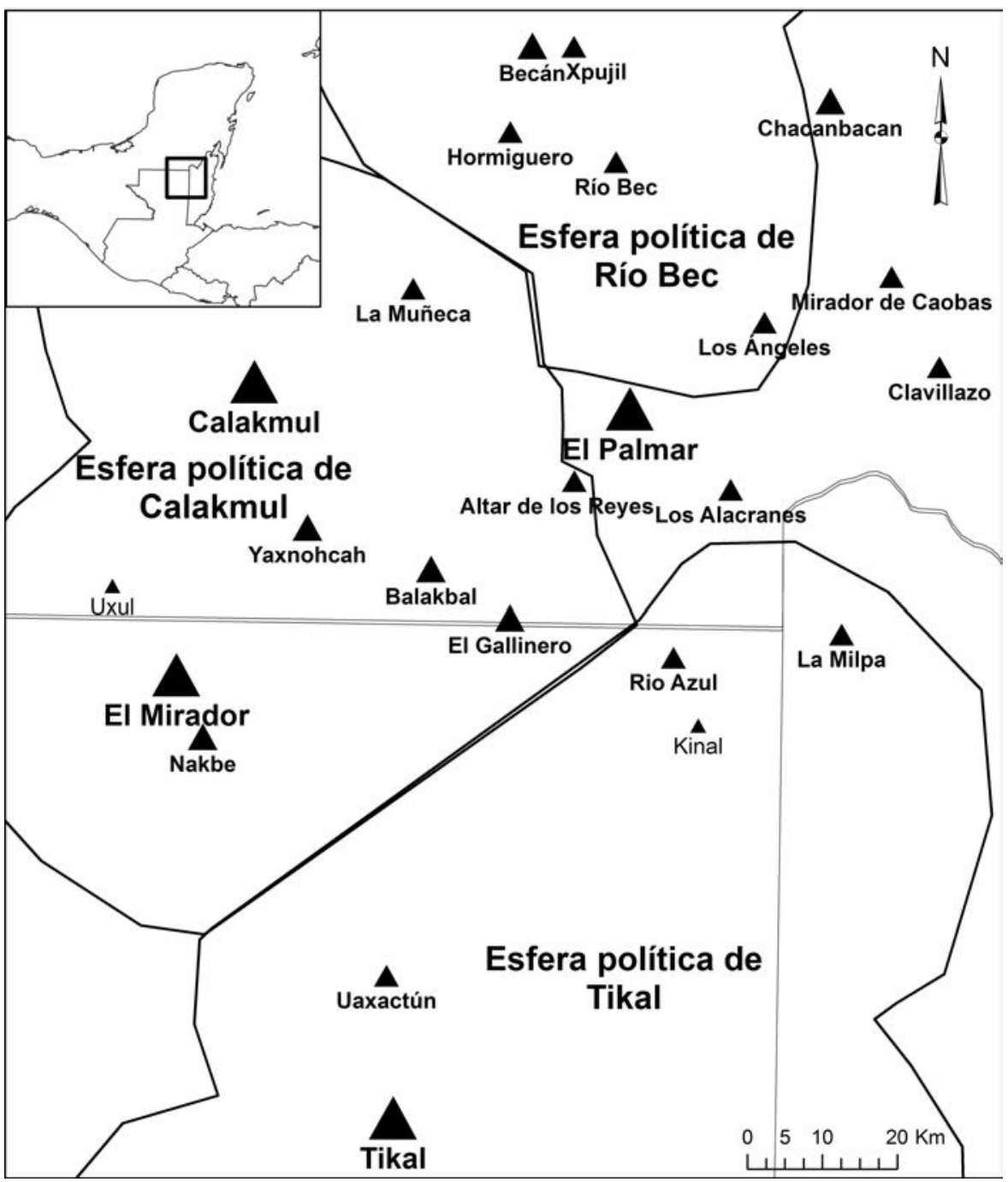

Figura 1. Mapa de esferas políticas en las Tierras Bajas Mayas, basado en Adams y Jones, 1981: 309

un radio máximo de $2.5 \mathrm{~km}$ a partir del Grupo Principal. En la configuración espacial del Grupo Principal destacan dos templos piramidales, un extenso palacio, una gran cantidad de los monumentos grabados y, por supuesto, las plazas (Tsukamoto, López Camacho y Esparza Olguín, 2010; Tsukamoto y López Camacho, 2007) (figura 2). El diseño planificado del Grupo Principal contiene ocho plazas con dimensiones distintas: la Gran Plaza, la Plaza Central, la Plaza K'awiil, las Plazas E, F, G y H, y la Plaza López. 


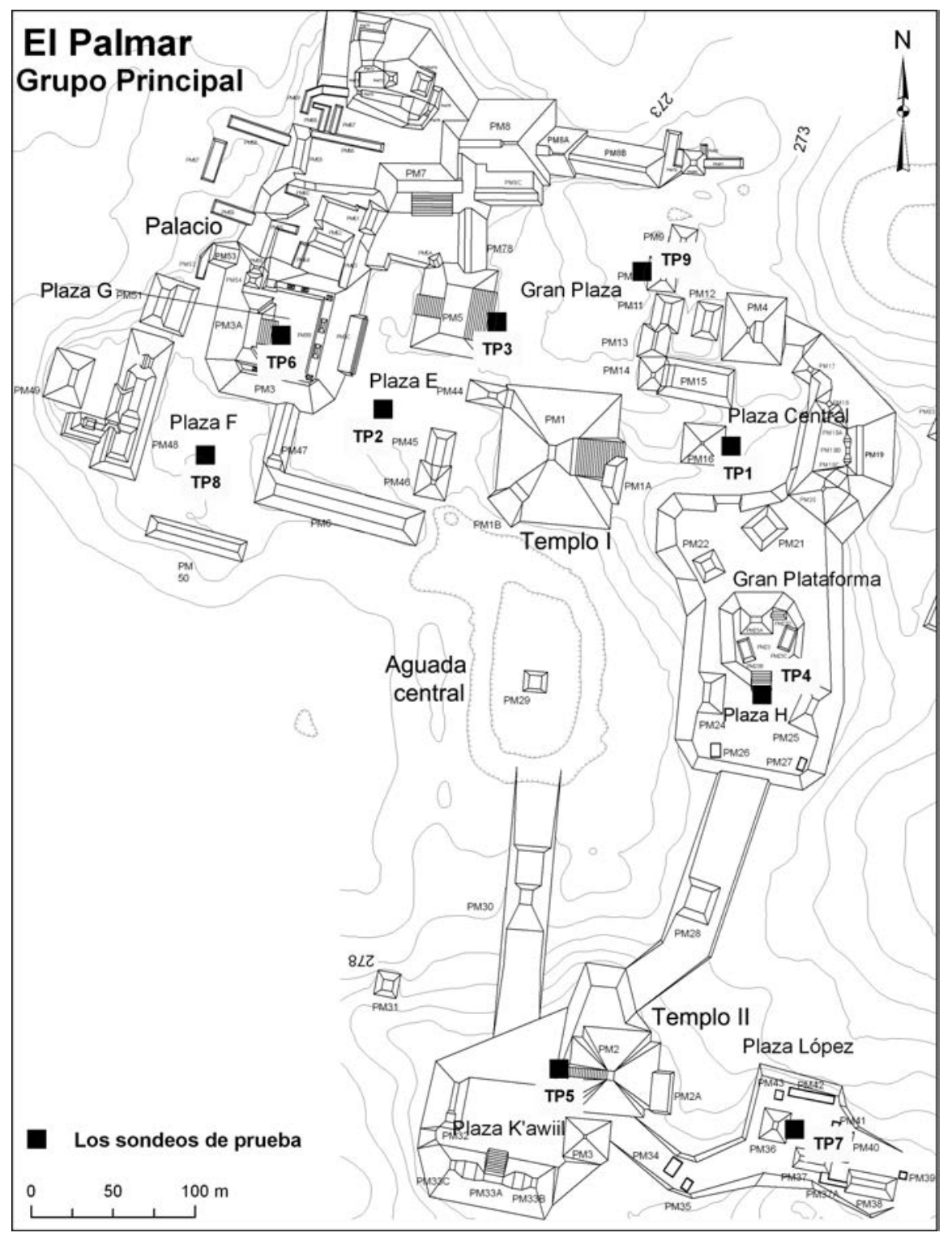

Figura 2. Plano del Grupo Principal de El Palmar con la ubicación de las excavaciones estratigráficas, dibujado por Kenichiro Tsukamoto y Javier López Camacho

La Gran Plaza es la más extensa, tiene una superficie de $14135 \mathrm{~m}^{2}$ y se encuentra en la parte norte del Grupo Principal. En el espacio abierto fueron colocados 11 monumentos grabados, cuatro de ellos (Estelas 8, 7, 10 y 16) con 
registros calendáricos para los años 721, 731, 746 y 800 d.C., respectivamente (Thompson, 1936). La Plaza Central, al sureste de la Gran Plaza, alcanza un área de $6674 \mathrm{~m}^{2}$ y contiene un complejo arquitectónico del tipo "Grupo E", considerado un espacio conmemorativo para rituales públicos (Aimers y Rice, 2006; Clark y Hansen, 2001; Joyce, 2001; Laporte y Fialko, 1995).

Al sur se ubica la Plaza K'awiil, con una superficie de $3161 \mathrm{~m}^{2}$, caracterizada por una ligera elevación sobre la cual desplanta el Templo II. Exhibe varios monumentos grabados, entre los cuales hay una estela con la fecha 884 d.C. (Estela 41) y un altar con una Rueda Calendárica del 554 d.C. Las Plazas E (9096 m²), F (6 134 $\left.\mathrm{m}^{2}\right)$ y G $\left(1877 \mathrm{~m}^{2}\right)$ se encuentran al suroeste de la Gran Plaza; en la Plaza E hay un monumento con registro del año 820 d.C. (Estela 14). La Plaza G constituye un espacio privado, pues está rodeada por estructuras abovedadas similares, se eleva $10 \mathrm{~m}$ sobre la superficie de la Plaza E, y se integra al sector del Palacio.

La Plaza H $\left(3130 \mathrm{~m}^{2}\right)$ se localiza sobre la Gran Plataforma, cuya elevación pudo haber configurado un espacio restringido. Finalmente, la Plaza López es un espacio pequeño $\left(890 \mathrm{~m}^{2}\right)$ al este de la Plaza K'awiil, donde no se han descubierto monumentos grabados.

\section{Secuencia constructiva de las plazas en el Grupo Principal de El Palmar}

Si bien el levantamiento topográfico ha permitido representar la configuración espacial de las ocho plazas, nueve sondeos estratigráficos de 2 × $2 \mathrm{~m}$ realizados durante la temporada de campo 2009 han revelado su dimensión temporal. Los resultados sugieren que el Grupo Principal fue ocupado desde el Preclásico Tardío (250 a.C.-250 d.C.) hasta el Clásico Terminal (800-1000 d.C.). El plan de construcción de los espacios públicos fue realizado de manera intensa durante el Clásico Medio (400-700 d.C.). A continuación se describen los eventos constructivos de las plazas con base en los resultados de las excavaciones, del análisis de los materiales recuperados y del fechamiento por carbono 14 .

Preclásico Tardío (250 a.C.-250 d.C.) y Clásico Temprano (250-400 d.C.)

En el Preclásico Tardío (250 a.C.-250 d.C.) sólo se construyeron la Plaza Central y la Plaza H. En la ocupación más antigua de la Plaza Central, que llegó hasta 3.5 $m$ de profundidad desde la superficie actual (TP1), se encontró una construcción (Piso 7) con rocas alineadas aunque no se pudo identificar su forma ni función debido a la dimensión del sondeo (figura 3). Una muestra de carbono 14 tomada del relleno de la construcción lo fecha entre el 353 y el 122 a.C. con $68.2 \%$ en rango de probabilidad. Para cubrir la construcción se niveló la plaza con un piso de estuco (Piso 6) al final del mismo periodo o al principio del Clásico Temprano (250-400 d.C.). Aunque una muestra de carbono 14 sugiere una fecha temprana (386 a.C.-63 d.C.), a juzgar por un tiesto del tipo Águila Naranja con variedad 


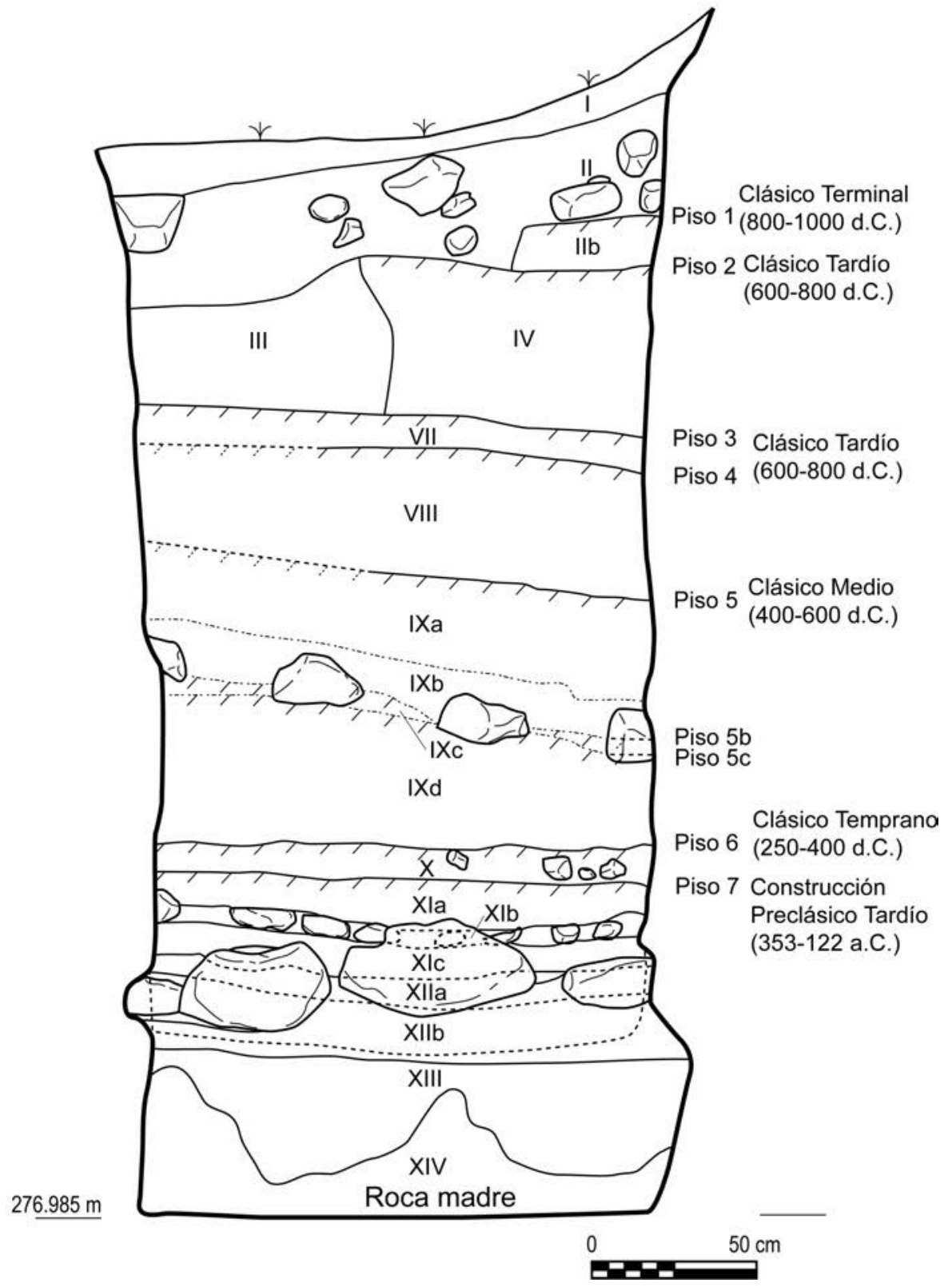

FIgurA 3. Perfil estratigráfico sur de la operación TP1 en la Plaza Central de El Palmar, dibujado por Hirokazu Kotegawa 
Águila y el fechamiento del piso anterior deducimos que el Piso 6 se construyó durante la transición entre los periodos Preclásico Tardío y Clásico Temprano.

La Plaza H fue contemporánea a la Plaza Central. Aun cuando no fue posible fechar su piso más antiguo (Piso 7) por la ausencia de materiales diagnósticos, el Piso 6 pudo haber sido construido durante el Preclásico Tardío de acuerdo con los materiales cerámicos identificados como Sierra Rojo/Sierra, Polvero Negro/ Polvero y Flor Crema/Flor (TP4). Dos muestras de carbono 14 datadas apoyan tal interpretación: $198-36$ a.C. con $91.6 \%$ en rango de probabilidad y 205-40 a.C. con 93\%. La Plaza H fue remodelada con otro piso de estuco (Piso 5) durante el Clásico Temprano (250-400 d.C.).

Las excavaciones sugieren que durante estos dos periodos las áreas alrededor de las Plazas Central y H, que ahora se denominan Gran Plaza y Plazas E y F, eran zonas inundables ya que el material parental hallado fue un suelo limoso de tipo luvisol (TP2, 3, 8 y 9).

Debido al límite de las excavaciones, los cálculos del área total de las plazas e inversión de trabajo en ellas no reflejarían con certeza el número absoluto de participantes en los rituales públicos y en las construcciones. En los cálculos del área total de las plazas no se incluyeron las plataformas que posiblemente fueron utilizadas para las danzas y la colocación de objetos rituales como vasijas, comidas y bebidas (Grube, 1992). Es muy probable que las extensiones de cada plaza fueran transformadas a través del tiempo y sus usos fueran múltiples, con diferentes clases de participantes y objetos. Particularmente, los cálculos sobre la inversión de trabajo son resultados preliminares, ya que no hemos excavado toda la plaza. El cálculo sólo se basó en el área de cada plaza multiplicada por la profundidad de los estratos correspondientes; posteriormente se sumó el volumen de todas las plazas por periodo.

No obstante, estos cálculos nos proporcionan una idea sobre en qué período las plazas y los rituales públicos asociados fueron más relevantes. Además, nos permiten evaluar cuantitativamente su capacidad. Aunque los cálculos se basaron en el plano más reciente del sitio, el área total de las plazas durante los dos periodos era de $9129 \mathrm{~m}^{2}$ (figura 4) y la inversión de trabajo por metro cúbico fue de $6777.65 \mathrm{~m}^{3}$ en el Preclásico Tardío y $2316.8 \mathrm{~m}^{3}$ en el Clásico Temprano, ambas cifras relativamente bajas en comparación con la del Clásico Medio (figura 5).

\section{Clásico Medio (400-600 d.C.)}

El paisaje urbano del Grupo Principal de El Palmar durante el Clásico Medio cambió de manera dramática. Las excavaciones y el análisis de los materiales indican que la Gran Plaza, la Plaza K'awiil y las Plazas E y G fueron construidas en ese periodo, además de que la Plaza Central se elevó casi un metro. Nivelando el suelo de luvisol, en la Gran Plaza y en la Plaza E se construyó un delgado piso de estuco sin colocar relleno de grava. El proyecto arquitectónico sobresaliente 


\begin{tabular}{|l|r|r|r|r|}
\hline \multicolumn{2}{|c|}{} & \multicolumn{3}{|c|}{ Capacidad Estimada de Plaza } \\
\hline Nombre de Plaza & Área $\left(\mathrm{m}^{2}\right)$ & $0.46 \mathrm{~m}^{2} /$ persona & $1 \mathrm{~m}^{2} /$ persona & $3.6 \mathrm{~m}^{2} /$ persona \\
\hline Gran Plaza & 14135 & 30728 & 14135 & 3926 \\
\hline Plaza Central & 6674 & 14509 & 6674 & 1854 \\
\hline Plaza E & 9096 & 19774 & 9096 & 2527 \\
\hline Plaza F & 6134 & 13335 & 6134 & 1704 \\
\hline Plaza G & 1230 & 2673 & 1230 & 341 \\
\hline Plaza H & 2455 & 5336 & 2455 & 681 \\
\hline Plaza K'awiil & 3161 & 6872 & 3161 & 878 \\
\hline Plaza López & 890 & 1935 & 890 & 247 \\
\hline Área total & 40090 & 87152 & 40090 & 11136 \\
\hline
\end{tabular}

FIgura 4. Tabla de la capacidad estimada en las plazas del Grupo Principal de El Palmar

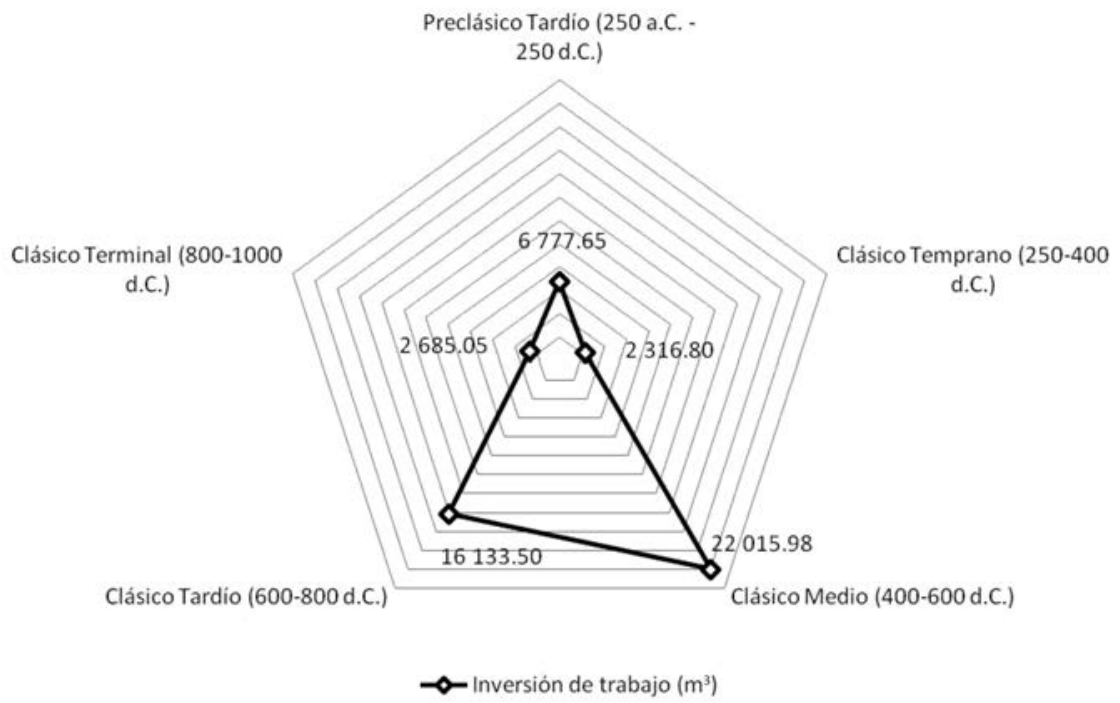

Figura 5. Gráfica de la inversión de trabajo $\left(\mathrm{m}^{3}\right)$ estimada en El Palmar

del Clásico Medio fue, sin duda, la edificación de la Estructura PM3 en la Plaza $\mathrm{G}$ (tomando como base los resultados del TP6). El sondeo estratigráfico sugiere que el piso más antiguo (Piso 3) alcanzó $10 \mathrm{~m}$ de elevación desde la superficie de la Plaza E. Tres muestras de carbono 14 tomadas del relleno constructivo de la Plaza G lo datan entre el 196 y el 353 d.C. con $98.20 \%$ en rango de probabili- 
dad; entre el 421 y el 533 d.C. y entre el 425 y el 533 d.C. con $68.20 \%$ en rango de probabilidad. Estas últimas muestras, en conjunto con el análisis cerámico, revelan que la Plaza G fue construida entre los años 425 y 533 d.C.

Si bien la Plaza G fue el proyecto arquitectónico más voluminoso, la Gran Plaza (TP3 y TP9) fue diseñada con mayor extensión con el fin de acomodar a la mayor población en un evento público. En el relleno de la Gran Plaza no se encontraron materiales cerámicos diagnósticos del Clásico Medio, sino del Clásico Temprano (250-600 d.C.). Sin embargo, el análisis preliminar del estuco por medio de la catodoluminisencia realizado por Tatsuya Murakami indicó que el primer piso de la Gran Plaza fue construido durante el primer periodo mencionado, ya que la tecnología de los pisos más antiguos en ésta y en la Plaza G fue idéntica a la del Clásico Medio. Además se encontró un artefacto lítico del tipo "cepillo" (Domed Smoother) (figura 6) en el mismo relleno, que Rovner, Lewenstein y Nelson (1997) señalan como material diagnóstico del principio del Clásico Tardío. Es decir, se puede interpretar la emergencia de la mencionada plaza a partir del Clásico Medio. Con base en todos los resultados anteriores, sugerimos que la Gran Plaza, la Plaza G y probablemente la Plaza E fueron construidas durante el Clásico Medio.

En el caso de la Plaza K'awiil, el periodo constructivo tiene una fecha aún más exacta. Durante la excavación de prueba (TP5) se encontró un escondite (Escondite 3) o cache asociado al Altar 10, debajo del piso más antiguo de la plaza (figuras 7 y 8). Debido a la ausencia de una intrusión, creemos que el ente-
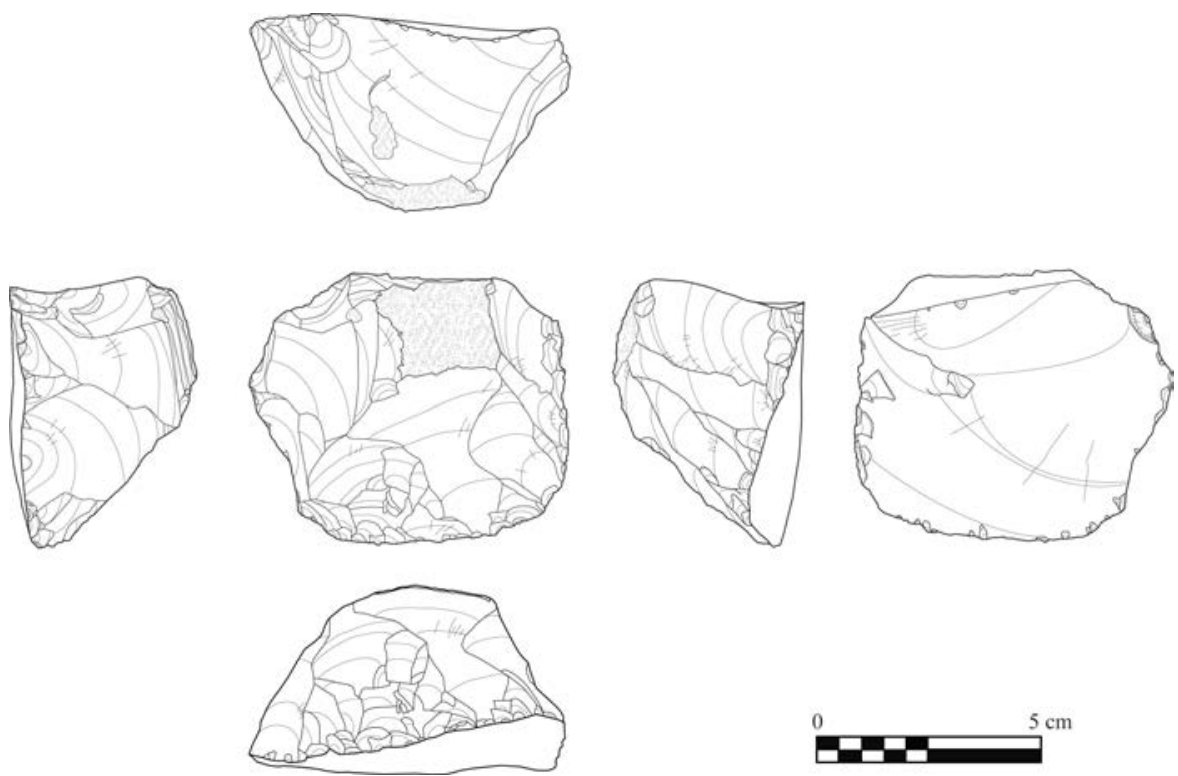

Figura 6. Herramienta lítica denominada "cepillo" (Domed Smoother), dibujado por Kenichiro Tsukamoto 
rramiento del Escondite 3 y la construcción de la plaza fueron contemporáneos. $\mathrm{Si}$ se considera que el Altar 10 contiene una Rueda Calendárica que registra la fecha del 20 de marzo del 554 d.C., la construcción de la Plaza K'awiil en el siglo sexto es contemporánea a la de las tres plazas anteriores.

El área total de las plazas se extendió $36571 \mathrm{~m}^{2}$, cifra cuatro veces más grande que la de los periodos anteriores (figura 4). Si una persona ocupa un metro cuadrado durante rituales públicos, las plazas pudieron haber acomodado más de 36000 participantes. Asimismo, la inversión de trabajo se incrementó de $9094.45 \mathrm{~m}^{3}$ a $22015.98 \mathrm{~m}^{3}$ en tan sólo 200 años (figura 5).

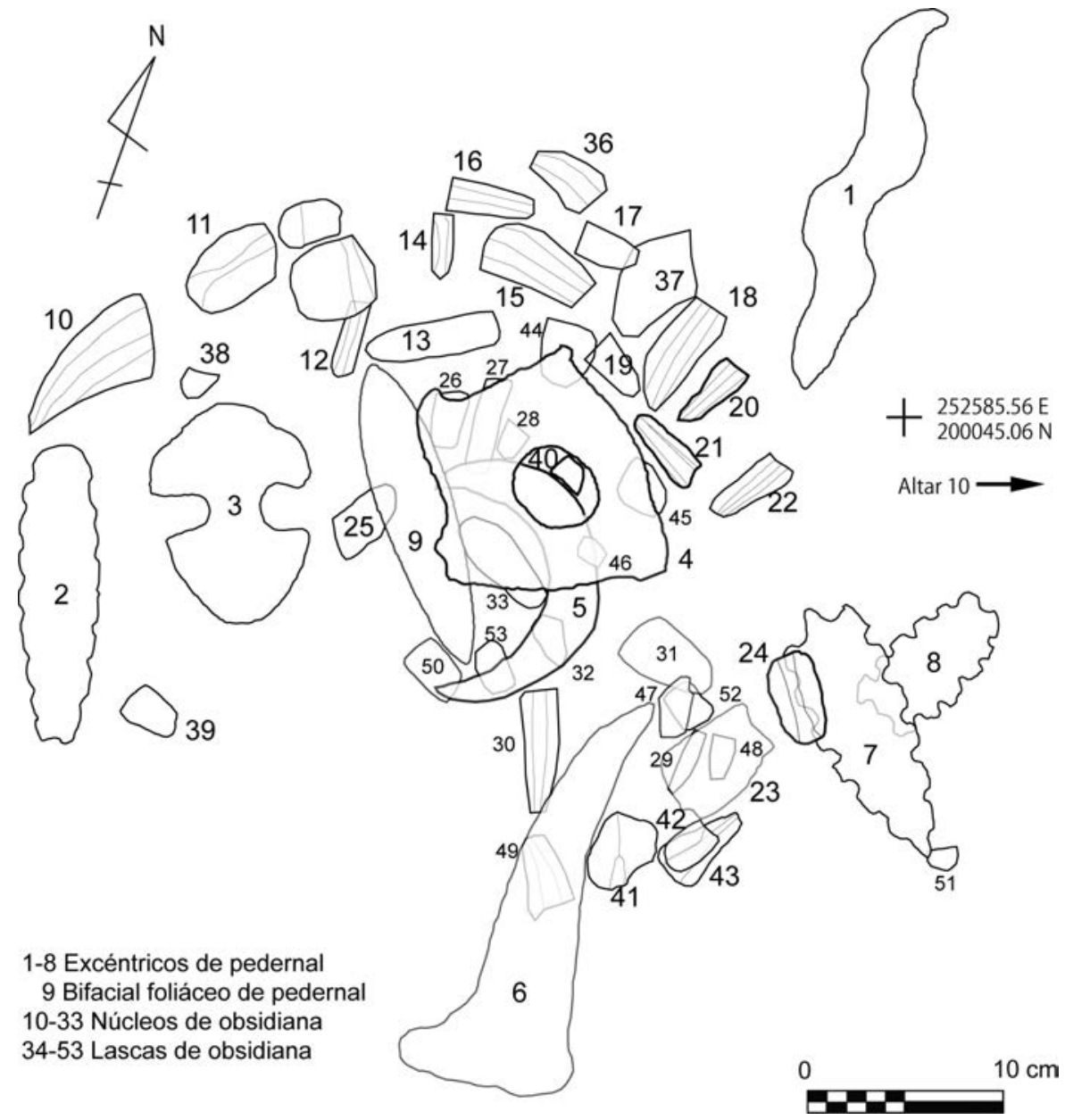

Figura 7. Plano del Escondite 3 descubierto en El Palmar, dibujado por Kenichiro Tsukamoto y Luz Evelia Campaña 


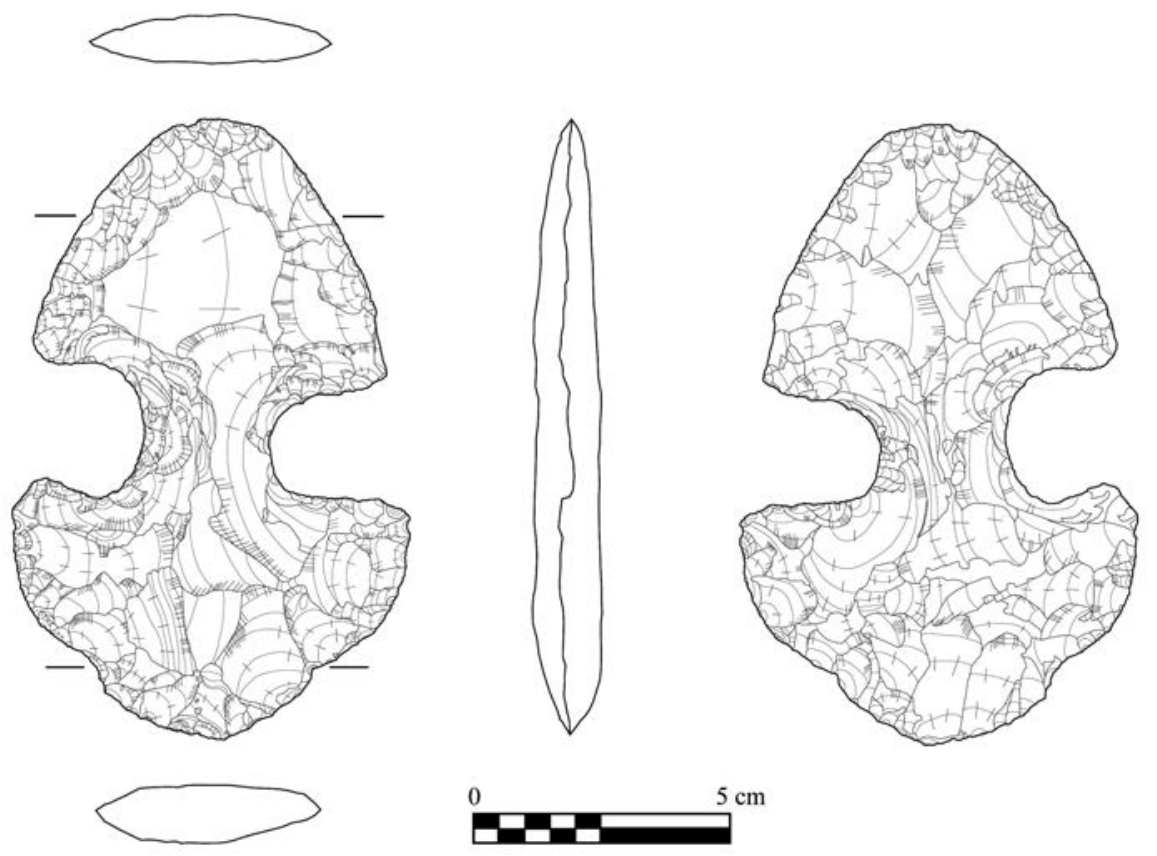

Figura 8. Excéntrico proveniente del Escondite 3 de El Palmar, dibujado por Kenichiro Tsukamoto

Clásico Tardío (600-800 d.C.)

Los mayas de El Palmar continuaron construyendo espacios abiertos, como la Plaza F (TP8) y la Plaza López (TP7) durante el Clásico Tardío (600-800 d.C.), además de remodelar las plazas anteriores. Sin embargo, la dimensión de estas nuevas plazas fue más pequeña. Al mismo tiempo, las élites gobernantes erigieron una gran cantidad de monumentos grabados en la Gran Plaza, la Plaza Central y la Plaza E. El área total de las plazas aumentó a $43595 \mathrm{~m}^{2}$ con la construcción de las Plazas F y López (figura 4), pero la inversión de trabajo disminuyó a 16133.5 $\mathrm{m}^{3}$ (figura 5).

Clásico Terminal (800-1000 d.C.)

La construcción o remodelación de plazas disminuyó de manera significativa durante el Clásico Terminal, aunque las estelas con inscripciones sugieren que la Gran Plaza, la Plaza E y la Plaza K'awiil siguieron funcionando para ceremonias conmemorativas en los años 800, 820 y 884 d.C., respectivamente. La Plaza H es 
la única que presenta evidencia de la remodelación, con una inversión laboral de $2685.05 \mathrm{~m}^{3}$ (figura 5).

\section{Construcciones y remodelaciones de plazas como una estrategia política}

Los resultados de las excavaciones de prueba y del análisis de los materiales señalan que las construcciones y remodelaciones de las plazas eran importantes para la sociedad de El Palmar. Nosotros creemos que la construcción intensiva de las plazas mayores refleja una estrategia de las élites gobernantes para organizar a la sociedad. En periodos premodernos, los espectáculos en un amplio espacio abierto, como la plaza, jugaban un papel preponderante para la organización política (Connerton, 1989; Foucault, 1984, 1995[1978]; Inomata, 2006; Joyce, 2004; Low, 1995; Moore, 1996). Es posible que la construcción y remodelación de las plazas públicas fueran proyectos importantes para las élites gobernantes de El Palmar, quienes requerían manifestar su conocimiento especial en la ejecución de los rituales para establecer contacto con los ancestros y las deidades. Investigaciones previas sugieren que, en Mesoamérica, ciertos saberes como la comunicación con los ancestros y la escritura jeroglífica eran exclusivos de las élites gobernantes, y mediante ellos reclamaban y sostenían su poder político con manipulaciones ideológicas y religiosas (Houston, Robertson y Stuart, 2000; Inomata, 2001; Joyce y Winter, 1996; McAnany, 1993, 1995).

Bajo esta condición, las plazas fueron los escenarios donde las élites gobernantes legitimaban su autoridad política a través de prácticas rituales. En este sentido, consideramos que el número de plazas en un sitio y su continua remodelación revela que las relaciones de poder entre las élites gobernantes y otros segmentos sociales fueron equilibradas por medio de rituales públicos celebrados en los espacios abiertos (Scott, 1998). Además, el súbito incremento de la capacidad para acomodar a los participantes en las plazas sugiere la transformación del sitio, de pueblo local a centro regional, ya que los espacios para la realización de espectáculos regularmente son diseñados en función del número de participantes. La construcción de nuevos espacios públicos, como la Gran Plaza y la Plaza E, indican que El Palmar se convirtió en un centro regional que albergaba a un gran auditorio que participaba del teatro político de las ceremonias conmemorativas.

Otros segmentos sociales no eran receptores pasivos de la ideología y dominación, sino sus evaluadores. Sus resultados (aceptación o rechazo) influían en su participación en otras construcciones (Geertz, 1980; Inomata, 2006), ya que los rituales públicos no funcionan con la ausencia del público: este y los protagonistas interactúan mutuamente para crear un ambiente de espectáculo.

Mientras las regiones colindantes se involucraron en las interacción política debido a la confrontación entre Tikal y Calakmul a partir del Clásico Medio 
(Adams, 1999; Martin, 2000; Stuart, 2000; Wright, 2005a y b), las remodelaciones de la Gran Plaza, la Plaza E y la Plaza G, así como las numerosas erecciones de las estelas y altares sugieren que los rituales-espectáculos públicos fueron exitosos y ayudaron a cimentar la identidad social. Particularmente, la edificación de la Plaza $\mathrm{G}$ como un espacio exclusivo de las élites revela que los otros grupos sociales consintieron su legitimación política y poder, y que aquellas consolidaban identidades distintas a las de los rituales públicos.

La construcción de plazas y de templos piramidales no sólo fue importante desde el punto de vista arquitectónico, sino también ideológico, pues convirtieron la ciudad en un lugar mitológico. Garza (2010: 43) sugiere que la plaza y la pirámide son símbolos de la tierra cuadrangular y de la montaña sagrada (véase también Ashmore, 1991, 2004; Brady y Ashmore, 1999; Schele y Freidel, 1990). Esta cosmovisión inscrita en el paisaje y las ceremonias conmemorativas repetitivas pudieron haber ayudado a producir y reproducir la memoria social (Connerton, 1989; Van Dyke y Alcock, 2003). Con base en el análisis de la sicología política, Caspary (1993) sugiere que la obediencia al poder ideológico con representaciones simbólicas tiende a desarrollarse durante periodos de crisis (véase también Joyce y Winter, 1996: 35; Volkan, 1985). Es decir, la intensa interacción política de las regiones cercanas pudo haber servido para cimentar la ideología política de El Palmar a partir del Clásico Medio, y la construcción y remodelación de las plazas grandes y privadas fue una respuesta de la solidaridad y la obediencia social.

\section{Conclusión}

La excavación y el análisis de los materiales evidencian que las grandes plazas, como la Gran Plaza y las Plazas E, G y K'awiil fueron construidas durante el periodo Clásico Medio (400-600 d.C.). Su construcción, junto con la de los templos piramidales monumentales, sugiere que la celebración de rituales públicos - como teatro político- era un elemento importante para las élites gobernantes, quienes legitimaban las autoridades políticas a través de los espectáculos y la materialización de ellos en los monumentos grabados. El fenómeno del proyecto arquitectónico en El Palmar es parecido al de Río Azul (Adams, 1999) y Uaxactún (Valdés y Fahsen, 1995). No obstante, por el momento la información limita la interpretación y aún no es posible revelar la relación de El Palmar con las superpotencias Tikal y Calakmul. Sólo podemos anotar que, al igual que esos sitios, el periodo Clásico Medio fue fundamental para su organización política y espacial. 


\section{BIBLIOGRAFÍA}

Adams, Richard E. W.

1999 Rio Azul: An Ancient Maya city. Norman: University of Oklahoma Press.

Adams, Richard E. W. y Richard C. Jones

1981 "Spatial Patterns and Regional Growth among Classic Maya Cities", American Antiquity, 46 (2): 301-322. Washington, D. C.: Society for American Archaeology.

Aimers, James J. y Prudence M. Rice

2006 "Astronomy, Ritual, and the Interpretation of Maya "E-Group" Architectural Assemblages”, Ancient Mesoamerica, 17: 79-96. Cambridge: Cambridge University Press.

Ashmore, Wendy

1991 "Site-planning principles and concepts of directionality among the ancient Maya”, Latin American Antiquity, 2 (3): 199-226. Washington, D. C.: Society for American Archaeology.

2004 "Ancient Maya Landscape", Continuities and Changes in Maya Archaeology: Perspectives at the Millennium. Charles W. Golden y Greg Borgstede (eds.). Nueva York: Routledge, 97-11.

Brady, James E. y Wendy Ashmore

1999 "Mountains, Caves, Water: Ideational Landscapes of the Ancient Maya", Archaeology of Landscape: Contemporary Persipective. Wendy Ashmore y Arthur B. Knapp (eds.). Malden [Estados Unidos]: Blackwell Publisher, 124-145.

Bueno, Ricardo

1999 Entre un río de robles: un acercamiento a la arqueología de la región Río Bec. México: Instituto Nacional de Antropología e Historia (Colección Científica, 411).

Campaña, Luz Evelia

2005 “Contribuciones a la historia de Becán”, Arqueología Mexicana, XIII (75): 4853. México: Raíces.

Caspary, William R.

1993 "New Psychoanalytic Perspectives on the Causes of War", Political Psychology, 14 (3): 417-446. Malden [Estados Unidos]: Wiley-Blackwell Publishers.

Clark, John E. y Richard D. Hansen

2001 The Architecture of Early Kingship: Comparative Perspectives on the Origins of the Maya Royal Court. Royal Courts of the Ancient Maya, Volume Two: Data and Case Studies. Colorado: Westview Press.

Connerton, Paul

1989 How Societies Remember. Nueva York: Cambridge University Press. 
Demarest, Arthur A.

1992 "The Dynamics of Galactic Polities", Ideology and Pre-Columbian Civilizations. Arthur A. Demarest y Geoffrey W. Conrad (eds.). Santa Fe: School of American Research Press, 135-157.

Foucault, Michel

1984 "Space, Knowledge, and Power", The Foucault Reader. Paul Rabinow (ed.). Nueva York: Pantheon Books, 239-256.

1995 Discipline and Punish: The Birth of the Prison. Nueva York: Vintage Books.

[1978]

Freidel, David A. y Linda Schele

1988 "Kingship in the Late Pre-Classic Maya Lowlands: The Instruments and Places of Ritual Power”, American Anthropologist, 90: 547-567. Arlington: American Anthropological Association

Garza, Mercedes de la

2010 "El universo temporal en el pensamiento maya”, Arqueología Mexicana 103: 38-44. México: Raíces.

Geertz, Clifford

$1980 \quad$ Negara: The Theatre State in Nineteenth-Century Bali. Princeton: Princeton University Press.

Grube, Nikolai

1992 "Classic May dance: Evidence from hieroglyphs and iconography", Ancient Mesoamerica, 3: 201-218. Cambridge: Cambridge University Press.

Houston, Stephen D.

1998 "Classic Maya Depictions of the Built Environment", Function and Meaning in Classic Maya Architecture: A Symposium at Dumbarton Oaks 7th and 8th October 1994. Stephen D. Houston (ed.). Washington, D. C.: Harvard University Press, 333-372.

Houston, Stephen, John Robertson y David Stuart

2000 "The Language of Classic Maya Inscriptions", Current Anthropology, 41 (3): 321-356. Chicago: Chicago University Press.

Inomata, Takeshi

2001 "Power and Ideology of Artistic Creation: Elite Craft Specialists in Classic Maya Society”, Current Anthropology, 42 (3): 321-349. Chicago: Chicago University Press.

2006 "Plazas, Performers, and Spectators: Political Theaters of the Classic Maya", Current Anthropology, 47 (5): 805-841. Chicago: Chicago University Press.

Joyce, Arthur A.

2004 "Sacred Space and Social Relations in Oaxaca", Mesoamerican Archaeology. Julia A. Hendon y Rosemary A. Joyce (eds.). Malden [Estados Unidos]: Blackwell Publishing, 192-216. 
Joyce, Arthur A. y Marcus Winter

1996 "Ideology, Power, and Urban Society in Pre-Hispanic Oaxaca", Current Anthropology, 37 (1): 33-47. Chicago: Chicago University Press.

Joyce, Rosemary A.

2001 "Planificación urbana y escala social: reflexiones sobre datos de comunidades clásicas en Honduras", Reconstruyendo la ciudad maya: el urbanismo en las sociedades antiguas. Andrés Ciudad, María Josefa Iglesias y María del Carmen Martínez (eds.). Madrid: Sociedad Española de Estudios Mayas (Publicación 6), 123-136.

Laporte, Juan Pedro y Vilma Fialko

1995 "Un reencuentro con Mundo Perdido, Tikal, Guatemala”, Ancient Mesoamerica, 6: 41-94. Cambridge: Cambridge University Press.

Low, Setha M.

1995 "Indigenous Architecture and the Spanish American Plaza in Mesoamerican and the Caribbean”, American Anthropologist, 97 (4): 748-762. Arlington: American Anthropological Association

Martin, Simon

2000 “Los Señores de Calakmul”, Arqueología Mexicana, VII (42): 40-45. México: Raíces.

McAnany, Patricia A.

1993 "The Economics of Wealth among Eighth-Century Maya Households", Lowland Maya Civilization in the Eight Century A.D.: A Symposium at Dumbarton Oaks 7th and 8thOctober 1989. Jeremy A. Sabloff y John S. Henderson (eds.). Washington, D. C.: Dumbarton Oaks Research Library and Collection, 6579.

1995 Living with Ancestors: Kingship and Kingship in Ancient Maya Society. Austin: University of Texas Press.

Moore, Jerry D.

1996 Architecture \& Power In the Ancient Andes: The Archaeology of Public Buildings. Cambridge: Cambridge University Press.

Restall, Matthew

2001 "The People of the Patio: Ethnohistorical Evidence of Yucatec Maya Royal Courts", Royal Courts of the Ancient Maya, Vol. 2. Takeshi Inomata y Stephen D. Houston (eds.). Boulder [Estados Unidos]: Westview Press, 335-377.

Ringle, William M. y George J. Bey III

2001 "Post-Classic and Terminal Classic Courts of the Northern Maya Lowlands", Royal Courts of the Ancient Maya, vol 2. Takeshi Inomata y Stephen D. Houston (eds.). Boulder [Estados Unidos]: Westview Press, 266-307. 
Rovner, Irwin, Suzanne M. Lewenstein y Fred W. Nelson

1997 Maya stone tools of Dzibilchaltún, Yucatán, and Becán and Chicanná, Campeche. Nueva Orleans: Tulane University, Middle American Research Institute.

Schechner, Richard

1985 Between Theater and Anthropology. Filadelfia. University of Pennsylvania Press.

Schele, Linda y David Freidel

1990 A Forest of Kings: The Untold Story of The Ancient Maya. Nueva York: Quill William Morrow.

Scott, James C.

1998 Seeing Like A State: How Certain Schemes To Improve the Human Condition Have Failed. New Haven / Londres: Yale University Press.

Sharer, Robert J. y Charles W. Golden

2004 "Kingship and Polity: Conceptualizing the Maya Body Politic", Continuities and Changes in Maya Archaeology: Perspectives at the Millennium. C. W. Golden y G. Borgstede (eds.). Nueva York: Routledge, 23-50.

Šprajc, Ivan

2008 Reconocimiento arqueológico en el sureste del estado de Campeche, México: 1996-2005. Ljubljana [Eslovenia]: Centro de Investigaciones Científicas de la Academia Eslovena de Ciencias y Artes (British Archaeological Reports, International Series 1742. Paris Monographs in America Archaeology, 19).

Stuart, David

2000 “' “The Arrival of Strangers': Teotihuacan and Tollan in Classic Maya History”, Mesoamerican's Classic Heritage: From Teotihuacan to the Aztecs. David Carrasco, Lindsay Jones y Scott Sessions (eds.). Niwot: Colorado University Press, 465-513.

Thompson, J. Eric S.

1936 "Exploration in Campeche and Quintana Roo and excavations at San José, British Honduras", Carnegie Institution of Washington Year Book 35. Washington, D. C.: Carnegie Institution, 125-128.

Tsukamoto, Kenichiro y Javier López Camacho

2007 "El Palmar: una ciudad ubicada en una antigua frontera maya", Antropología e Historia, por sus especialistas, vol. 1. Campeche: Consejo Nacional para la Cultura y las Artes / Instituto Nacional de Antropología e Historia, 20-21.

Tsukamoto, Kenichiro, Javier López Camacho y Octavio Q. Esparza Olguín 2010 "El Palmar, Campeche”, Arqueología Mexicana, 17(101): 72-77. México: Raíces.

Turner, Victor

1986 From Ritual to Theatre and Back. Nueva York: Performing Arts Journal Publications. 
Valdés, Juan Antonio y Federico Fahsen

1995 "The Reigning Dynasty of Uaxactun during the Early Classic: The Rulers and the Ruled", Ancient Mesoamerica, 6: 197-219. Cambridge: Cambridge University Press.

Van Dyke, Ruth M. y Susan E. Alcock

2003 "Archaeologies of Memory: An Introduction", Archaeologies of Memory, pp. 1-13; Ruth M. Van Dyke y Susan E. Alcock (eds.). Malden [Estados Unidos]: Blackwell Publishers.

Volkan, Vamik D.

1985 "The Need to Have Enemies and Allies: A Developmental Approach", Political Psychology, 6 (2): 219-247. Malden [Estados Unidos]: Wiley-Blackwell Publishers.

Wright, Lori E.

2005a "Identifying Immigrants to Tikal, Guatemala: Defining local variability in strontium isotope ratios of human tooth enamel", Journal of Archaeological Science, 32: 555-566. Londres: Elsevier.

2005b "In Search of Yax Nuun Ayiin", Ancient Mesoamerica, 16: 89-100. Cambridge: Cambridge University Press. 


\title{
SECUENCIA CONSTRUCTIVA DE LAS PLAZAS EN EL GRUPO PRINCIPAL DE EL PALMAR, CAMPECHE, MÉXICO
}

\author{
Kenichiro TSUKAmoto \\ School of Anthropology, University of Arizona \\ HiRokAZU Kotegawa \\ Posgrado en Antropología, Facultad de Filosofía y Letras / Instituto de Investi- \\ gaciones Antropológicas, Universidad Nacional Autónoma de México \\ Facultad de Antropología, Universidad Veracruzana \\ LuZ Evelia CAmpaña \\ Proyecto Arqueológico El Palmar
}

\section{Introducción}

En las Tierras Bajas Mayas, la construcción y remodelación de la plaza estaba relacionada con la organización política (Inomata, 2006; Restall, 2001; Ringle y Bey III, 2001; Sharer y Golden, 2004). Recientes estudios arqueológicos, epigráficos e iconográficos han profundizado sobre la organización política, particularmente sobre la institución encabezada por el Ajaw, que se fundó en el periodo Preclásico Tardío (250 a.C.-250 d.C.) (Freidel y Schele, 1988) y floreció durante todo el Clásico (250-900 d.C.). Las élites gobernantes fueron promotoras de la construcción de estructuras monumentales, del desarrollo de guerras, de la erección de monumentos conmemorativos y de la celebración de sacrificios humanos y rituales públicos. Durante periodos de agitación política, ejecutaron esas actividades de manera acelerada para mantener su autoridad política, no siempre estable. Una de las estrategias de la institución Ajaw para la legitimización del poder fue quizás el teatro político, hipótesis originalmente propuesta por Geertz (1980) al estudiar la sociedad de Bali en el siglo xIx (Demarest, 1992; Houston,

Agradecemos al Instituto Nacional de Antropología e Historia (INAH), institución que otorgó los permisos C.A. 401-361/138 y C.A. 401-36/0837 para realizar el proyecto arqueológico El Palmar: Urbanización del espacio social en las tierras bajas mayas. Reconocemos de manera especial al arqueólogo Javier López Camacho, de la Escuela Nacional de Antropología e Historia (ENAH), quien es codirector del proyecto. Asimismo a Octavio Esparza Olguín, Alejandra Salinas, Tatsuya Murakami, Yuki Tanaka, estudiantes de la enAH, y a los trabajadores locales del ejido Kiché las Pailas, por su participación desinteresada. Finalmente, a Takeshi Inomata y Daniela Triadan por su apoyo académico. El proyecto fue financiado por la SBSRI Pre-doctoral Grant de la Universidad de Arizona. 
1998; Sharer y Golden, 2004), quien sugirió que la razón de existir del Estado era mantener el teatro político (Inomata, 2006: 808). Turner (1986) y Schechner (1985) indican que en cualquier sociedad los rituales públicos tienen un carácter teatral; sin duda, estos tuvieron un carácter teatral en la antigua sociedad maya del Clásico, a juzgar por las reiteradas representaciones grabadas en sus monumentos escultóricos. Los personajes que aparecen en estos últimos, por lo regular llevan máscaras, ornamentos, bastones ceremoniales y atavíos espléndidos, los cuales pudieron haber complementado el carácter teatral de rituales públicos. Con el fin de utilizar el teatro político como espectáculo, las plazas públicas fueron el escenario propicio para concentrar y acomodar a la población o a grupos seleccionados de la sociedad, dependiendo de la dimensión y ubicación de los espacios abiertos. En este sentido, su construcción y remodelación revelaría las huellas de una cultura material donde la gente consentía o era coercionada por las decisiones políticas de la élite gobernante, pues la mayor parte de la población debió participar en la erección de obras monumentales, incluidos los espacios públicos. Así, a través del estudio de su secuencia constructiva y de los materiales arqueológicos asociados es factible aproximarse al papel de los rituales públicos en la sociedad maya y al comportamiento de la población ante el teatro político de las élites gobernantes.

El presente trabajo presenta la secuencia constructiva de ocho plazas del Grupo Principal en el sitio arqueológico de El Palmar, ubicado al sureste de Campeche, México, como un caso de estudio.

\section{El Palmar}

El Palmar posee un carácter peculiar en cuanto a su ubicación. Se localiza en el sureste de Campeche, México, relativamente cerca de varios centros mayores: $90 \mathrm{~km}$ al sur se ubica Tikal; $50 \mathrm{~km}$ al oriente, Calakmul; y $70 \mathrm{~km}$ al norte, Becán (figura 1). En sus inmediaciones se encuentran también Mucaancah, Río Azul, Los Alacranes, La Milpa, Río Bec y Altar de los Reyes (Šprajc, 2008). De acuerdo con Adams y Jones (1981), esta área fue ocupada por tres esferas geopolíticas (Tikal, Calakmul y Río Bec) durante el Clásico Tardío y, por su localización, El Palmar pudo haber sido el centro de gravedad limítrofe de las tres regiones. Además de los conflictos políticos entre Tikal y Calakmul, en los sitios de la región Río Bec, como Becán, Río Bec y Hormiguero, se construyeron estructuras monumentales con un estilo arquitectónico propio durante el Clásico Tardío (600-800 d.C.) (Bueno, 1999; Campaña, 2005). Es decir, en términos de las interacciones políticas, los años transcurridos entre el 400 d.C. y el 700 d.C. debieron constituir un periodo dinámico y es probable que la participación de El Palmar fuera inevitable en los asuntos políticos.

Los recorridos de superficie y el levantamiento topográfico han detectado que

El Palmar tiene al menos otros ocho grupos arquitectónicos agrupados dentro de 


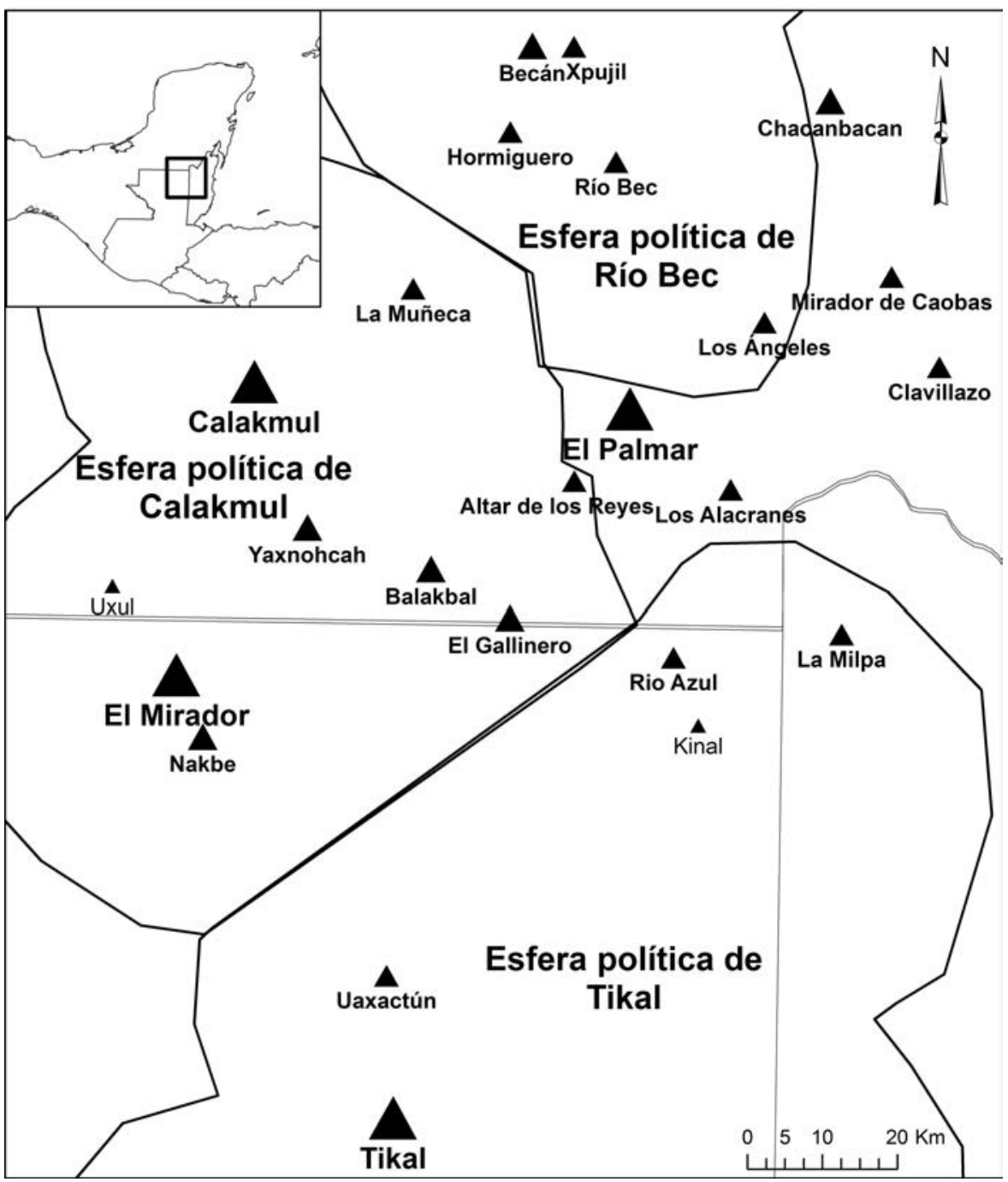

Figura 1. Mapa de esferas políticas en las Tierras Bajas Mayas, basado en Adams y Jones, 1981: 309

un radio máximo de $2.5 \mathrm{~km}$ a partir del Grupo Principal. En la configuración espacial del Grupo Principal destacan dos templos piramidales, un extenso palacio, una gran cantidad de los monumentos grabados y, por supuesto, las plazas (Tsukamoto, López Camacho y Esparza Olguín, 2010; Tsukamoto y López Camacho, 2007) (figura 2). El diseño planificado del Grupo Principal contiene ocho plazas con dimensiones distintas: la Gran Plaza, la Plaza Central, la Plaza K'awiil, las Plazas E, F, G y H, y la Plaza López. 


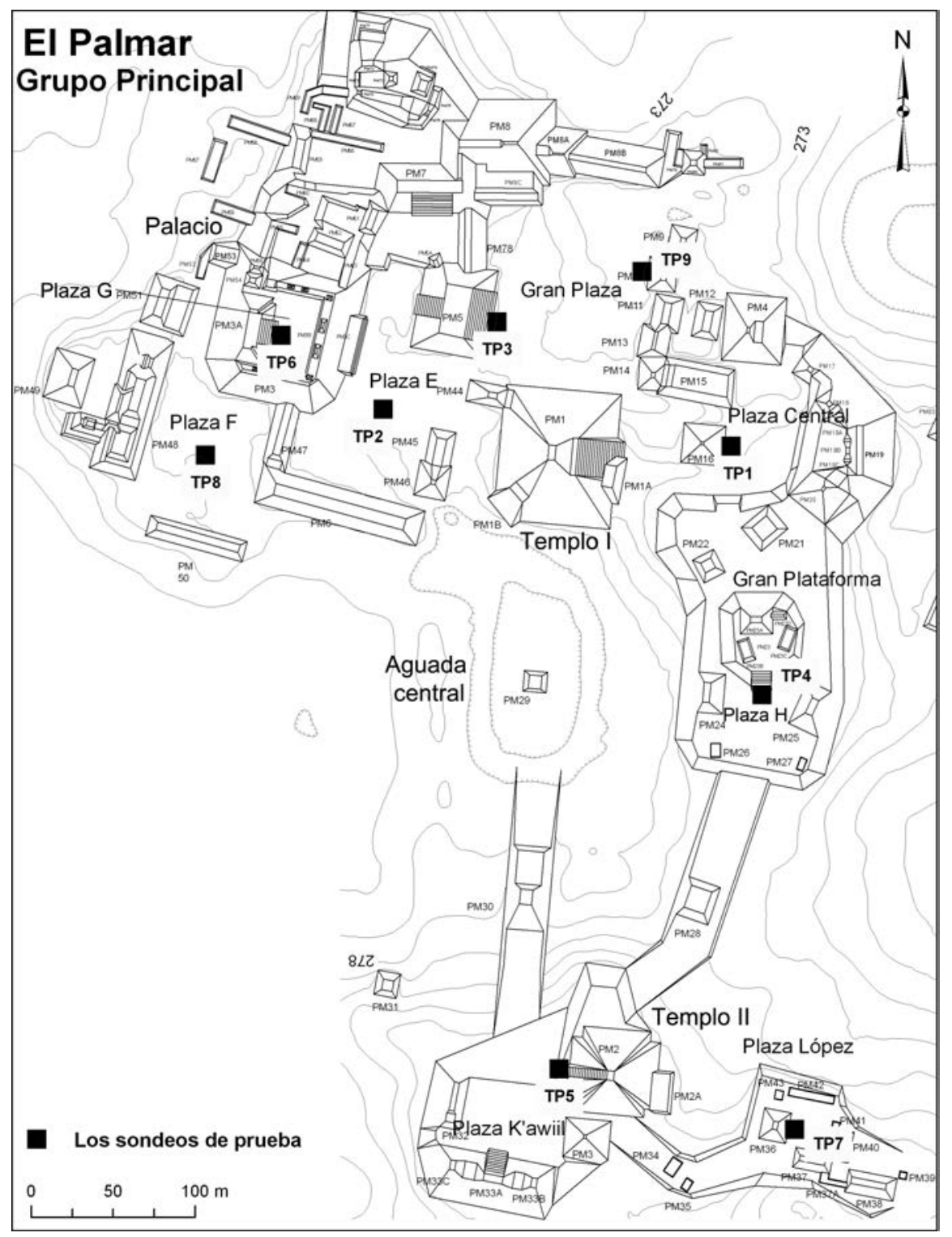

Figura 2. Plano del Grupo Principal de El Palmar con la ubicación de las excavaciones estratigráficas, dibujado por Kenichiro Tsukamoto y Javier López Camacho

La Gran Plaza es la más extensa, tiene una superficie de $14135 \mathrm{~m}^{2}$ y se encuentra en la parte norte del Grupo Principal. En el espacio abierto fueron colocados 11 monumentos grabados, cuatro de ellos (Estelas 8, 7, 10 y 16) con 
registros calendáricos para los años 721, 731, 746 y 800 d.C., respectivamente (Thompson, 1936). La Plaza Central, al sureste de la Gran Plaza, alcanza un área de $6674 \mathrm{~m}^{2}$ y contiene un complejo arquitectónico del tipo "Grupo E", considerado un espacio conmemorativo para rituales públicos (Aimers y Rice, 2006; Clark y Hansen, 2001; Joyce, 2001; Laporte y Fialko, 1995).

Al sur se ubica la Plaza K'awiil, con una superficie de $3161 \mathrm{~m}^{2}$, caracterizada por una ligera elevación sobre la cual desplanta el Templo II. Exhibe varios monumentos grabados, entre los cuales hay una estela con la fecha 884 d.C. (Estela 41) y un altar con una Rueda Calendárica del 554 d.C. Las Plazas E (9096 m²), F (6 134 $\left.\mathrm{m}^{2}\right)$ y G $\left(1877 \mathrm{~m}^{2}\right)$ se encuentran al suroeste de la Gran Plaza; en la Plaza E hay un monumento con registro del año 820 d.C. (Estela 14). La Plaza G constituye un espacio privado, pues está rodeada por estructuras abovedadas similares, se eleva $10 \mathrm{~m}$ sobre la superficie de la Plaza E, y se integra al sector del Palacio.

La Plaza H $\left(3130 \mathrm{~m}^{2}\right)$ se localiza sobre la Gran Plataforma, cuya elevación pudo haber configurado un espacio restringido. Finalmente, la Plaza López es un espacio pequeño $\left(890 \mathrm{~m}^{2}\right)$ al este de la Plaza K'awiil, donde no se han descubierto monumentos grabados.

\section{Secuencia constructiva de las plazas en el Grupo Principal de El Palmar}

Si bien el levantamiento topográfico ha permitido representar la configuración espacial de las ocho plazas, nueve sondeos estratigráficos de 2 × $2 \mathrm{~m}$ realizados durante la temporada de campo 2009 han revelado su dimensión temporal. Los resultados sugieren que el Grupo Principal fue ocupado desde el Preclásico Tardío (250 a.C.-250 d.C.) hasta el Clásico Terminal (800-1000 d.C.). El plan de construcción de los espacios públicos fue realizado de manera intensa durante el Clásico Medio (400-700 d.C.). A continuación se describen los eventos constructivos de las plazas con base en los resultados de las excavaciones, del análisis de los materiales recuperados y del fechamiento por carbono 14 .

Preclásico Tardío (250 a.C.-250 d.C.) y Clásico Temprano (250-400 d.C.)

En el Preclásico Tardío (250 a.C.-250 d.C.) sólo se construyeron la Plaza Central y la Plaza H. En la ocupación más antigua de la Plaza Central, que llegó hasta 3.5 $m$ de profundidad desde la superficie actual (TP1), se encontró una construcción (Piso 7) con rocas alineadas aunque no se pudo identificar su forma ni función debido a la dimensión del sondeo (figura 3). Una muestra de carbono 14 tomada del relleno de la construcción lo fecha entre el 353 y el 122 a.C. con $68.2 \%$ en rango de probabilidad. Para cubrir la construcción se niveló la plaza con un piso de estuco (Piso 6) al final del mismo periodo o al principio del Clásico Temprano (250-400 d.C.). Aunque una muestra de carbono 14 sugiere una fecha temprana (386 a.C.-63 d.C.), a juzgar por un tiesto del tipo Águila Naranja con variedad 


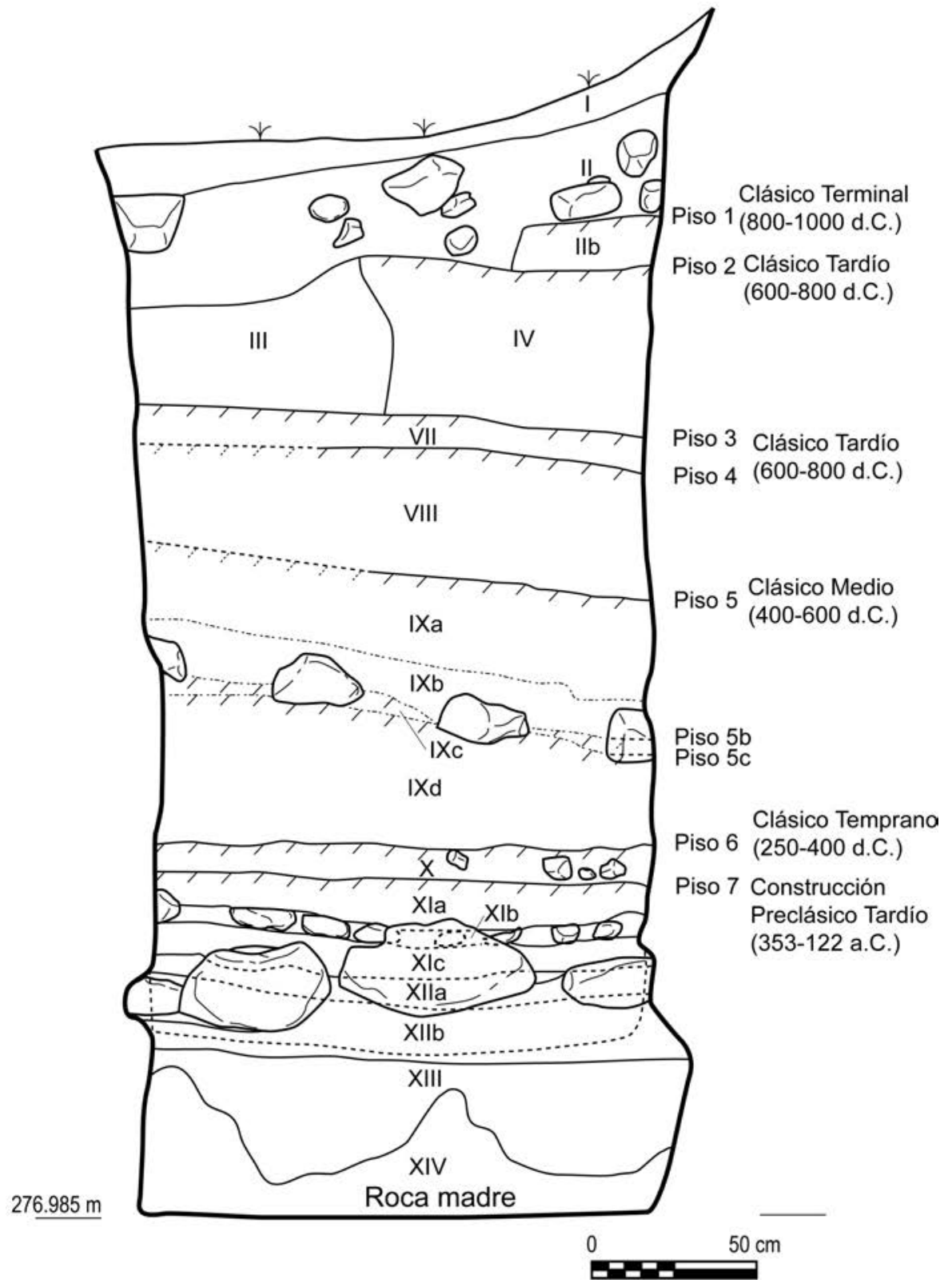

FIgurA 3. Perfil estratigráfico sur de la operación TP1 en la Plaza Central de El Palmar, dibujado por Hirokazu Kotegawa 
Águila y el fechamiento del piso anterior deducimos que el Piso 6 se construyó durante la transición entre los periodos Preclásico Tardío y Clásico Temprano.

La Plaza H fue contemporánea a la Plaza Central. Aun cuando no fue posible fechar su piso más antiguo (Piso 7) por la ausencia de materiales diagnósticos, el Piso 6 pudo haber sido construido durante el Preclásico Tardío de acuerdo con los materiales cerámicos identificados como Sierra Rojo/Sierra, Polvero Negro/ Polvero y Flor Crema/Flor (TP4). Dos muestras de carbono 14 datadas apoyan tal interpretación: $198-36$ a.C. con $91.6 \%$ en rango de probabilidad y 205-40 a.C. con 93\%. La Plaza H fue remodelada con otro piso de estuco (Piso 5) durante el Clásico Temprano (250-400 d.C.).

Las excavaciones sugieren que durante estos dos periodos las áreas alrededor de las Plazas Central y H, que ahora se denominan Gran Plaza y Plazas E y F, eran zonas inundables ya que el material parental hallado fue un suelo limoso de tipo luvisol (TP2, 3, 8 y 9).

Debido al límite de las excavaciones, los cálculos del área total de las plazas e inversión de trabajo en ellas no reflejarían con certeza el número absoluto de participantes en los rituales públicos y en las construcciones. En los cálculos del área total de las plazas no se incluyeron las plataformas que posiblemente fueron utilizadas para las danzas y la colocación de objetos rituales como vasijas, comidas y bebidas (Grube, 1992). Es muy probable que las extensiones de cada plaza fueran transformadas a través del tiempo y sus usos fueran múltiples, con diferentes clases de participantes y objetos. Particularmente, los cálculos sobre la inversión de trabajo son resultados preliminares, ya que no hemos excavado toda la plaza. El cálculo sólo se basó en el área de cada plaza multiplicada por la profundidad de los estratos correspondientes; posteriormente se sumó el volumen de todas las plazas por periodo.

No obstante, estos cálculos nos proporcionan una idea sobre en qué período las plazas y los rituales públicos asociados fueron más relevantes. Además, nos permiten evaluar cuantitativamente su capacidad. Aunque los cálculos se basaron en el plano más reciente del sitio, el área total de las plazas durante los dos periodos era de $9129 \mathrm{~m}^{2}$ (figura 4) y la inversión de trabajo por metro cúbico fue de $6777.65 \mathrm{~m}^{3}$ en el Preclásico Tardío y $2316.8 \mathrm{~m}^{3}$ en el Clásico Temprano, ambas cifras relativamente bajas en comparación con la del Clásico Medio (figura 5).

\section{Clásico Medio (400-600 d.C.)}

El paisaje urbano del Grupo Principal de El Palmar durante el Clásico Medio cambió de manera dramática. Las excavaciones y el análisis de los materiales indican que la Gran Plaza, la Plaza K'awiil y las Plazas E y G fueron construidas en ese periodo, además de que la Plaza Central se elevó casi un metro. Nivelando el suelo de luvisol, en la Gran Plaza y en la Plaza E se construyó un delgado piso de estuco sin colocar relleno de grava. El proyecto arquitectónico sobresaliente 


\begin{tabular}{|l|r|r|r|r|}
\hline \multicolumn{2}{|c|}{} & \multicolumn{3}{|c|}{ Capacidad Estimada de Plaza } \\
\hline Nombre de Plaza & Área $\left(\mathrm{m}^{2}\right)$ & $0.46 \mathrm{~m}^{2} /$ persona & $1 \mathrm{~m}^{2} /$ persona & $3.6 \mathrm{~m}^{2} /$ persona \\
\hline Gran Plaza & 14135 & 30728 & 14135 & 3926 \\
\hline Plaza Central & 6674 & 14509 & 6674 & 1854 \\
\hline Plaza E & 9096 & 19774 & 9096 & 2527 \\
\hline Plaza F & 6134 & 13335 & 6134 & 1704 \\
\hline Plaza G & 1230 & 2673 & 1230 & 341 \\
\hline Plaza H & 2455 & 5336 & 2455 & 681 \\
\hline Plaza K'awiil & 3161 & 6872 & 3161 & 878 \\
\hline Plaza López & 890 & 1935 & 890 & 247 \\
\hline Área total & 40090 & 87152 & 40090 & 11136 \\
\hline
\end{tabular}

FIgura 4. Tabla de la capacidad estimada en las plazas del Grupo Principal de El Palmar

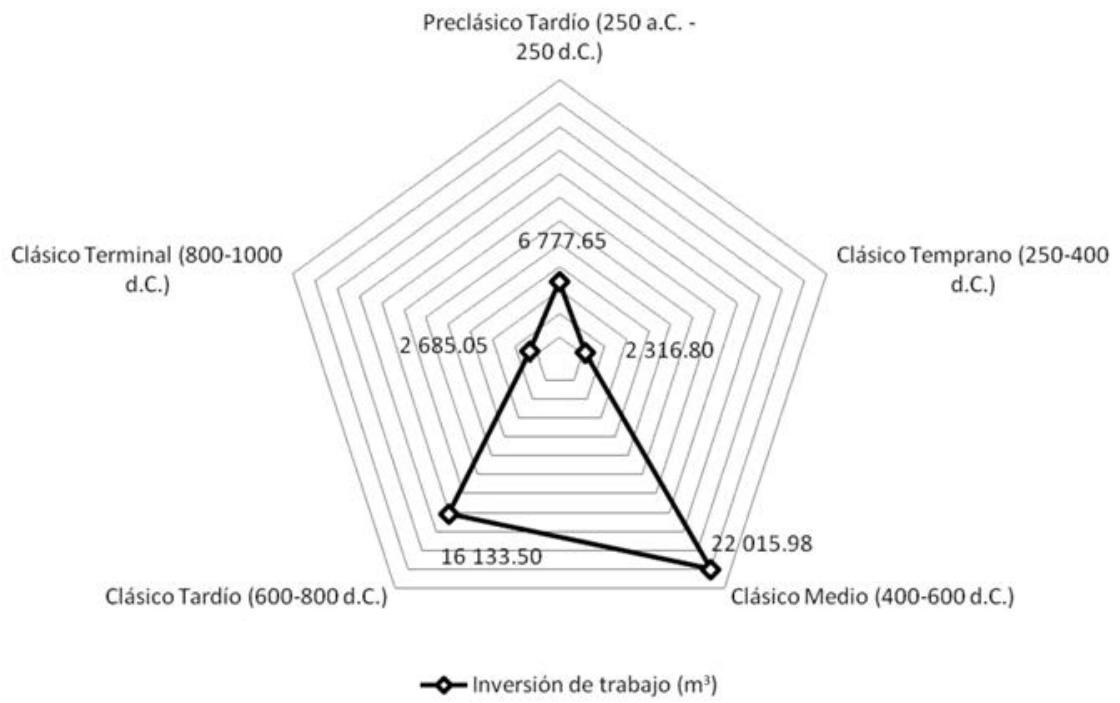

Figura 5. Gráfica de la inversión de trabajo $\left(\mathrm{m}^{3}\right)$ estimada en El Palmar

del Clásico Medio fue, sin duda, la edificación de la Estructura PM3 en la Plaza $\mathrm{G}$ (tomando como base los resultados del TP6). El sondeo estratigráfico sugiere que el piso más antiguo (Piso 3) alcanzó $10 \mathrm{~m}$ de elevación desde la superficie de la Plaza E. Tres muestras de carbono 14 tomadas del relleno constructivo de la Plaza G lo datan entre el 196 y el 353 d.C. con $98.20 \%$ en rango de probabili- 
dad; entre el 421 y el 533 d.C. y entre el 425 y el 533 d.C. con $68.20 \%$ en rango de probabilidad. Estas últimas muestras, en conjunto con el análisis cerámico, revelan que la Plaza G fue construida entre los años 425 y 533 d.C.

Si bien la Plaza G fue el proyecto arquitectónico más voluminoso, la Gran Plaza (TP3 y TP9) fue diseñada con mayor extensión con el fin de acomodar a la mayor población en un evento público. En el relleno de la Gran Plaza no se encontraron materiales cerámicos diagnósticos del Clásico Medio, sino del Clásico Temprano (250-600 d.C.). Sin embargo, el análisis preliminar del estuco por medio de la catodoluminisencia realizado por Tatsuya Murakami indicó que el primer piso de la Gran Plaza fue construido durante el primer periodo mencionado, ya que la tecnología de los pisos más antiguos en ésta y en la Plaza G fue idéntica a la del Clásico Medio. Además se encontró un artefacto lítico del tipo "cepillo" (Domed Smoother) (figura 6) en el mismo relleno, que Rovner, Lewenstein y Nelson (1997) señalan como material diagnóstico del principio del Clásico Tardío. Es decir, se puede interpretar la emergencia de la mencionada plaza a partir del Clásico Medio. Con base en todos los resultados anteriores, sugerimos que la Gran Plaza, la Plaza G y probablemente la Plaza E fueron construidas durante el Clásico Medio.

En el caso de la Plaza K'awiil, el periodo constructivo tiene una fecha aún más exacta. Durante la excavación de prueba (TP5) se encontró un escondite (Escondite 3) o cache asociado al Altar 10, debajo del piso más antiguo de la plaza (figuras 7 y 8). Debido a la ausencia de una intrusión, creemos que el ente-
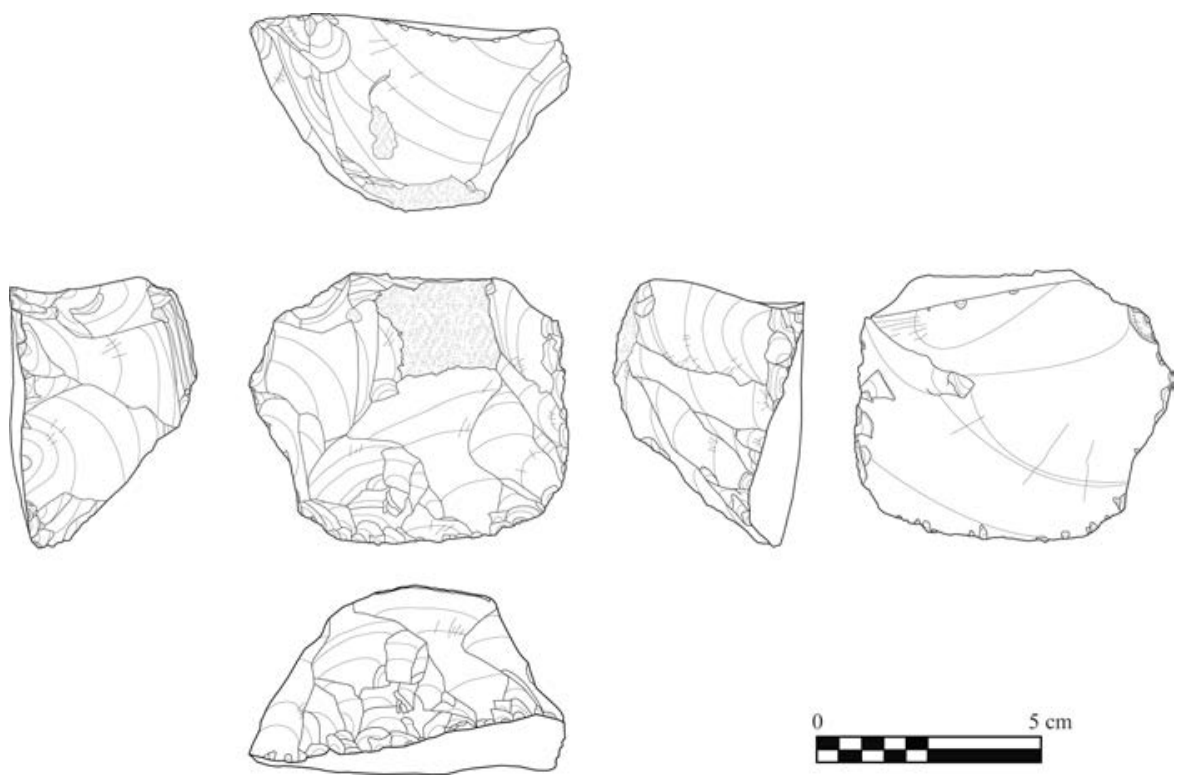

Figura 6. Herramienta lítica denominada "cepillo" (Domed Smoother), dibujado por Kenichiro Tsukamoto 
rramiento del Escondite 3 y la construcción de la plaza fueron contemporáneos. $\mathrm{Si}$ se considera que el Altar 10 contiene una Rueda Calendárica que registra la fecha del 20 de marzo del 554 d.C., la construcción de la Plaza K'awiil en el siglo sexto es contemporánea a la de las tres plazas anteriores.

El área total de las plazas se extendió $36571 \mathrm{~m}^{2}$, cifra cuatro veces más grande que la de los periodos anteriores (figura 4). Si una persona ocupa un metro cuadrado durante rituales públicos, las plazas pudieron haber acomodado más de 36000 participantes. Asimismo, la inversión de trabajo se incrementó de $9094.45 \mathrm{~m}^{3}$ a $22015.98 \mathrm{~m}^{3}$ en tan sólo 200 años (figura 5).

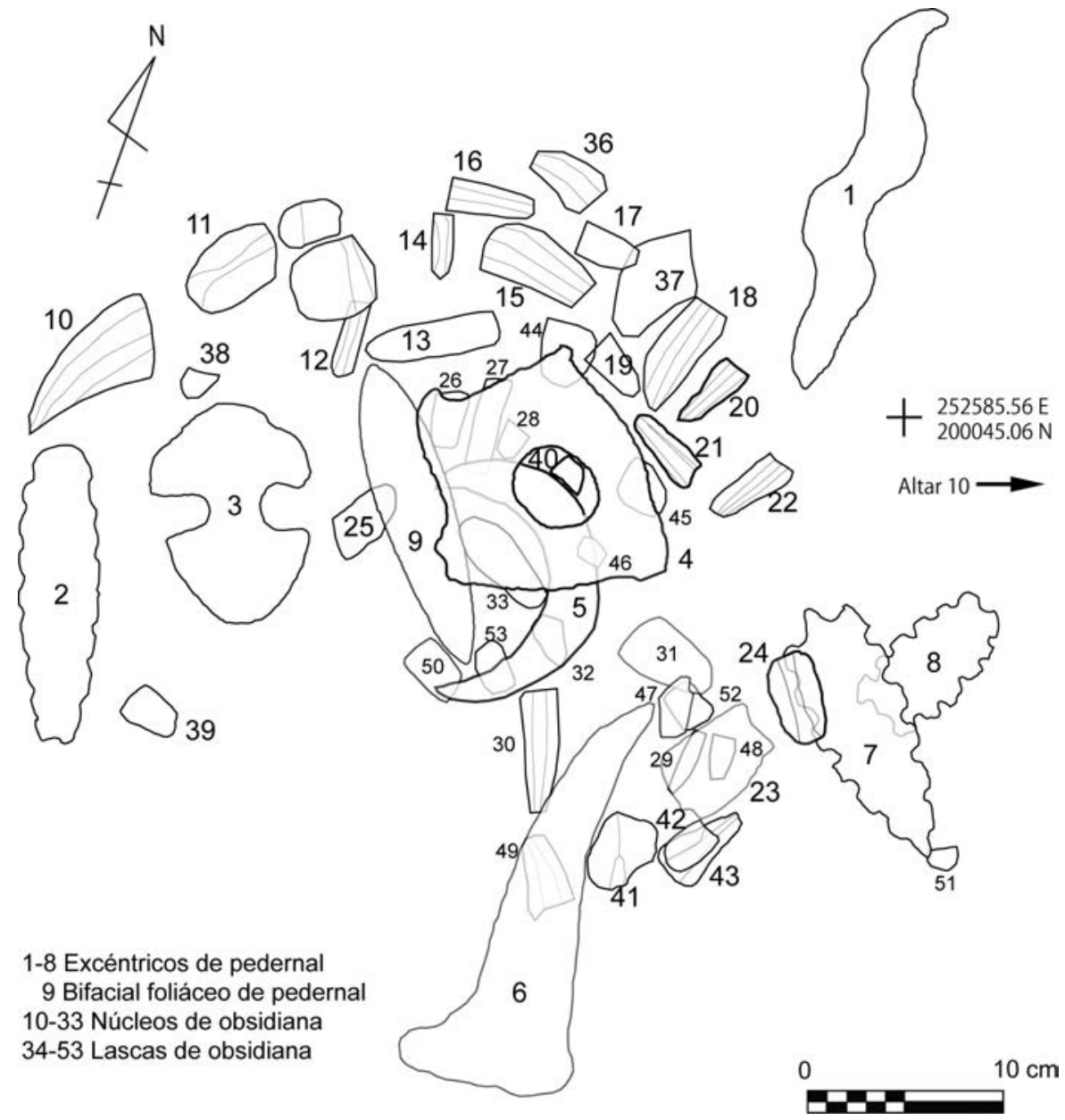

Figura 7. Plano del Escondite 3 descubierto en El Palmar, dibujado por Kenichiro Tsukamoto y Luz Evelia Campaña 


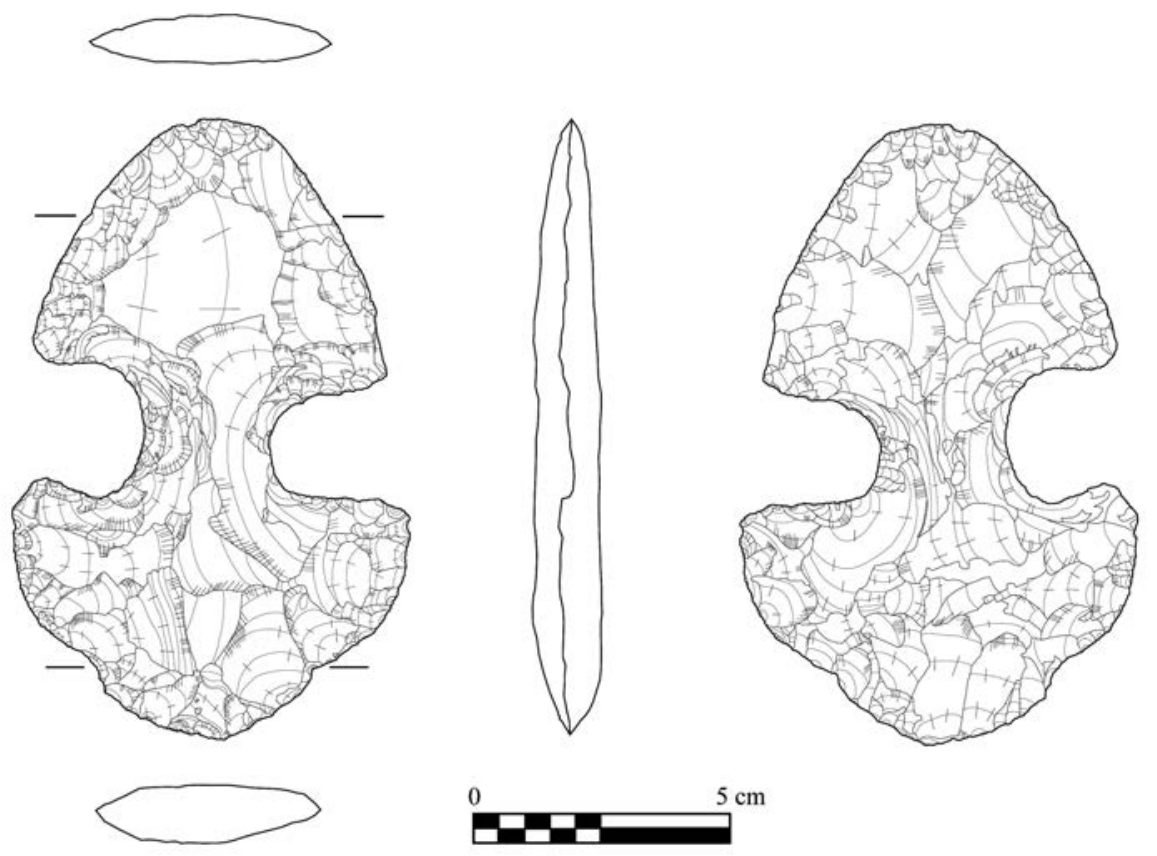

Figura 8. Excéntrico proveniente del Escondite 3 de El Palmar, dibujado por Kenichiro Tsukamoto

Clásico Tardío (600-800 d.C.)

Los mayas de El Palmar continuaron construyendo espacios abiertos, como la Plaza F (TP8) y la Plaza López (TP7) durante el Clásico Tardío (600-800 d.C.), además de remodelar las plazas anteriores. Sin embargo, la dimensión de estas nuevas plazas fue más pequeña. Al mismo tiempo, las élites gobernantes erigieron una gran cantidad de monumentos grabados en la Gran Plaza, la Plaza Central y la Plaza E. El área total de las plazas aumentó a $43595 \mathrm{~m}^{2}$ con la construcción de las Plazas F y López (figura 4), pero la inversión de trabajo disminuyó a 16133.5 $\mathrm{m}^{3}$ (figura 5).

Clásico Terminal (800-1000 d.C.)

La construcción o remodelación de plazas disminuyó de manera significativa durante el Clásico Terminal, aunque las estelas con inscripciones sugieren que la Gran Plaza, la Plaza E y la Plaza K'awiil siguieron funcionando para ceremonias conmemorativas en los años 800, 820 y 884 d.C., respectivamente. La Plaza H es 
la única que presenta evidencia de la remodelación, con una inversión laboral de $2685.05 \mathrm{~m}^{3}$ (figura 5).

\section{Construcciones y remodelaciones de plazas como una estrategia política}

Los resultados de las excavaciones de prueba y del análisis de los materiales señalan que las construcciones y remodelaciones de las plazas eran importantes para la sociedad de El Palmar. Nosotros creemos que la construcción intensiva de las plazas mayores refleja una estrategia de las élites gobernantes para organizar a la sociedad. En periodos premodernos, los espectáculos en un amplio espacio abierto, como la plaza, jugaban un papel preponderante para la organización política (Connerton, 1989; Foucault, 1984, 1995[1978]; Inomata, 2006; Joyce, 2004; Low, 1995; Moore, 1996). Es posible que la construcción y remodelación de las plazas públicas fueran proyectos importantes para las élites gobernantes de El Palmar, quienes requerían manifestar su conocimiento especial en la ejecución de los rituales para establecer contacto con los ancestros y las deidades. Investigaciones previas sugieren que, en Mesoamérica, ciertos saberes como la comunicación con los ancestros y la escritura jeroglífica eran exclusivos de las élites gobernantes, y mediante ellos reclamaban y sostenían su poder político con manipulaciones ideológicas y religiosas (Houston, Robertson y Stuart, 2000; Inomata, 2001; Joyce y Winter, 1996; McAnany, 1993, 1995).

Bajo esta condición, las plazas fueron los escenarios donde las élites gobernantes legitimaban su autoridad política a través de prácticas rituales. En este sentido, consideramos que el número de plazas en un sitio y su continua remodelación revela que las relaciones de poder entre las élites gobernantes y otros segmentos sociales fueron equilibradas por medio de rituales públicos celebrados en los espacios abiertos (Scott, 1998). Además, el súbito incremento de la capacidad para acomodar a los participantes en las plazas sugiere la transformación del sitio, de pueblo local a centro regional, ya que los espacios para la realización de espectáculos regularmente son diseñados en función del número de participantes. La construcción de nuevos espacios públicos, como la Gran Plaza y la Plaza E, indican que El Palmar se convirtió en un centro regional que albergaba a un gran auditorio que participaba del teatro político de las ceremonias conmemorativas.

Otros segmentos sociales no eran receptores pasivos de la ideología y dominación, sino sus evaluadores. Sus resultados (aceptación o rechazo) influían en su participación en otras construcciones (Geertz, 1980; Inomata, 2006), ya que los rituales públicos no funcionan con la ausencia del público: este y los protagonistas interactúan mutuamente para crear un ambiente de espectáculo.

Mientras las regiones colindantes se involucraron en las interacción política debido a la confrontación entre Tikal y Calakmul a partir del Clásico Medio 
(Adams, 1999; Martin, 2000; Stuart, 2000; Wright, 2005a y b), las remodelaciones de la Gran Plaza, la Plaza E y la Plaza G, así como las numerosas erecciones de las estelas y altares sugieren que los rituales-espectáculos públicos fueron exitosos y ayudaron a cimentar la identidad social. Particularmente, la edificación de la Plaza $\mathrm{G}$ como un espacio exclusivo de las élites revela que los otros grupos sociales consintieron su legitimación política y poder, y que aquellas consolidaban identidades distintas a las de los rituales públicos.

La construcción de plazas y de templos piramidales no sólo fue importante desde el punto de vista arquitectónico, sino también ideológico, pues convirtieron la ciudad en un lugar mitológico. Garza (2010: 43) sugiere que la plaza y la pirámide son símbolos de la tierra cuadrangular y de la montaña sagrada (véase también Ashmore, 1991, 2004; Brady y Ashmore, 1999; Schele y Freidel, 1990). Esta cosmovisión inscrita en el paisaje y las ceremonias conmemorativas repetitivas pudieron haber ayudado a producir y reproducir la memoria social (Connerton, 1989; Van Dyke y Alcock, 2003). Con base en el análisis de la sicología política, Caspary (1993) sugiere que la obediencia al poder ideológico con representaciones simbólicas tiende a desarrollarse durante periodos de crisis (véase también Joyce y Winter, 1996: 35; Volkan, 1985). Es decir, la intensa interacción política de las regiones cercanas pudo haber servido para cimentar la ideología política de El Palmar a partir del Clásico Medio, y la construcción y remodelación de las plazas grandes y privadas fue una respuesta de la solidaridad y la obediencia social.

\section{Conclusión}

La excavación y el análisis de los materiales evidencian que las grandes plazas, como la Gran Plaza y las Plazas E, G y K'awiil fueron construidas durante el periodo Clásico Medio (400-600 d.C.). Su construcción, junto con la de los templos piramidales monumentales, sugiere que la celebración de rituales públicos - como teatro político- era un elemento importante para las élites gobernantes, quienes legitimaban las autoridades políticas a través de los espectáculos y la materialización de ellos en los monumentos grabados. El fenómeno del proyecto arquitectónico en El Palmar es parecido al de Río Azul (Adams, 1999) y Uaxactún (Valdés y Fahsen, 1995). No obstante, por el momento la información limita la interpretación y aún no es posible revelar la relación de El Palmar con las superpotencias Tikal y Calakmul. Sólo podemos anotar que, al igual que esos sitios, el periodo Clásico Medio fue fundamental para su organización política y espacial. 


\section{BIBLIOGRAFÍA}

Adams, Richard E. W.

1999 Rio Azul: An Ancient Maya city. Norman: University of Oklahoma Press.

Adams, Richard E. W. y Richard C. Jones

1981 "Spatial Patterns and Regional Growth among Classic Maya Cities", American Antiquity, 46 (2): 301-322. Washington, D. C.: Society for American Archaeology.

Aimers, James J. y Prudence M. Rice

2006 "Astronomy, Ritual, and the Interpretation of Maya "E-Group" Architectural Assemblages”, Ancient Mesoamerica, 17: 79-96. Cambridge: Cambridge University Press.

Ashmore, Wendy

1991 "Site-planning principles and concepts of directionality among the ancient Maya”, Latin American Antiquity, 2 (3): 199-226. Washington, D. C.: Society for American Archaeology.

2004 "Ancient Maya Landscape", Continuities and Changes in Maya Archaeology: Perspectives at the Millennium. Charles W. Golden y Greg Borgstede (eds.). Nueva York: Routledge, 97-11.

Brady, James E. y Wendy Ashmore

1999 "Mountains, Caves, Water: Ideational Landscapes of the Ancient Maya", Archaeology of Landscape: Contemporary Persipective. Wendy Ashmore y Arthur B. Knapp (eds.). Malden [Estados Unidos]: Blackwell Publisher, 124-145.

Bueno, Ricardo

1999 Entre un río de robles: un acercamiento a la arqueología de la región Río Bec. México: Instituto Nacional de Antropología e Historia (Colección Científica, 411).

Campaña, Luz Evelia

2005 “Contribuciones a la historia de Becán”, Arqueología Mexicana, XIII (75): 4853. México: Raíces.

Caspary, William R.

1993 "New Psychoanalytic Perspectives on the Causes of War", Political Psychology, 14 (3): 417-446. Malden [Estados Unidos]: Wiley-Blackwell Publishers.

Clark, John E. y Richard D. Hansen

2001 The Architecture of Early Kingship: Comparative Perspectives on the Origins of the Maya Royal Court. Royal Courts of the Ancient Maya, Volume Two: Data and Case Studies. Colorado: Westview Press.

Connerton, Paul

1989 How Societies Remember. Nueva York: Cambridge University Press. 
Demarest, Arthur A.

1992 "The Dynamics of Galactic Polities", Ideology and Pre-Columbian Civilizations. Arthur A. Demarest y Geoffrey W. Conrad (eds.). Santa Fe: School of American Research Press, 135-157.

Foucault, Michel

1984 "Space, Knowledge, and Power", The Foucault Reader. Paul Rabinow (ed.). Nueva York: Pantheon Books, 239-256.

1995 Discipline and Punish: The Birth of the Prison. Nueva York: Vintage Books.

[1978]

Freidel, David A. y Linda Schele

1988 "Kingship in the Late Pre-Classic Maya Lowlands: The Instruments and Places of Ritual Power”, American Anthropologist, 90: 547-567. Arlington: American Anthropological Association

Garza, Mercedes de la

2010 "El universo temporal en el pensamiento maya”, Arqueología Mexicana 103: 38-44. México: Raíces.

Geertz, Clifford

$1980 \quad$ Negara: The Theatre State in Nineteenth-Century Bali. Princeton: Princeton University Press.

Grube, Nikolai

1992 "Classic May dance: Evidence from hieroglyphs and iconography", Ancient Mesoamerica, 3: 201-218. Cambridge: Cambridge University Press.

Houston, Stephen D.

1998 "Classic Maya Depictions of the Built Environment", Function and Meaning in Classic Maya Architecture: A Symposium at Dumbarton Oaks 7th and 8th October 1994. Stephen D. Houston (ed.). Washington, D. C.: Harvard University Press, 333-372.

Houston, Stephen, John Robertson y David Stuart

2000 "The Language of Classic Maya Inscriptions", Current Anthropology, 41 (3): 321-356. Chicago: Chicago University Press.

Inomata, Takeshi

2001 "Power and Ideology of Artistic Creation: Elite Craft Specialists in Classic Maya Society”, Current Anthropology, 42 (3): 321-349. Chicago: Chicago University Press.

2006 "Plazas, Performers, and Spectators: Political Theaters of the Classic Maya", Current Anthropology, 47 (5): 805-841. Chicago: Chicago University Press.

Joyce, Arthur A.

2004 "Sacred Space and Social Relations in Oaxaca", Mesoamerican Archaeology. Julia A. Hendon y Rosemary A. Joyce (eds.). Malden [Estados Unidos]: Blackwell Publishing, 192-216. 
Joyce, Arthur A. y Marcus Winter

1996 "Ideology, Power, and Urban Society in Pre-Hispanic Oaxaca", Current Anthropology, 37 (1): 33-47. Chicago: Chicago University Press.

Joyce, Rosemary A.

2001 "Planificación urbana y escala social: reflexiones sobre datos de comunidades clásicas en Honduras", Reconstruyendo la ciudad maya: el urbanismo en las sociedades antiguas. Andrés Ciudad, María Josefa Iglesias y María del Carmen Martínez (eds.). Madrid: Sociedad Española de Estudios Mayas (Publicación 6), 123-136.

Laporte, Juan Pedro y Vilma Fialko

1995 "Un reencuentro con Mundo Perdido, Tikal, Guatemala”, Ancient Mesoamerica, 6: 41-94. Cambridge: Cambridge University Press.

Low, Setha M.

1995 "Indigenous Architecture and the Spanish American Plaza in Mesoamerican and the Caribbean”, American Anthropologist, 97 (4): 748-762. Arlington: American Anthropological Association

Martin, Simon

2000 “Los Señores de Calakmul”, Arqueología Mexicana, VII (42): 40-45. México: Raíces.

McAnany, Patricia A.

1993 "The Economics of Wealth among Eighth-Century Maya Households", Lowland Maya Civilization in the Eight Century A.D.: A Symposium at Dumbarton Oaks 7th and 8thOctober 1989. Jeremy A. Sabloff y John S. Henderson (eds.). Washington, D. C.: Dumbarton Oaks Research Library and Collection, 6579.

1995 Living with Ancestors: Kingship and Kingship in Ancient Maya Society. Austin: University of Texas Press.

Moore, Jerry D.

1996 Architecture \& Power In the Ancient Andes: The Archaeology of Public Buildings. Cambridge: Cambridge University Press.

Restall, Matthew

2001 "The People of the Patio: Ethnohistorical Evidence of Yucatec Maya Royal Courts", Royal Courts of the Ancient Maya, Vol. 2. Takeshi Inomata y Stephen D. Houston (eds.). Boulder [Estados Unidos]: Westview Press, 335-377.

Ringle, William M. y George J. Bey III

2001 "Post-Classic and Terminal Classic Courts of the Northern Maya Lowlands", Royal Courts of the Ancient Maya, vol 2. Takeshi Inomata y Stephen D. Houston (eds.). Boulder [Estados Unidos]: Westview Press, 266-307. 
Rovner, Irwin, Suzanne M. Lewenstein y Fred W. Nelson

1997 Maya stone tools of Dzibilchaltún, Yucatán, and Becán and Chicanná, Campeche. Nueva Orleans: Tulane University, Middle American Research Institute.

Schechner, Richard

1985 Between Theater and Anthropology. Filadelfia. University of Pennsylvania Press.

Schele, Linda y David Freidel

1990 A Forest of Kings: The Untold Story of The Ancient Maya. Nueva York: Quill William Morrow.

Scott, James C.

1998 Seeing Like A State: How Certain Schemes To Improve the Human Condition Have Failed. New Haven / Londres: Yale University Press.

Sharer, Robert J. y Charles W. Golden

2004 "Kingship and Polity: Conceptualizing the Maya Body Politic", Continuities and Changes in Maya Archaeology: Perspectives at the Millennium. C. W. Golden y G. Borgstede (eds.). Nueva York: Routledge, 23-50.

Šprajc, Ivan

2008 Reconocimiento arqueológico en el sureste del estado de Campeche, México: 1996-2005. Ljubljana [Eslovenia]: Centro de Investigaciones Científicas de la Academia Eslovena de Ciencias y Artes (British Archaeological Reports, International Series 1742. Paris Monographs in America Archaeology, 19).

Stuart, David

2000 “' “The Arrival of Strangers': Teotihuacan and Tollan in Classic Maya History”, Mesoamerican's Classic Heritage: From Teotihuacan to the Aztecs. David Carrasco, Lindsay Jones y Scott Sessions (eds.). Niwot: Colorado University Press, 465-513.

Thompson, J. Eric S.

1936 "Exploration in Campeche and Quintana Roo and excavations at San José, British Honduras", Carnegie Institution of Washington Year Book 35. Washington, D. C.: Carnegie Institution, 125-128.

Tsukamoto, Kenichiro y Javier López Camacho

2007 "El Palmar: una ciudad ubicada en una antigua frontera maya", Antropología e Historia, por sus especialistas, vol. 1. Campeche: Consejo Nacional para la Cultura y las Artes / Instituto Nacional de Antropología e Historia, 20-21.

Tsukamoto, Kenichiro, Javier López Camacho y Octavio Q. Esparza Olguín 2010 "El Palmar, Campeche”, Arqueología Mexicana, 17(101): 72-77. México: Raíces.

Turner, Victor

1986 From Ritual to Theatre and Back. Nueva York: Performing Arts Journal Publications. 
Valdés, Juan Antonio y Federico Fahsen

1995 "The Reigning Dynasty of Uaxactun during the Early Classic: The Rulers and the Ruled", Ancient Mesoamerica, 6: 197-219. Cambridge: Cambridge University Press.

Van Dyke, Ruth M. y Susan E. Alcock

2003 "Archaeologies of Memory: An Introduction", Archaeologies of Memory, pp. 1-13; Ruth M. Van Dyke y Susan E. Alcock (eds.). Malden [Estados Unidos]: Blackwell Publishers.

Volkan, Vamik D.

1985 "The Need to Have Enemies and Allies: A Developmental Approach", Political Psychology, 6 (2): 219-247. Malden [Estados Unidos]: Wiley-Blackwell Publishers.

Wright, Lori E.

2005a "Identifying Immigrants to Tikal, Guatemala: Defining local variability in strontium isotope ratios of human tooth enamel", Journal of Archaeological Science, 32: 555-566. Londres: Elsevier.

2005b "In Search of Yax Nuun Ayiin", Ancient Mesoamerica, 16: 89-100. Cambridge: Cambridge University Press. 


\title{
SECUENCIA CONSTRUCTIVA DE LAS PLAZAS \\ EN EL GRUPO PRINCIPAL DE EL PALMAR, CAMPECHE, MÉXICO
}

\author{
Kenichiro TSUKAmoto \\ School of Anthropology, University of Arizona
}

\author{
HiRokazu Kotegawa \\ Posgrado en Antropología, Facultad de Filosofía y Letras / Instituto \\ de Investigaciones Antropológicas, Universidad Nacional Autónoma de México \\ Facultad de Antropología, Universidad Veracruzana
}

\author{
Luz Evelia Campaña \\ Proyecto Arqueológico El Palmar
}

\begin{abstract}
Resumen: La ubicación y dimensión de los espacios abiertos fueron aspectos considerados al planificar las ciudades de las Tierras Bajas Mayas en el periodo prehispánico. Las plazas eran los espacios políticos donde las élites gobernantes legitimaban a sus autoridades y manifestaban a otros participantes sus capacidades para comunicarse con los ancestros o deidades. Este trabajo se centra en la secuencia constructiva de ocho plazas en el Grupo Principal del sitio arqueológico de El Palmar, Campeche, México. Los resultados obtenidos durante las temporadas de campo en el 2007 y el 2009 indican que las grandes plazas fueron construidas durante la segunda mitad del Clásico Temprano (400-600 d.C.) y que en ellas se celebraron ceremonias públicas inscritas en los monumentos conmemorativos.
\end{abstract}

Palabras clave: plaza, El Palmar, teatro político, secuencia constructiva, antigua sociedad maya del Clásico.

ABSTRACT: The location and dimension of open spaces were important aspects involved in Maya Lowlands planning during the prehispanic period. Plazas were political spaces in which ruling elites legitimated their authorities and manifested to other participants their capacities of communication with ancestors or deities. This paper focuses on the construction sequence of eight plazas at the Main Group of El Palmar, Campeche, Mexico. The results recovered from the 2007 and 2009 fieldwork seasons indicate that large plazas were build during the second part of the Early Classic period (400-600 AD), with the erection of commemorative monuments narrating public ceremonies.

Kerwords: plaza, El Palmar, political theater, construction sequence, Classic Maya society.

ReCEPCIÓn: 31 de agosto del 2010.

ACEPTACIÓN: 24 de marzo del 2011. 


\title{
SECUENCIA CONSTRUCTIVA DE LAS PLAZAS EN EL GRUPO PRINCIPAL DE EL PALMAR, CAMPECHE, MÉXICO
}

\author{
Kenichiro TSUKAmoto \\ School of Anthropology, University of Arizona \\ HiRokAZU Kotegawa \\ Posgrado en Antropología, Facultad de Filosofía y Letras / Instituto de Investi- \\ gaciones Antropológicas, Universidad Nacional Autónoma de México \\ Facultad de Antropología, Universidad Veracruzana \\ LuZ Evelia CAmpaña \\ Proyecto Arqueológico El Palmar
}

\section{Introducción}

En las Tierras Bajas Mayas, la construcción y remodelación de la plaza estaba relacionada con la organización política (Inomata, 2006; Restall, 2001; Ringle y Bey III, 2001; Sharer y Golden, 2004). Recientes estudios arqueológicos, epigráficos e iconográficos han profundizado sobre la organización política, particularmente sobre la institución encabezada por el Ajaw, que se fundó en el periodo Preclásico Tardío (250 a.C.-250 d.C.) (Freidel y Schele, 1988) y floreció durante todo el Clásico (250-900 d.C.). Las élites gobernantes fueron promotoras de la construcción de estructuras monumentales, del desarrollo de guerras, de la erección de monumentos conmemorativos y de la celebración de sacrificios humanos y rituales públicos. Durante periodos de agitación política, ejecutaron esas actividades de manera acelerada para mantener su autoridad política, no siempre estable. Una de las estrategias de la institución Ajaw para la legitimización del poder fue quizás el teatro político, hipótesis originalmente propuesta por Geertz (1980) al estudiar la sociedad de Bali en el siglo xIx (Demarest, 1992; Houston,

Agradecemos al Instituto Nacional de Antropología e Historia (INAH), institución que otorgó los permisos C.A. 401-361/138 y C.A. 401-36/0837 para realizar el proyecto arqueológico El Palmar: Urbanización del espacio social en las tierras bajas mayas. Reconocemos de manera especial al arqueólogo Javier López Camacho, de la Escuela Nacional de Antropología e Historia (ENAH), quien es codirector del proyecto. Asimismo a Octavio Esparza Olguín, Alejandra Salinas, Tatsuya Murakami, Yuki Tanaka, estudiantes de la enAH, y a los trabajadores locales del ejido Kiché las Pailas, por su participación desinteresada. Finalmente, a Takeshi Inomata y Daniela Triadan por su apoyo académico. El proyecto fue financiado por la SBSRI Pre-doctoral Grant de la Universidad de Arizona. 
1998; Sharer y Golden, 2004), quien sugirió que la razón de existir del Estado era mantener el teatro político (Inomata, 2006: 808). Turner (1986) y Schechner (1985) indican que en cualquier sociedad los rituales públicos tienen un carácter teatral; sin duda, estos tuvieron un carácter teatral en la antigua sociedad maya del Clásico, a juzgar por las reiteradas representaciones grabadas en sus monumentos escultóricos. Los personajes que aparecen en estos últimos, por lo regular llevan máscaras, ornamentos, bastones ceremoniales y atavíos espléndidos, los cuales pudieron haber complementado el carácter teatral de rituales públicos. Con el fin de utilizar el teatro político como espectáculo, las plazas públicas fueron el escenario propicio para concentrar y acomodar a la población o a grupos seleccionados de la sociedad, dependiendo de la dimensión y ubicación de los espacios abiertos. En este sentido, su construcción y remodelación revelaría las huellas de una cultura material donde la gente consentía o era coercionada por las decisiones políticas de la élite gobernante, pues la mayor parte de la población debió participar en la erección de obras monumentales, incluidos los espacios públicos. Así, a través del estudio de su secuencia constructiva y de los materiales arqueológicos asociados es factible aproximarse al papel de los rituales públicos en la sociedad maya y al comportamiento de la población ante el teatro político de las élites gobernantes.

El presente trabajo presenta la secuencia constructiva de ocho plazas del Grupo Principal en el sitio arqueológico de El Palmar, ubicado al sureste de Campeche, México, como un caso de estudio.

\section{El Palmar}

El Palmar posee un carácter peculiar en cuanto a su ubicación. Se localiza en el sureste de Campeche, México, relativamente cerca de varios centros mayores: $90 \mathrm{~km}$ al sur se ubica Tikal; $50 \mathrm{~km}$ al oriente, Calakmul; y $70 \mathrm{~km}$ al norte, Becán (figura 1). En sus inmediaciones se encuentran también Mucaancah, Río Azul, Los Alacranes, La Milpa, Río Bec y Altar de los Reyes (Šprajc, 2008). De acuerdo con Adams y Jones (1981), esta área fue ocupada por tres esferas geopolíticas (Tikal, Calakmul y Río Bec) durante el Clásico Tardío y, por su localización, El Palmar pudo haber sido el centro de gravedad limítrofe de las tres regiones. Además de los conflictos políticos entre Tikal y Calakmul, en los sitios de la región Río Bec, como Becán, Río Bec y Hormiguero, se construyeron estructuras monumentales con un estilo arquitectónico propio durante el Clásico Tardío (600-800 d.C.) (Bueno, 1999; Campaña, 2005). Es decir, en términos de las interacciones políticas, los años transcurridos entre el 400 d.C. y el 700 d.C. debieron constituir un periodo dinámico y es probable que la participación de El Palmar fuera inevitable en los asuntos políticos.

Los recorridos de superficie y el levantamiento topográfico han detectado que

El Palmar tiene al menos otros ocho grupos arquitectónicos agrupados dentro de 


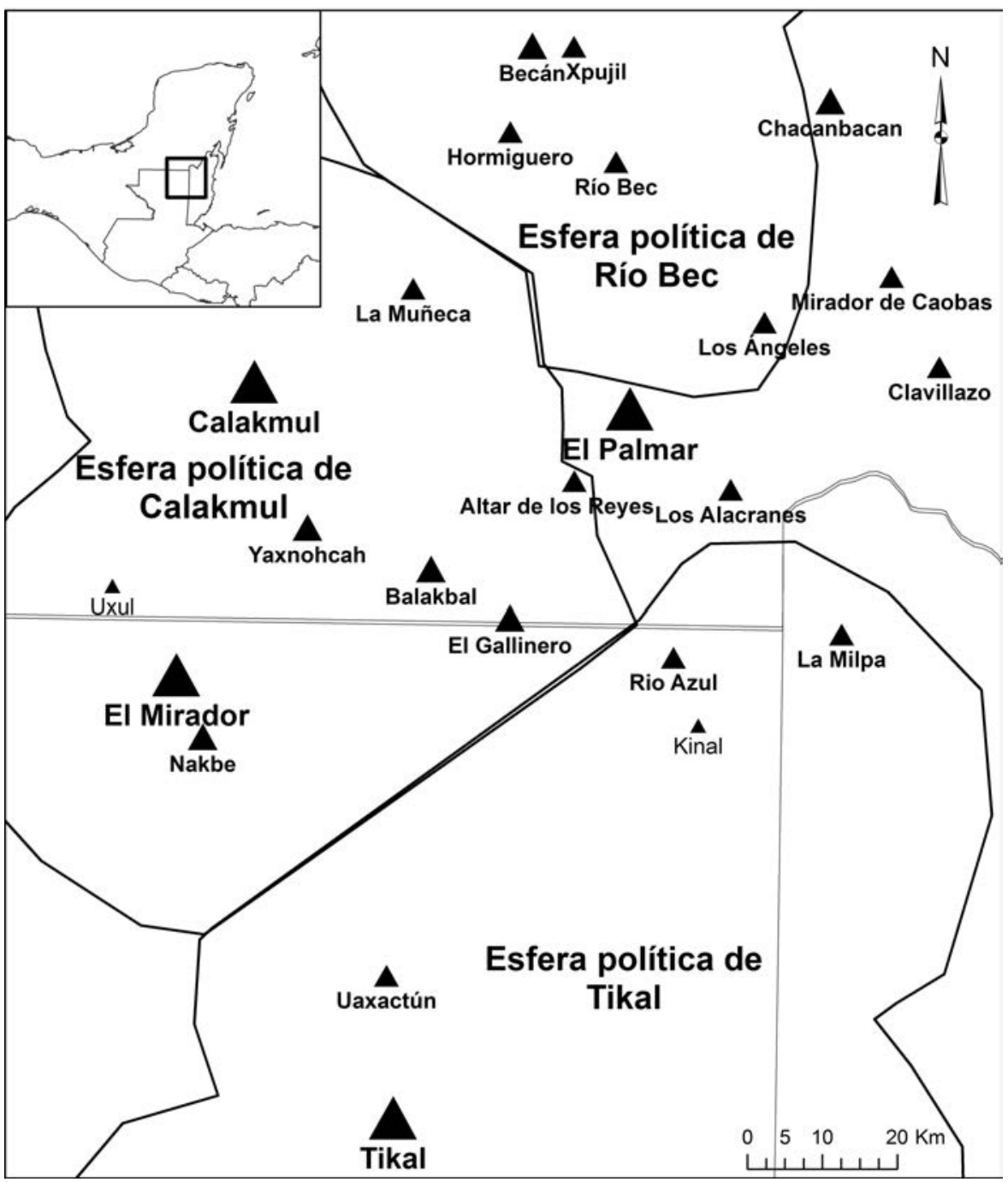

Figura 1. Mapa de esferas políticas en las Tierras Bajas Mayas, basado en Adams y Jones, 1981: 309

un radio máximo de $2.5 \mathrm{~km}$ a partir del Grupo Principal. En la configuración espacial del Grupo Principal destacan dos templos piramidales, un extenso palacio, una gran cantidad de los monumentos grabados y, por supuesto, las plazas (Tsukamoto, López Camacho y Esparza Olguín, 2010; Tsukamoto y López Camacho, 2007) (figura 2). El diseño planificado del Grupo Principal contiene ocho plazas con dimensiones distintas: la Gran Plaza, la Plaza Central, la Plaza K'awiil, las Plazas E, F, G y H, y la Plaza López. 


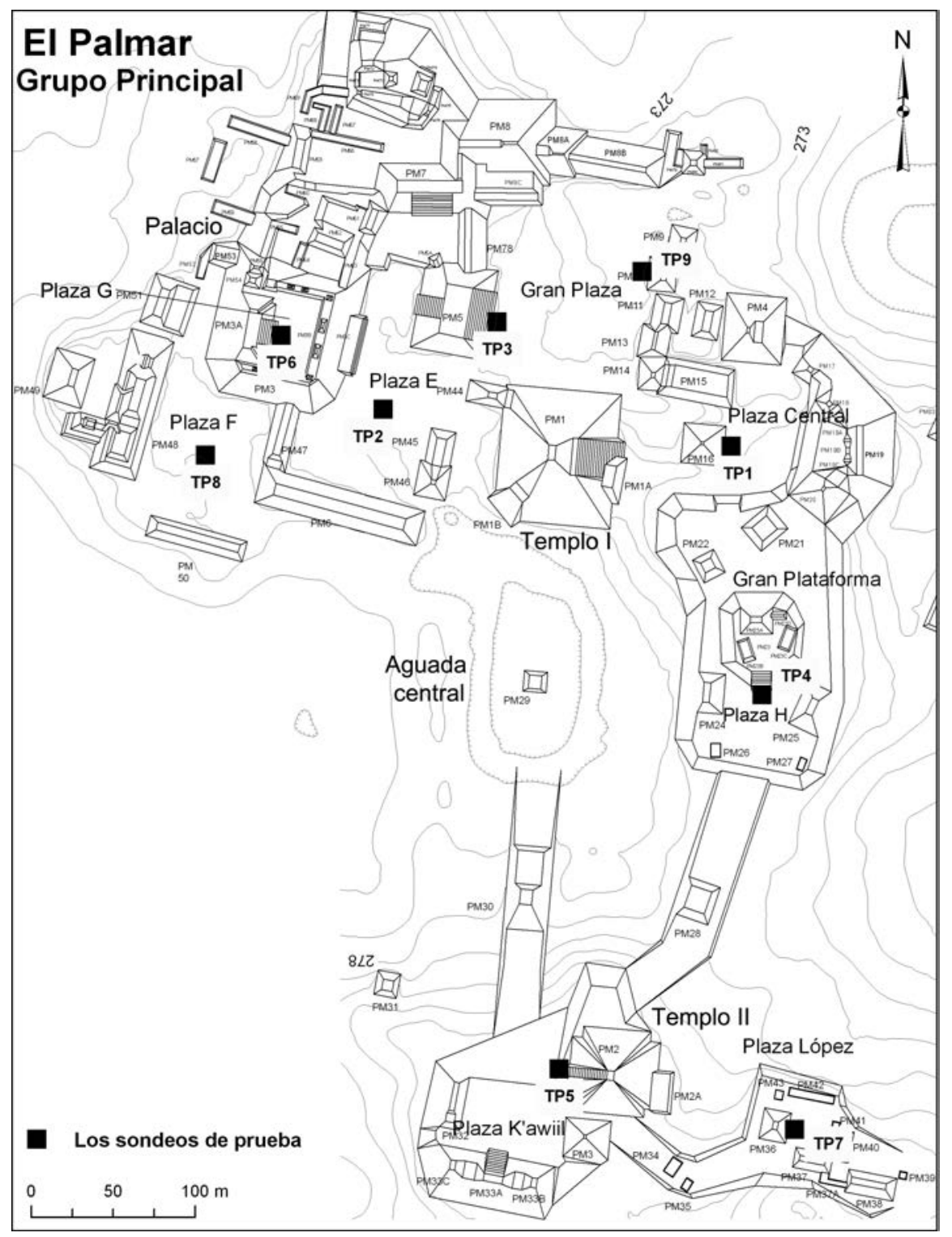

Figura 2. Plano del Grupo Principal de El Palmar con la ubicación de las excavaciones estratigráficas, dibujado por Kenichiro Tsukamoto y Javier López Camacho

La Gran Plaza es la más extensa, tiene una superficie de $14135 \mathrm{~m}^{2}$ y se encuentra en la parte norte del Grupo Principal. En el espacio abierto fueron colocados 11 monumentos grabados, cuatro de ellos (Estelas 8, 7, 10 y 16) con 
registros calendáricos para los años 721, 731, 746 y 800 d.C., respectivamente (Thompson, 1936). La Plaza Central, al sureste de la Gran Plaza, alcanza un área de $6674 \mathrm{~m}^{2}$ y contiene un complejo arquitectónico del tipo "Grupo E", considerado un espacio conmemorativo para rituales públicos (Aimers y Rice, 2006; Clark y Hansen, 2001; Joyce, 2001; Laporte y Fialko, 1995).

Al sur se ubica la Plaza K'awiil, con una superficie de $3161 \mathrm{~m}^{2}$, caracterizada por una ligera elevación sobre la cual desplanta el Templo II. Exhibe varios monumentos grabados, entre los cuales hay una estela con la fecha 884 d.C. (Estela 41) y un altar con una Rueda Calendárica del 554 d.C. Las Plazas E (9096 m²), F (6 134 $\left.\mathrm{m}^{2}\right)$ y G $\left(1877 \mathrm{~m}^{2}\right)$ se encuentran al suroeste de la Gran Plaza; en la Plaza E hay un monumento con registro del año 820 d.C. (Estela 14). La Plaza G constituye un espacio privado, pues está rodeada por estructuras abovedadas similares, se eleva $10 \mathrm{~m}$ sobre la superficie de la Plaza E, y se integra al sector del Palacio.

La Plaza H $\left(3130 \mathrm{~m}^{2}\right)$ se localiza sobre la Gran Plataforma, cuya elevación pudo haber configurado un espacio restringido. Finalmente, la Plaza López es un espacio pequeño $\left(890 \mathrm{~m}^{2}\right)$ al este de la Plaza K'awiil, donde no se han descubierto monumentos grabados.

\section{Secuencia constructiva de las plazas en el Grupo Principal de El Palmar}

Si bien el levantamiento topográfico ha permitido representar la configuración espacial de las ocho plazas, nueve sondeos estratigráficos de 2 × $2 \mathrm{~m}$ realizados durante la temporada de campo 2009 han revelado su dimensión temporal. Los resultados sugieren que el Grupo Principal fue ocupado desde el Preclásico Tardío (250 a.C.-250 d.C.) hasta el Clásico Terminal (800-1000 d.C.). El plan de construcción de los espacios públicos fue realizado de manera intensa durante el Clásico Medio (400-700 d.C.). A continuación se describen los eventos constructivos de las plazas con base en los resultados de las excavaciones, del análisis de los materiales recuperados y del fechamiento por carbono 14 .

Preclásico Tardío (250 a.C.-250 d.C.) y Clásico Temprano (250-400 d.C.)

En el Preclásico Tardío (250 a.C.-250 d.C.) sólo se construyeron la Plaza Central y la Plaza H. En la ocupación más antigua de la Plaza Central, que llegó hasta 3.5 $m$ de profundidad desde la superficie actual (TP1), se encontró una construcción (Piso 7) con rocas alineadas aunque no se pudo identificar su forma ni función debido a la dimensión del sondeo (figura 3). Una muestra de carbono 14 tomada del relleno de la construcción lo fecha entre el 353 y el 122 a.C. con $68.2 \%$ en rango de probabilidad. Para cubrir la construcción se niveló la plaza con un piso de estuco (Piso 6) al final del mismo periodo o al principio del Clásico Temprano (250-400 d.C.). Aunque una muestra de carbono 14 sugiere una fecha temprana (386 a.C.-63 d.C.), a juzgar por un tiesto del tipo Águila Naranja con variedad 


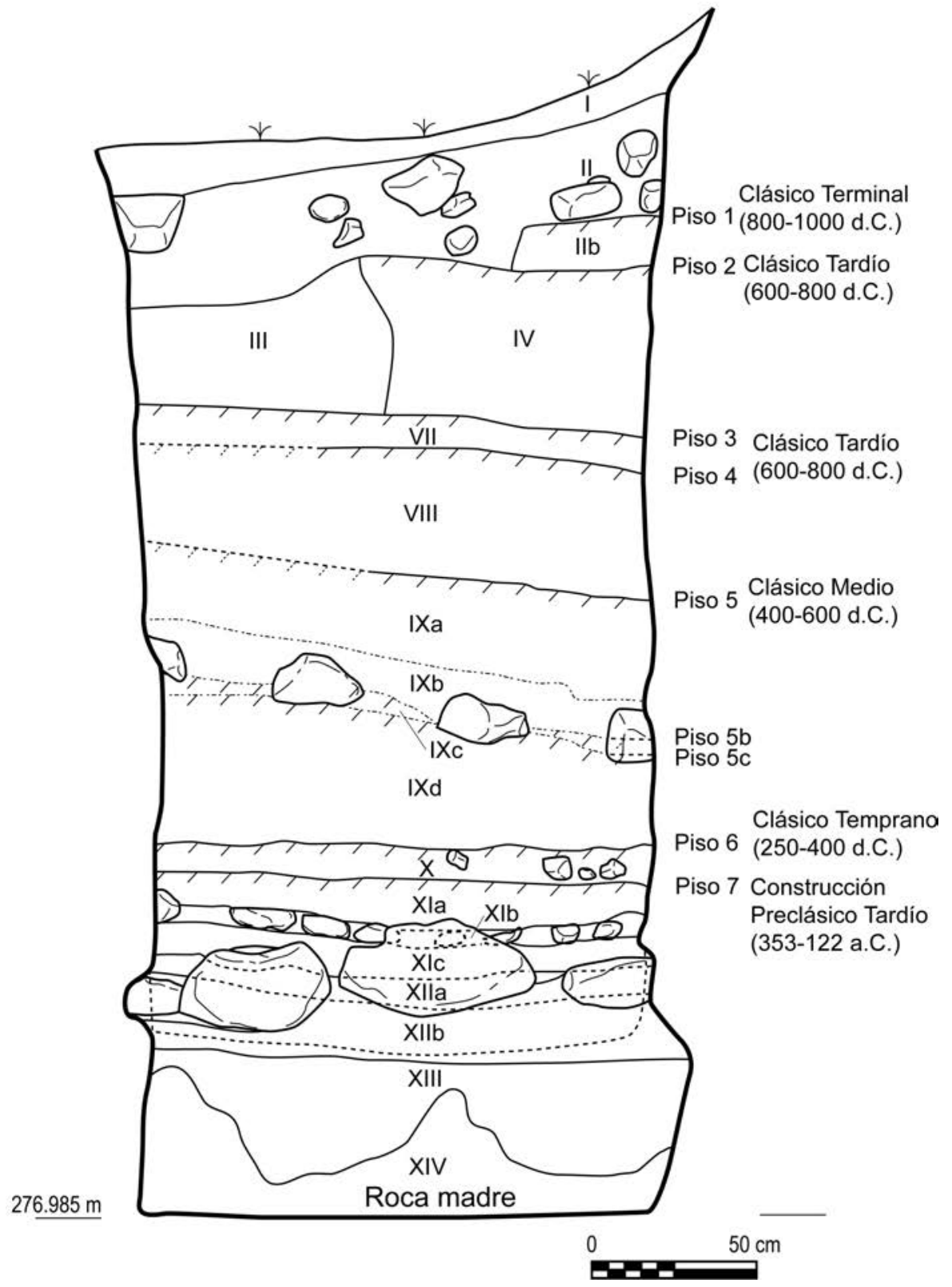

FIgurA 3. Perfil estratigráfico sur de la operación TP1 en la Plaza Central de El Palmar, dibujado por Hirokazu Kotegawa 
Águila y el fechamiento del piso anterior deducimos que el Piso 6 se construyó durante la transición entre los periodos Preclásico Tardío y Clásico Temprano.

La Plaza H fue contemporánea a la Plaza Central. Aun cuando no fue posible fechar su piso más antiguo (Piso 7) por la ausencia de materiales diagnósticos, el Piso 6 pudo haber sido construido durante el Preclásico Tardío de acuerdo con los materiales cerámicos identificados como Sierra Rojo/Sierra, Polvero Negro/ Polvero y Flor Crema/Flor (TP4). Dos muestras de carbono 14 datadas apoyan tal interpretación: $198-36$ a.C. con $91.6 \%$ en rango de probabilidad y 205-40 a.C. con 93\%. La Plaza H fue remodelada con otro piso de estuco (Piso 5) durante el Clásico Temprano (250-400 d.C.).

Las excavaciones sugieren que durante estos dos periodos las áreas alrededor de las Plazas Central y H, que ahora se denominan Gran Plaza y Plazas E y F, eran zonas inundables ya que el material parental hallado fue un suelo limoso de tipo luvisol (TP2, 3, 8 y 9).

Debido al límite de las excavaciones, los cálculos del área total de las plazas e inversión de trabajo en ellas no reflejarían con certeza el número absoluto de participantes en los rituales públicos y en las construcciones. En los cálculos del área total de las plazas no se incluyeron las plataformas que posiblemente fueron utilizadas para las danzas y la colocación de objetos rituales como vasijas, comidas y bebidas (Grube, 1992). Es muy probable que las extensiones de cada plaza fueran transformadas a través del tiempo y sus usos fueran múltiples, con diferentes clases de participantes y objetos. Particularmente, los cálculos sobre la inversión de trabajo son resultados preliminares, ya que no hemos excavado toda la plaza. El cálculo sólo se basó en el área de cada plaza multiplicada por la profundidad de los estratos correspondientes; posteriormente se sumó el volumen de todas las plazas por periodo.

No obstante, estos cálculos nos proporcionan una idea sobre en qué período las plazas y los rituales públicos asociados fueron más relevantes. Además, nos permiten evaluar cuantitativamente su capacidad. Aunque los cálculos se basaron en el plano más reciente del sitio, el área total de las plazas durante los dos periodos era de $9129 \mathrm{~m}^{2}$ (figura 4) y la inversión de trabajo por metro cúbico fue de $6777.65 \mathrm{~m}^{3}$ en el Preclásico Tardío y $2316.8 \mathrm{~m}^{3}$ en el Clásico Temprano, ambas cifras relativamente bajas en comparación con la del Clásico Medio (figura 5).

\section{Clásico Medio (400-600 d.C.)}

El paisaje urbano del Grupo Principal de El Palmar durante el Clásico Medio cambió de manera dramática. Las excavaciones y el análisis de los materiales indican que la Gran Plaza, la Plaza K'awiil y las Plazas E y G fueron construidas en ese periodo, además de que la Plaza Central se elevó casi un metro. Nivelando el suelo de luvisol, en la Gran Plaza y en la Plaza E se construyó un delgado piso de estuco sin colocar relleno de grava. El proyecto arquitectónico sobresaliente 


\begin{tabular}{|l|r|r|r|r|}
\hline \multicolumn{2}{|c|}{} & \multicolumn{3}{|c|}{ Capacidad Estimada de Plaza } \\
\hline Nombre de Plaza & Área $\left(\mathrm{m}^{2}\right)$ & $0.46 \mathrm{~m}^{2} /$ persona & $1 \mathrm{~m}^{2} /$ persona & $3.6 \mathrm{~m}^{2} /$ persona \\
\hline Gran Plaza & 14135 & 30728 & 14135 & 3926 \\
\hline Plaza Central & 6674 & 14509 & 6674 & 1854 \\
\hline Plaza E & 9096 & 19774 & 9096 & 2527 \\
\hline Plaza F & 6134 & 13335 & 6134 & 1704 \\
\hline Plaza G & 1230 & 2673 & 1230 & 341 \\
\hline Plaza H & 2455 & 5336 & 2455 & 681 \\
\hline Plaza K'awiil & 3161 & 6872 & 3161 & 878 \\
\hline Plaza López & 890 & 1935 & 890 & 247 \\
\hline Área total & 40090 & 87152 & 40090 & 11136 \\
\hline
\end{tabular}

FIgura 4. Tabla de la capacidad estimada en las plazas del Grupo Principal de El Palmar

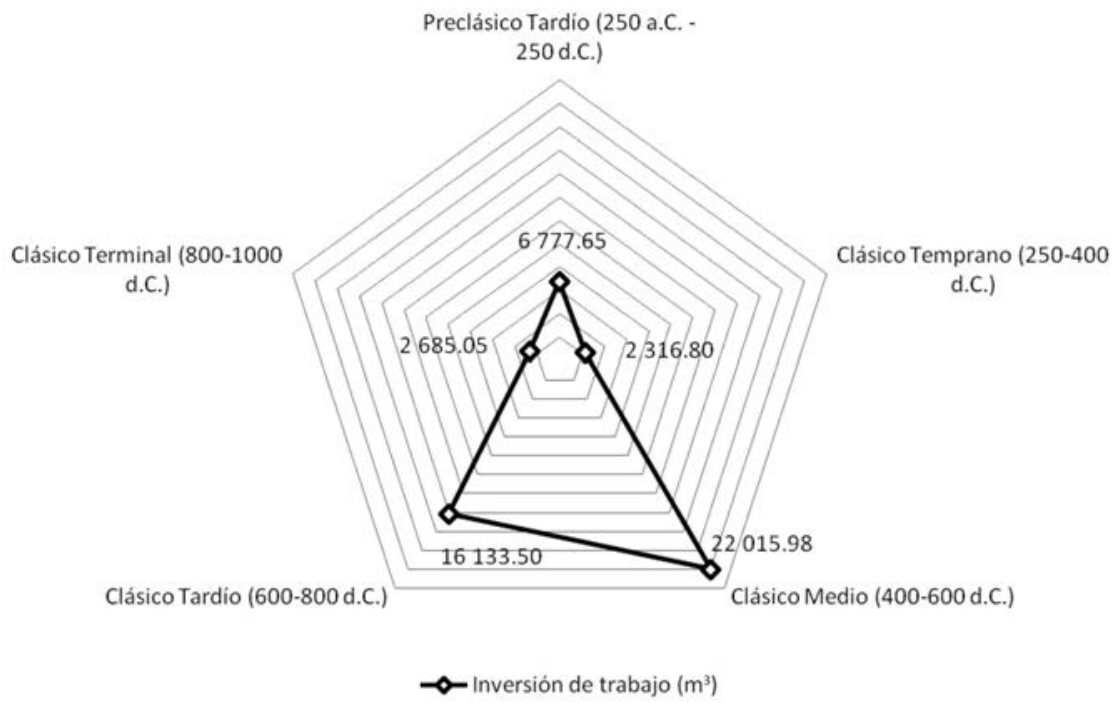

Figura 5. Gráfica de la inversión de trabajo $\left(\mathrm{m}^{3}\right)$ estimada en El Palmar

del Clásico Medio fue, sin duda, la edificación de la Estructura PM3 en la Plaza $\mathrm{G}$ (tomando como base los resultados del TP6). El sondeo estratigráfico sugiere que el piso más antiguo (Piso 3) alcanzó $10 \mathrm{~m}$ de elevación desde la superficie de la Plaza E. Tres muestras de carbono 14 tomadas del relleno constructivo de la Plaza G lo datan entre el 196 y el 353 d.C. con $98.20 \%$ en rango de probabili- 
dad; entre el 421 y el 533 d.C. y entre el 425 y el 533 d.C. con $68.20 \%$ en rango de probabilidad. Estas últimas muestras, en conjunto con el análisis cerámico, revelan que la Plaza G fue construida entre los años 425 y 533 d.C.

Si bien la Plaza G fue el proyecto arquitectónico más voluminoso, la Gran Plaza (TP3 y TP9) fue diseñada con mayor extensión con el fin de acomodar a la mayor población en un evento público. En el relleno de la Gran Plaza no se encontraron materiales cerámicos diagnósticos del Clásico Medio, sino del Clásico Temprano (250-600 d.C.). Sin embargo, el análisis preliminar del estuco por medio de la catodoluminisencia realizado por Tatsuya Murakami indicó que el primer piso de la Gran Plaza fue construido durante el primer periodo mencionado, ya que la tecnología de los pisos más antiguos en ésta y en la Plaza G fue idéntica a la del Clásico Medio. Además se encontró un artefacto lítico del tipo "cepillo" (Domed Smoother) (figura 6) en el mismo relleno, que Rovner, Lewenstein y Nelson (1997) señalan como material diagnóstico del principio del Clásico Tardío. Es decir, se puede interpretar la emergencia de la mencionada plaza a partir del Clásico Medio. Con base en todos los resultados anteriores, sugerimos que la Gran Plaza, la Plaza G y probablemente la Plaza E fueron construidas durante el Clásico Medio.

En el caso de la Plaza K'awiil, el periodo constructivo tiene una fecha aún más exacta. Durante la excavación de prueba (TP5) se encontró un escondite (Escondite 3) o cache asociado al Altar 10, debajo del piso más antiguo de la plaza (figuras 7 y 8). Debido a la ausencia de una intrusión, creemos que el ente-
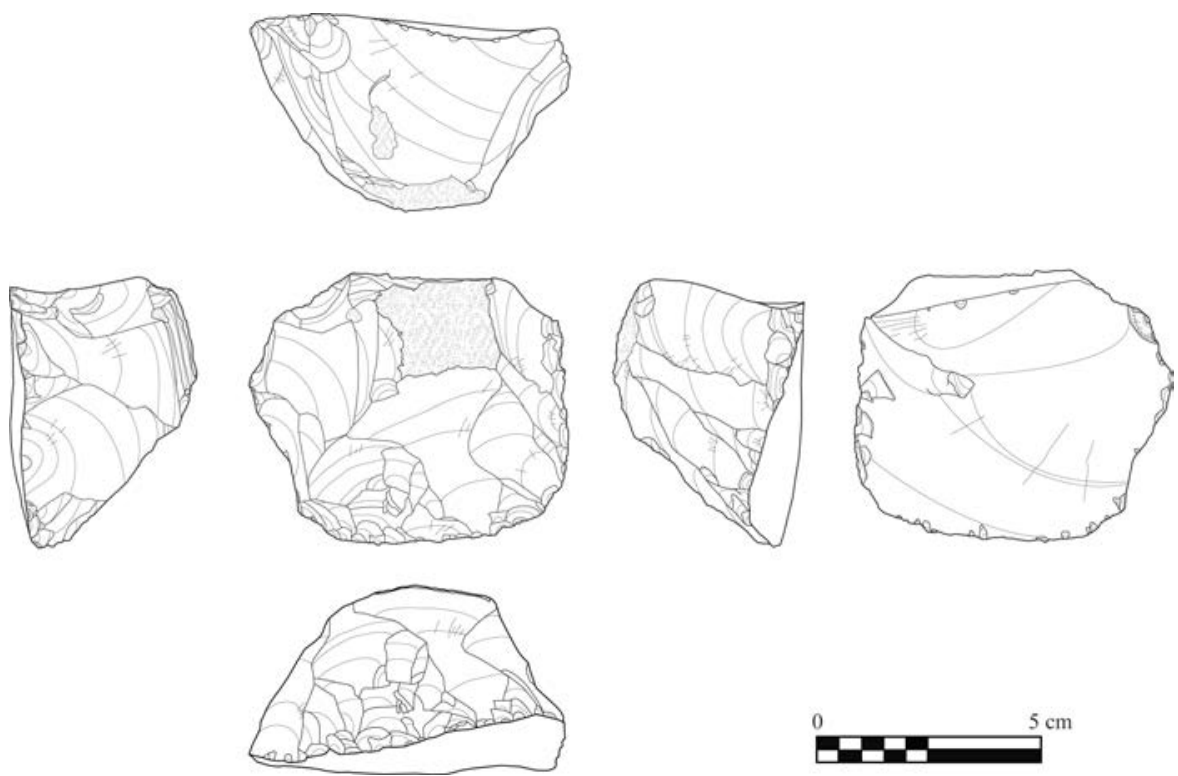

Figura 6. Herramienta lítica denominada "cepillo" (Domed Smoother), dibujado por Kenichiro Tsukamoto 
rramiento del Escondite 3 y la construcción de la plaza fueron contemporáneos. $\mathrm{Si}$ se considera que el Altar 10 contiene una Rueda Calendárica que registra la fecha del 20 de marzo del 554 d.C., la construcción de la Plaza K'awiil en el siglo sexto es contemporánea a la de las tres plazas anteriores.

El área total de las plazas se extendió $36571 \mathrm{~m}^{2}$, cifra cuatro veces más grande que la de los periodos anteriores (figura 4). Si una persona ocupa un metro cuadrado durante rituales públicos, las plazas pudieron haber acomodado más de 36000 participantes. Asimismo, la inversión de trabajo se incrementó de $9094.45 \mathrm{~m}^{3}$ a $22015.98 \mathrm{~m}^{3}$ en tan sólo 200 años (figura 5).

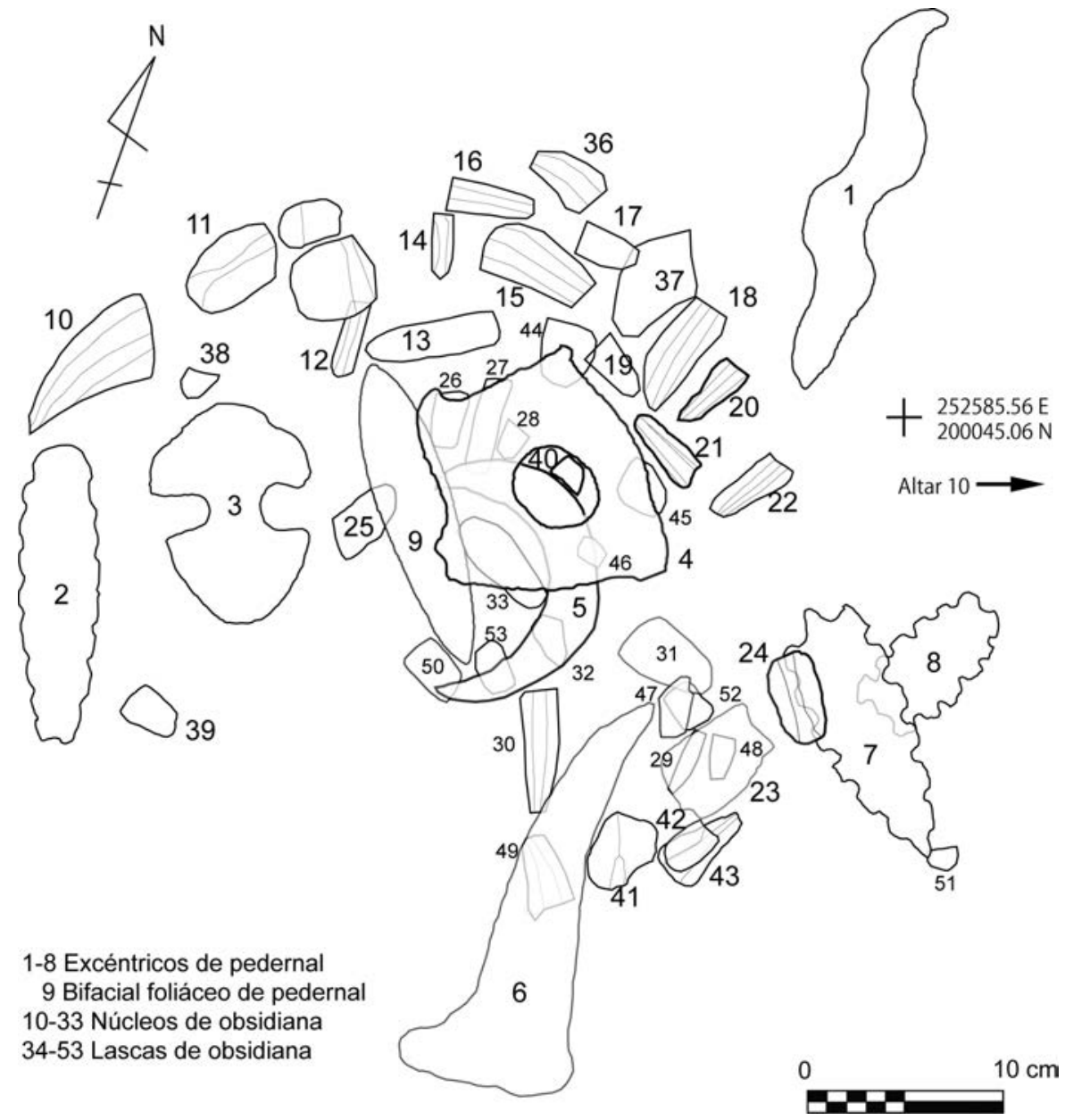

Figura 7. Plano del Escondite 3 descubierto en El Palmar, dibujado por Kenichiro Tsukamoto y Luz Evelia Campaña 


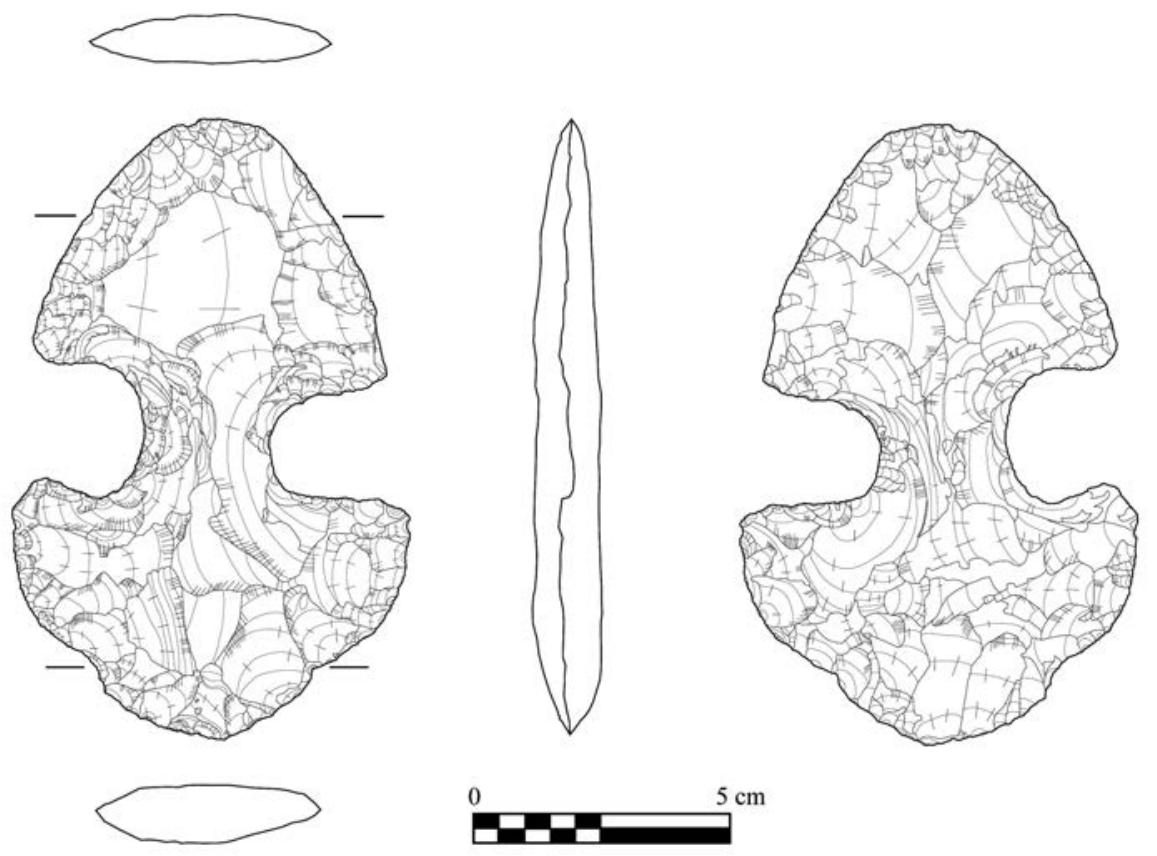

Figura 8. Excéntrico proveniente del Escondite 3 de El Palmar, dibujado por Kenichiro Tsukamoto

Clásico Tardío (600-800 d.C.)

Los mayas de El Palmar continuaron construyendo espacios abiertos, como la Plaza F (TP8) y la Plaza López (TP7) durante el Clásico Tardío (600-800 d.C.), además de remodelar las plazas anteriores. Sin embargo, la dimensión de estas nuevas plazas fue más pequeña. Al mismo tiempo, las élites gobernantes erigieron una gran cantidad de monumentos grabados en la Gran Plaza, la Plaza Central y la Plaza E. El área total de las plazas aumentó a $43595 \mathrm{~m}^{2}$ con la construcción de las Plazas F y López (figura 4), pero la inversión de trabajo disminuyó a 16133.5 $\mathrm{m}^{3}$ (figura 5).

Clásico Terminal (800-1000 d.C.)

La construcción o remodelación de plazas disminuyó de manera significativa durante el Clásico Terminal, aunque las estelas con inscripciones sugieren que la Gran Plaza, la Plaza E y la Plaza K'awiil siguieron funcionando para ceremonias conmemorativas en los años 800, 820 y 884 d.C., respectivamente. La Plaza H es 
la única que presenta evidencia de la remodelación, con una inversión laboral de $2685.05 \mathrm{~m}^{3}$ (figura 5).

\section{Construcciones y remodelaciones de plazas como una estrategia política}

Los resultados de las excavaciones de prueba y del análisis de los materiales señalan que las construcciones y remodelaciones de las plazas eran importantes para la sociedad de El Palmar. Nosotros creemos que la construcción intensiva de las plazas mayores refleja una estrategia de las élites gobernantes para organizar a la sociedad. En periodos premodernos, los espectáculos en un amplio espacio abierto, como la plaza, jugaban un papel preponderante para la organización política (Connerton, 1989; Foucault, 1984, 1995[1978]; Inomata, 2006; Joyce, 2004; Low, 1995; Moore, 1996). Es posible que la construcción y remodelación de las plazas públicas fueran proyectos importantes para las élites gobernantes de El Palmar, quienes requerían manifestar su conocimiento especial en la ejecución de los rituales para establecer contacto con los ancestros y las deidades. Investigaciones previas sugieren que, en Mesoamérica, ciertos saberes como la comunicación con los ancestros y la escritura jeroglífica eran exclusivos de las élites gobernantes, y mediante ellos reclamaban y sostenían su poder político con manipulaciones ideológicas y religiosas (Houston, Robertson y Stuart, 2000; Inomata, 2001; Joyce y Winter, 1996; McAnany, 1993, 1995).

Bajo esta condición, las plazas fueron los escenarios donde las élites gobernantes legitimaban su autoridad política a través de prácticas rituales. En este sentido, consideramos que el número de plazas en un sitio y su continua remodelación revela que las relaciones de poder entre las élites gobernantes y otros segmentos sociales fueron equilibradas por medio de rituales públicos celebrados en los espacios abiertos (Scott, 1998). Además, el súbito incremento de la capacidad para acomodar a los participantes en las plazas sugiere la transformación del sitio, de pueblo local a centro regional, ya que los espacios para la realización de espectáculos regularmente son diseñados en función del número de participantes. La construcción de nuevos espacios públicos, como la Gran Plaza y la Plaza E, indican que El Palmar se convirtió en un centro regional que albergaba a un gran auditorio que participaba del teatro político de las ceremonias conmemorativas.

Otros segmentos sociales no eran receptores pasivos de la ideología y dominación, sino sus evaluadores. Sus resultados (aceptación o rechazo) influían en su participación en otras construcciones (Geertz, 1980; Inomata, 2006), ya que los rituales públicos no funcionan con la ausencia del público: este y los protagonistas interactúan mutuamente para crear un ambiente de espectáculo.

Mientras las regiones colindantes se involucraron en las interacción política debido a la confrontación entre Tikal y Calakmul a partir del Clásico Medio 
(Adams, 1999; Martin, 2000; Stuart, 2000; Wright, 2005a y b), las remodelaciones de la Gran Plaza, la Plaza E y la Plaza G, así como las numerosas erecciones de las estelas y altares sugieren que los rituales-espectáculos públicos fueron exitosos y ayudaron a cimentar la identidad social. Particularmente, la edificación de la Plaza $\mathrm{G}$ como un espacio exclusivo de las élites revela que los otros grupos sociales consintieron su legitimación política y poder, y que aquellas consolidaban identidades distintas a las de los rituales públicos.

La construcción de plazas y de templos piramidales no sólo fue importante desde el punto de vista arquitectónico, sino también ideológico, pues convirtieron la ciudad en un lugar mitológico. Garza (2010: 43) sugiere que la plaza y la pirámide son símbolos de la tierra cuadrangular y de la montaña sagrada (véase también Ashmore, 1991, 2004; Brady y Ashmore, 1999; Schele y Freidel, 1990). Esta cosmovisión inscrita en el paisaje y las ceremonias conmemorativas repetitivas pudieron haber ayudado a producir y reproducir la memoria social (Connerton, 1989; Van Dyke y Alcock, 2003). Con base en el análisis de la sicología política, Caspary (1993) sugiere que la obediencia al poder ideológico con representaciones simbólicas tiende a desarrollarse durante periodos de crisis (véase también Joyce y Winter, 1996: 35; Volkan, 1985). Es decir, la intensa interacción política de las regiones cercanas pudo haber servido para cimentar la ideología política de El Palmar a partir del Clásico Medio, y la construcción y remodelación de las plazas grandes y privadas fue una respuesta de la solidaridad y la obediencia social.

\section{Conclusión}

La excavación y el análisis de los materiales evidencian que las grandes plazas, como la Gran Plaza y las Plazas E, G y K'awiil fueron construidas durante el periodo Clásico Medio (400-600 d.C.). Su construcción, junto con la de los templos piramidales monumentales, sugiere que la celebración de rituales públicos - como teatro político- era un elemento importante para las élites gobernantes, quienes legitimaban las autoridades políticas a través de los espectáculos y la materialización de ellos en los monumentos grabados. El fenómeno del proyecto arquitectónico en El Palmar es parecido al de Río Azul (Adams, 1999) y Uaxactún (Valdés y Fahsen, 1995). No obstante, por el momento la información limita la interpretación y aún no es posible revelar la relación de El Palmar con las superpotencias Tikal y Calakmul. Sólo podemos anotar que, al igual que esos sitios, el periodo Clásico Medio fue fundamental para su organización política y espacial. 


\section{BIBLIOGRAFÍA}

Adams, Richard E. W.

1999 Rio Azul: An Ancient Maya city. Norman: University of Oklahoma Press.

Adams, Richard E. W. y Richard C. Jones

1981 "Spatial Patterns and Regional Growth among Classic Maya Cities", American Antiquity, 46 (2): 301-322. Washington, D. C.: Society for American Archaeology.

Aimers, James J. y Prudence M. Rice

2006 "Astronomy, Ritual, and the Interpretation of Maya "E-Group" Architectural Assemblages”, Ancient Mesoamerica, 17: 79-96. Cambridge: Cambridge University Press.

Ashmore, Wendy

1991 "Site-planning principles and concepts of directionality among the ancient Maya”, Latin American Antiquity, 2 (3): 199-226. Washington, D. C.: Society for American Archaeology.

2004 "Ancient Maya Landscape", Continuities and Changes in Maya Archaeology: Perspectives at the Millennium. Charles W. Golden y Greg Borgstede (eds.). Nueva York: Routledge, 97-11.

Brady, James E. y Wendy Ashmore

1999 "Mountains, Caves, Water: Ideational Landscapes of the Ancient Maya", Archaeology of Landscape: Contemporary Persipective. Wendy Ashmore y Arthur B. Knapp (eds.). Malden [Estados Unidos]: Blackwell Publisher, 124-145.

Bueno, Ricardo

1999 Entre un río de robles: un acercamiento a la arqueología de la región Río Bec. México: Instituto Nacional de Antropología e Historia (Colección Científica, 411).

Campaña, Luz Evelia

2005 “Contribuciones a la historia de Becán”, Arqueología Mexicana, XIII (75): 4853. México: Raíces.

Caspary, William R.

1993 "New Psychoanalytic Perspectives on the Causes of War", Political Psychology, 14 (3): 417-446. Malden [Estados Unidos]: Wiley-Blackwell Publishers.

Clark, John E. y Richard D. Hansen

2001 The Architecture of Early Kingship: Comparative Perspectives on the Origins of the Maya Royal Court. Royal Courts of the Ancient Maya, Volume Two: Data and Case Studies. Colorado: Westview Press.

Connerton, Paul

1989 How Societies Remember. Nueva York: Cambridge University Press. 
Demarest, Arthur A.

1992 "The Dynamics of Galactic Polities", Ideology and Pre-Columbian Civilizations. Arthur A. Demarest y Geoffrey W. Conrad (eds.). Santa Fe: School of American Research Press, 135-157.

Foucault, Michel

1984 "Space, Knowledge, and Power", The Foucault Reader. Paul Rabinow (ed.). Nueva York: Pantheon Books, 239-256.

1995 Discipline and Punish: The Birth of the Prison. Nueva York: Vintage Books.

[1978]

Freidel, David A. y Linda Schele

1988 "Kingship in the Late Pre-Classic Maya Lowlands: The Instruments and Places of Ritual Power”, American Anthropologist, 90: 547-567. Arlington: American Anthropological Association

Garza, Mercedes de la

2010 "El universo temporal en el pensamiento maya”, Arqueología Mexicana 103: 38-44. México: Raíces.

Geertz, Clifford

$1980 \quad$ Negara: The Theatre State in Nineteenth-Century Bali. Princeton: Princeton University Press.

Grube, Nikolai

1992 "Classic May dance: Evidence from hieroglyphs and iconography", Ancient Mesoamerica, 3: 201-218. Cambridge: Cambridge University Press.

Houston, Stephen D.

1998 "Classic Maya Depictions of the Built Environment", Function and Meaning in Classic Maya Architecture: A Symposium at Dumbarton Oaks 7th and 8th October 1994. Stephen D. Houston (ed.). Washington, D. C.: Harvard University Press, 333-372.

Houston, Stephen, John Robertson y David Stuart

2000 "The Language of Classic Maya Inscriptions", Current Anthropology, 41 (3): 321-356. Chicago: Chicago University Press.

Inomata, Takeshi

2001 "Power and Ideology of Artistic Creation: Elite Craft Specialists in Classic Maya Society”, Current Anthropology, 42 (3): 321-349. Chicago: Chicago University Press.

2006 "Plazas, Performers, and Spectators: Political Theaters of the Classic Maya", Current Anthropology, 47 (5): 805-841. Chicago: Chicago University Press.

Joyce, Arthur A.

2004 "Sacred Space and Social Relations in Oaxaca", Mesoamerican Archaeology. Julia A. Hendon y Rosemary A. Joyce (eds.). Malden [Estados Unidos]: Blackwell Publishing, 192-216. 
Joyce, Arthur A. y Marcus Winter

1996 "Ideology, Power, and Urban Society in Pre-Hispanic Oaxaca", Current Anthropology, 37 (1): 33-47. Chicago: Chicago University Press.

Joyce, Rosemary A.

2001 "Planificación urbana y escala social: reflexiones sobre datos de comunidades clásicas en Honduras", Reconstruyendo la ciudad maya: el urbanismo en las sociedades antiguas. Andrés Ciudad, María Josefa Iglesias y María del Carmen Martínez (eds.). Madrid: Sociedad Española de Estudios Mayas (Publicación 6), 123-136.

Laporte, Juan Pedro y Vilma Fialko

1995 "Un reencuentro con Mundo Perdido, Tikal, Guatemala”, Ancient Mesoamerica, 6: 41-94. Cambridge: Cambridge University Press.

Low, Setha M.

1995 "Indigenous Architecture and the Spanish American Plaza in Mesoamerican and the Caribbean”, American Anthropologist, 97 (4): 748-762. Arlington: American Anthropological Association

Martin, Simon

2000 “Los Señores de Calakmul”, Arqueología Mexicana, VII (42): 40-45. México: Raíces.

McAnany, Patricia A.

1993 "The Economics of Wealth among Eighth-Century Maya Households", Lowland Maya Civilization in the Eight Century A.D.: A Symposium at Dumbarton Oaks 7th and 8thOctober 1989. Jeremy A. Sabloff y John S. Henderson (eds.). Washington, D. C.: Dumbarton Oaks Research Library and Collection, 6579.

1995 Living with Ancestors: Kingship and Kingship in Ancient Maya Society. Austin: University of Texas Press.

Moore, Jerry D.

1996 Architecture \& Power In the Ancient Andes: The Archaeology of Public Buildings. Cambridge: Cambridge University Press.

Restall, Matthew

2001 "The People of the Patio: Ethnohistorical Evidence of Yucatec Maya Royal Courts", Royal Courts of the Ancient Maya, Vol. 2. Takeshi Inomata y Stephen D. Houston (eds.). Boulder [Estados Unidos]: Westview Press, 335-377.

Ringle, William M. y George J. Bey III

2001 "Post-Classic and Terminal Classic Courts of the Northern Maya Lowlands", Royal Courts of the Ancient Maya, vol 2. Takeshi Inomata y Stephen D. Houston (eds.). Boulder [Estados Unidos]: Westview Press, 266-307. 
Rovner, Irwin, Suzanne M. Lewenstein y Fred W. Nelson

1997 Maya stone tools of Dzibilchaltún, Yucatán, and Becán and Chicanná, Campeche. Nueva Orleans: Tulane University, Middle American Research Institute.

Schechner, Richard

1985 Between Theater and Anthropology. Filadelfia. University of Pennsylvania Press.

Schele, Linda y David Freidel

1990 A Forest of Kings: The Untold Story of The Ancient Maya. Nueva York: Quill William Morrow.

Scott, James C.

1998 Seeing Like A State: How Certain Schemes To Improve the Human Condition Have Failed. New Haven / Londres: Yale University Press.

Sharer, Robert J. y Charles W. Golden

2004 "Kingship and Polity: Conceptualizing the Maya Body Politic", Continuities and Changes in Maya Archaeology: Perspectives at the Millennium. C. W. Golden y G. Borgstede (eds.). Nueva York: Routledge, 23-50.

Šprajc, Ivan

2008 Reconocimiento arqueológico en el sureste del estado de Campeche, México: 1996-2005. Ljubljana [Eslovenia]: Centro de Investigaciones Científicas de la Academia Eslovena de Ciencias y Artes (British Archaeological Reports, International Series 1742. Paris Monographs in America Archaeology, 19).

Stuart, David

2000 “' “The Arrival of Strangers': Teotihuacan and Tollan in Classic Maya History”, Mesoamerican's Classic Heritage: From Teotihuacan to the Aztecs. David Carrasco, Lindsay Jones y Scott Sessions (eds.). Niwot: Colorado University Press, 465-513.

Thompson, J. Eric S.

1936 "Exploration in Campeche and Quintana Roo and excavations at San José, British Honduras", Carnegie Institution of Washington Year Book 35. Washington, D. C.: Carnegie Institution, 125-128.

Tsukamoto, Kenichiro y Javier López Camacho

2007 "El Palmar: una ciudad ubicada en una antigua frontera maya", Antropología e Historia, por sus especialistas, vol. 1. Campeche: Consejo Nacional para la Cultura y las Artes / Instituto Nacional de Antropología e Historia, 20-21.

Tsukamoto, Kenichiro, Javier López Camacho y Octavio Q. Esparza Olguín 2010 "El Palmar, Campeche”, Arqueología Mexicana, 17(101): 72-77. México: Raíces.

Turner, Victor

1986 From Ritual to Theatre and Back. Nueva York: Performing Arts Journal Publications. 
Valdés, Juan Antonio y Federico Fahsen

1995 "The Reigning Dynasty of Uaxactun during the Early Classic: The Rulers and the Ruled", Ancient Mesoamerica, 6: 197-219. Cambridge: Cambridge University Press.

Van Dyke, Ruth M. y Susan E. Alcock

2003 "Archaeologies of Memory: An Introduction", Archaeologies of Memory, pp. 1-13; Ruth M. Van Dyke y Susan E. Alcock (eds.). Malden [Estados Unidos]: Blackwell Publishers.

Volkan, Vamik D.

1985 "The Need to Have Enemies and Allies: A Developmental Approach", Political Psychology, 6 (2): 219-247. Malden [Estados Unidos]: Wiley-Blackwell Publishers.

Wright, Lori E.

2005a "Identifying Immigrants to Tikal, Guatemala: Defining local variability in strontium isotope ratios of human tooth enamel", Journal of Archaeological Science, 32: 555-566. Londres: Elsevier.

2005b "In Search of Yax Nuun Ayiin", Ancient Mesoamerica, 16: 89-100. Cambridge: Cambridge University Press. 


\title{
SECUENCIA CONSTRUCTIVA DE LAS PLAZAS EN EL GRUPO PRINCIPAL DE EL PALMAR, CAMPECHE, MÉXICO
}

\author{
Kenichiro TSUKAmoto \\ School of Anthropology, University of Arizona \\ HiRokAZU Kotegawa \\ Posgrado en Antropología, Facultad de Filosofía y Letras / Instituto de Investi- \\ gaciones Antropológicas, Universidad Nacional Autónoma de México \\ Facultad de Antropología, Universidad Veracruzana \\ LuZ Evelia CAmpaña \\ Proyecto Arqueológico El Palmar
}

\section{Introducción}

En las Tierras Bajas Mayas, la construcción y remodelación de la plaza estaba relacionada con la organización política (Inomata, 2006; Restall, 2001; Ringle y Bey III, 2001; Sharer y Golden, 2004). Recientes estudios arqueológicos, epigráficos e iconográficos han profundizado sobre la organización política, particularmente sobre la institución encabezada por el Ajaw, que se fundó en el periodo Preclásico Tardío (250 a.C.-250 d.C.) (Freidel y Schele, 1988) y floreció durante todo el Clásico (250-900 d.C.). Las élites gobernantes fueron promotoras de la construcción de estructuras monumentales, del desarrollo de guerras, de la erección de monumentos conmemorativos y de la celebración de sacrificios humanos y rituales públicos. Durante periodos de agitación política, ejecutaron esas actividades de manera acelerada para mantener su autoridad política, no siempre estable. Una de las estrategias de la institución Ajaw para la legitimización del poder fue quizás el teatro político, hipótesis originalmente propuesta por Geertz (1980) al estudiar la sociedad de Bali en el siglo xIx (Demarest, 1992; Houston,

Agradecemos al Instituto Nacional de Antropología e Historia (INAH), institución que otorgó los permisos C.A. 401-361/138 y C.A. 401-36/0837 para realizar el proyecto arqueológico El Palmar: Urbanización del espacio social en las tierras bajas mayas. Reconocemos de manera especial al arqueólogo Javier López Camacho, de la Escuela Nacional de Antropología e Historia (ENAH), quien es codirector del proyecto. Asimismo a Octavio Esparza Olguín, Alejandra Salinas, Tatsuya Murakami, Yuki Tanaka, estudiantes de la enAH, y a los trabajadores locales del ejido Kiché las Pailas, por su participación desinteresada. Finalmente, a Takeshi Inomata y Daniela Triadan por su apoyo académico. El proyecto fue financiado por la SBSRI Pre-doctoral Grant de la Universidad de Arizona. 
1998; Sharer y Golden, 2004), quien sugirió que la razón de existir del Estado era mantener el teatro político (Inomata, 2006: 808). Turner (1986) y Schechner (1985) indican que en cualquier sociedad los rituales públicos tienen un carácter teatral; sin duda, estos tuvieron un carácter teatral en la antigua sociedad maya del Clásico, a juzgar por las reiteradas representaciones grabadas en sus monumentos escultóricos. Los personajes que aparecen en estos últimos, por lo regular llevan máscaras, ornamentos, bastones ceremoniales y atavíos espléndidos, los cuales pudieron haber complementado el carácter teatral de rituales públicos. Con el fin de utilizar el teatro político como espectáculo, las plazas públicas fueron el escenario propicio para concentrar y acomodar a la población o a grupos seleccionados de la sociedad, dependiendo de la dimensión y ubicación de los espacios abiertos. En este sentido, su construcción y remodelación revelaría las huellas de una cultura material donde la gente consentía o era coercionada por las decisiones políticas de la élite gobernante, pues la mayor parte de la población debió participar en la erección de obras monumentales, incluidos los espacios públicos. Así, a través del estudio de su secuencia constructiva y de los materiales arqueológicos asociados es factible aproximarse al papel de los rituales públicos en la sociedad maya y al comportamiento de la población ante el teatro político de las élites gobernantes.

El presente trabajo presenta la secuencia constructiva de ocho plazas del Grupo Principal en el sitio arqueológico de El Palmar, ubicado al sureste de Campeche, México, como un caso de estudio.

\section{El Palmar}

El Palmar posee un carácter peculiar en cuanto a su ubicación. Se localiza en el sureste de Campeche, México, relativamente cerca de varios centros mayores: $90 \mathrm{~km}$ al sur se ubica Tikal; $50 \mathrm{~km}$ al oriente, Calakmul; y $70 \mathrm{~km}$ al norte, Becán (figura 1). En sus inmediaciones se encuentran también Mucaancah, Río Azul, Los Alacranes, La Milpa, Río Bec y Altar de los Reyes (Šprajc, 2008). De acuerdo con Adams y Jones (1981), esta área fue ocupada por tres esferas geopolíticas (Tikal, Calakmul y Río Bec) durante el Clásico Tardío y, por su localización, El Palmar pudo haber sido el centro de gravedad limítrofe de las tres regiones. Además de los conflictos políticos entre Tikal y Calakmul, en los sitios de la región Río Bec, como Becán, Río Bec y Hormiguero, se construyeron estructuras monumentales con un estilo arquitectónico propio durante el Clásico Tardío (600-800 d.C.) (Bueno, 1999; Campaña, 2005). Es decir, en términos de las interacciones políticas, los años transcurridos entre el 400 d.C. y el 700 d.C. debieron constituir un periodo dinámico y es probable que la participación de El Palmar fuera inevitable en los asuntos políticos.

Los recorridos de superficie y el levantamiento topográfico han detectado que

El Palmar tiene al menos otros ocho grupos arquitectónicos agrupados dentro de 


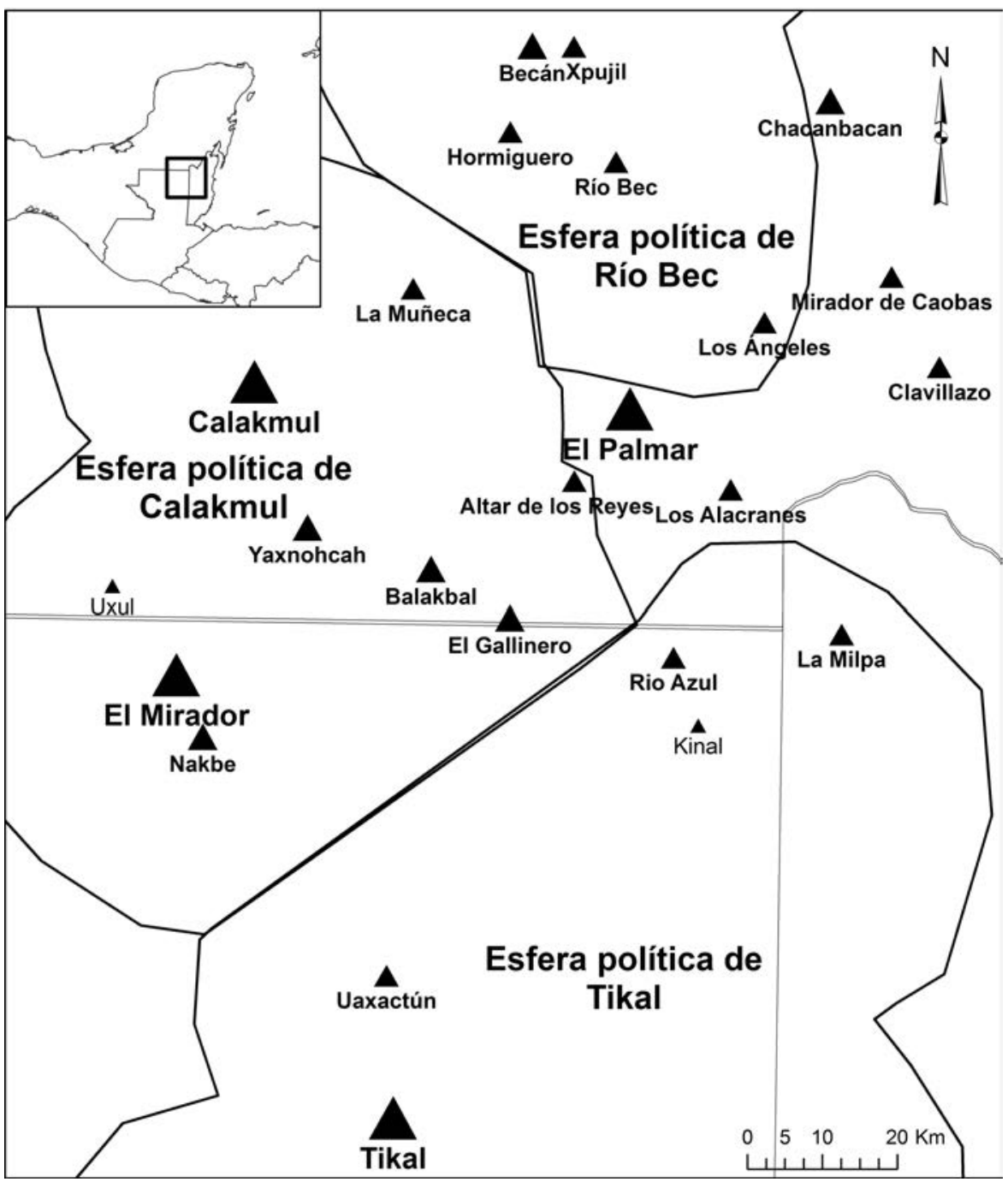

Figura 1. Mapa de esferas políticas en las Tierras Bajas Mayas, basado en Adams y Jones, 1981: 309

un radio máximo de $2.5 \mathrm{~km}$ a partir del Grupo Principal. En la configuración espacial del Grupo Principal destacan dos templos piramidales, un extenso palacio, una gran cantidad de los monumentos grabados y, por supuesto, las plazas (Tsukamoto, López Camacho y Esparza Olguín, 2010; Tsukamoto y López Camacho, 2007) (figura 2). El diseño planificado del Grupo Principal contiene ocho plazas con dimensiones distintas: la Gran Plaza, la Plaza Central, la Plaza K'awiil, las Plazas E, F, G y H, y la Plaza López. 


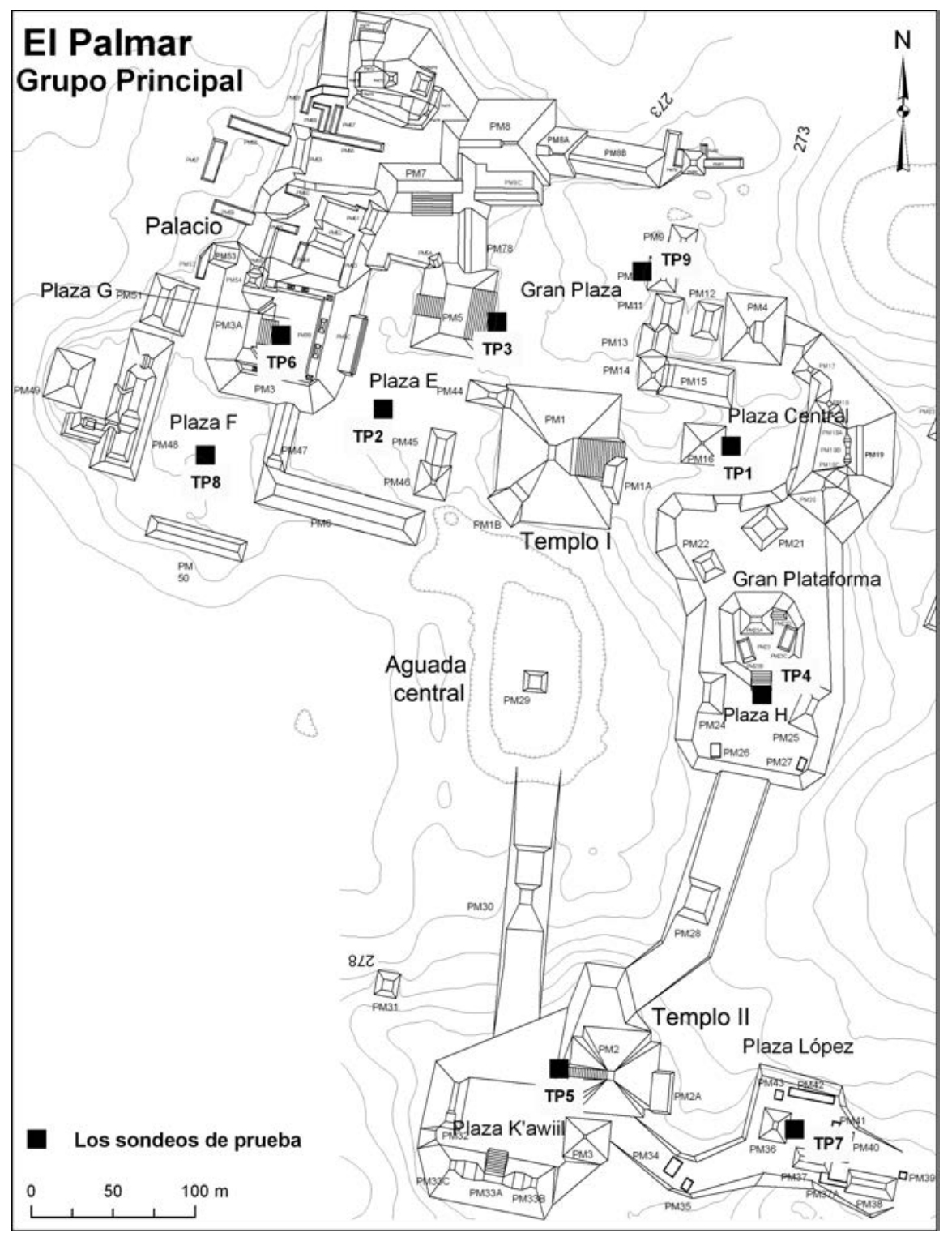

Figura 2. Plano del Grupo Principal de El Palmar con la ubicación de las excavaciones estratigráficas, dibujado por Kenichiro Tsukamoto y Javier López Camacho

La Gran Plaza es la más extensa, tiene una superficie de $14135 \mathrm{~m}^{2}$ y se encuentra en la parte norte del Grupo Principal. En el espacio abierto fueron colocados 11 monumentos grabados, cuatro de ellos (Estelas 8, 7, 10 y 16) con 
registros calendáricos para los años 721, 731, 746 y 800 d.C., respectivamente (Thompson, 1936). La Plaza Central, al sureste de la Gran Plaza, alcanza un área de $6674 \mathrm{~m}^{2}$ y contiene un complejo arquitectónico del tipo "Grupo E", considerado un espacio conmemorativo para rituales públicos (Aimers y Rice, 2006; Clark y Hansen, 2001; Joyce, 2001; Laporte y Fialko, 1995).

Al sur se ubica la Plaza K'awiil, con una superficie de $3161 \mathrm{~m}^{2}$, caracterizada por una ligera elevación sobre la cual desplanta el Templo II. Exhibe varios monumentos grabados, entre los cuales hay una estela con la fecha 884 d.C. (Estela 41) y un altar con una Rueda Calendárica del 554 d.C. Las Plazas E (9096 m²), F (6 134 $\left.\mathrm{m}^{2}\right)$ y G $\left(1877 \mathrm{~m}^{2}\right)$ se encuentran al suroeste de la Gran Plaza; en la Plaza E hay un monumento con registro del año 820 d.C. (Estela 14). La Plaza G constituye un espacio privado, pues está rodeada por estructuras abovedadas similares, se eleva $10 \mathrm{~m}$ sobre la superficie de la Plaza E, y se integra al sector del Palacio.

La Plaza H $\left(3130 \mathrm{~m}^{2}\right)$ se localiza sobre la Gran Plataforma, cuya elevación pudo haber configurado un espacio restringido. Finalmente, la Plaza López es un espacio pequeño $\left(890 \mathrm{~m}^{2}\right)$ al este de la Plaza K'awiil, donde no se han descubierto monumentos grabados.

\section{Secuencia constructiva de las plazas en el Grupo Principal de El Palmar}

Si bien el levantamiento topográfico ha permitido representar la configuración espacial de las ocho plazas, nueve sondeos estratigráficos de 2 × $2 \mathrm{~m}$ realizados durante la temporada de campo 2009 han revelado su dimensión temporal. Los resultados sugieren que el Grupo Principal fue ocupado desde el Preclásico Tardío (250 a.C.-250 d.C.) hasta el Clásico Terminal (800-1000 d.C.). El plan de construcción de los espacios públicos fue realizado de manera intensa durante el Clásico Medio (400-700 d.C.). A continuación se describen los eventos constructivos de las plazas con base en los resultados de las excavaciones, del análisis de los materiales recuperados y del fechamiento por carbono 14 .

Preclásico Tardío (250 a.C.-250 d.C.) y Clásico Temprano (250-400 d.C.)

En el Preclásico Tardío (250 a.C.-250 d.C.) sólo se construyeron la Plaza Central y la Plaza H. En la ocupación más antigua de la Plaza Central, que llegó hasta 3.5 $m$ de profundidad desde la superficie actual (TP1), se encontró una construcción (Piso 7) con rocas alineadas aunque no se pudo identificar su forma ni función debido a la dimensión del sondeo (figura 3). Una muestra de carbono 14 tomada del relleno de la construcción lo fecha entre el 353 y el 122 a.C. con $68.2 \%$ en rango de probabilidad. Para cubrir la construcción se niveló la plaza con un piso de estuco (Piso 6) al final del mismo periodo o al principio del Clásico Temprano (250-400 d.C.). Aunque una muestra de carbono 14 sugiere una fecha temprana (386 a.C.-63 d.C.), a juzgar por un tiesto del tipo Águila Naranja con variedad 


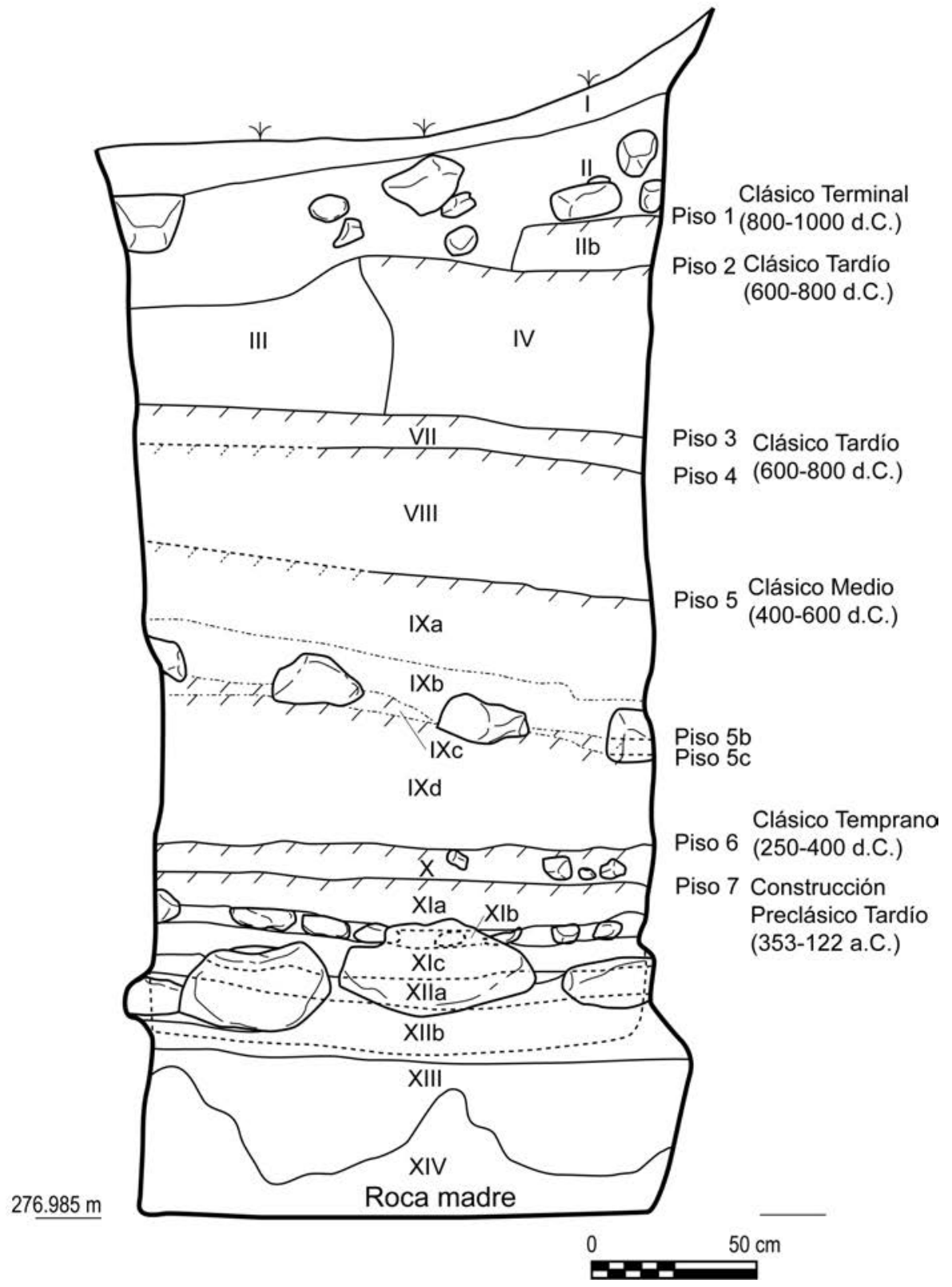

FIgurA 3. Perfil estratigráfico sur de la operación TP1 en la Plaza Central de El Palmar, dibujado por Hirokazu Kotegawa 
Águila y el fechamiento del piso anterior deducimos que el Piso 6 se construyó durante la transición entre los periodos Preclásico Tardío y Clásico Temprano.

La Plaza H fue contemporánea a la Plaza Central. Aun cuando no fue posible fechar su piso más antiguo (Piso 7) por la ausencia de materiales diagnósticos, el Piso 6 pudo haber sido construido durante el Preclásico Tardío de acuerdo con los materiales cerámicos identificados como Sierra Rojo/Sierra, Polvero Negro/ Polvero y Flor Crema/Flor (TP4). Dos muestras de carbono 14 datadas apoyan tal interpretación: $198-36$ a.C. con $91.6 \%$ en rango de probabilidad y 205-40 a.C. con 93\%. La Plaza H fue remodelada con otro piso de estuco (Piso 5) durante el Clásico Temprano (250-400 d.C.).

Las excavaciones sugieren que durante estos dos periodos las áreas alrededor de las Plazas Central y H, que ahora se denominan Gran Plaza y Plazas E y F, eran zonas inundables ya que el material parental hallado fue un suelo limoso de tipo luvisol (TP2, 3, 8 y 9).

Debido al límite de las excavaciones, los cálculos del área total de las plazas e inversión de trabajo en ellas no reflejarían con certeza el número absoluto de participantes en los rituales públicos y en las construcciones. En los cálculos del área total de las plazas no se incluyeron las plataformas que posiblemente fueron utilizadas para las danzas y la colocación de objetos rituales como vasijas, comidas y bebidas (Grube, 1992). Es muy probable que las extensiones de cada plaza fueran transformadas a través del tiempo y sus usos fueran múltiples, con diferentes clases de participantes y objetos. Particularmente, los cálculos sobre la inversión de trabajo son resultados preliminares, ya que no hemos excavado toda la plaza. El cálculo sólo se basó en el área de cada plaza multiplicada por la profundidad de los estratos correspondientes; posteriormente se sumó el volumen de todas las plazas por periodo.

No obstante, estos cálculos nos proporcionan una idea sobre en qué período las plazas y los rituales públicos asociados fueron más relevantes. Además, nos permiten evaluar cuantitativamente su capacidad. Aunque los cálculos se basaron en el plano más reciente del sitio, el área total de las plazas durante los dos periodos era de $9129 \mathrm{~m}^{2}$ (figura 4) y la inversión de trabajo por metro cúbico fue de $6777.65 \mathrm{~m}^{3}$ en el Preclásico Tardío y $2316.8 \mathrm{~m}^{3}$ en el Clásico Temprano, ambas cifras relativamente bajas en comparación con la del Clásico Medio (figura 5).

\section{Clásico Medio (400-600 d.C.)}

El paisaje urbano del Grupo Principal de El Palmar durante el Clásico Medio cambió de manera dramática. Las excavaciones y el análisis de los materiales indican que la Gran Plaza, la Plaza K'awiil y las Plazas E y G fueron construidas en ese periodo, además de que la Plaza Central se elevó casi un metro. Nivelando el suelo de luvisol, en la Gran Plaza y en la Plaza E se construyó un delgado piso de estuco sin colocar relleno de grava. El proyecto arquitectónico sobresaliente 


\begin{tabular}{|l|r|r|r|r|}
\hline \multicolumn{2}{|c|}{} & \multicolumn{3}{|c|}{ Capacidad Estimada de Plaza } \\
\hline Nombre de Plaza & Área $\left(\mathrm{m}^{2}\right)$ & $0.46 \mathrm{~m}^{2} /$ persona & $1 \mathrm{~m}^{2} /$ persona & $3.6 \mathrm{~m}^{2} /$ persona \\
\hline Gran Plaza & 14135 & 30728 & 14135 & 3926 \\
\hline Plaza Central & 6674 & 14509 & 6674 & 1854 \\
\hline Plaza E & 9096 & 19774 & 9096 & 2527 \\
\hline Plaza F & 6134 & 13335 & 6134 & 1704 \\
\hline Plaza G & 1230 & 2673 & 1230 & 341 \\
\hline Plaza H & 2455 & 5336 & 2455 & 681 \\
\hline Plaza K'awiil & 3161 & 6872 & 3161 & 878 \\
\hline Plaza López & 890 & 1935 & 890 & 247 \\
\hline Área total & 40090 & 87152 & 40090 & 11136 \\
\hline
\end{tabular}

FIgura 4. Tabla de la capacidad estimada en las plazas del Grupo Principal de El Palmar

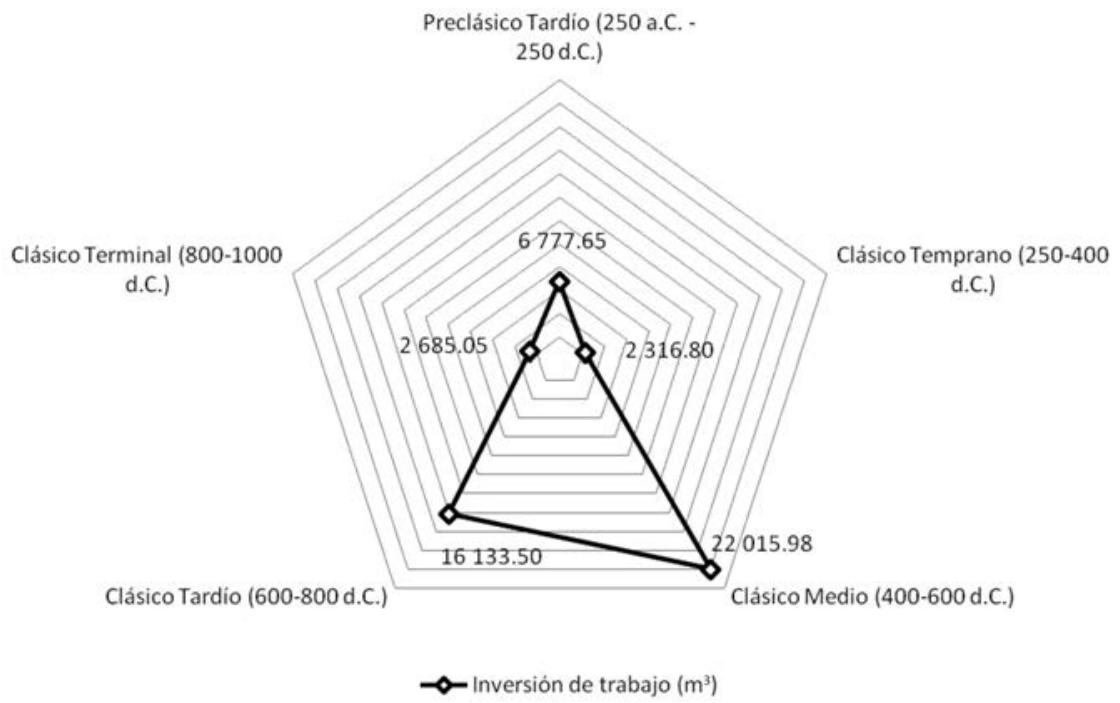

Figura 5. Gráfica de la inversión de trabajo $\left(\mathrm{m}^{3}\right)$ estimada en El Palmar

del Clásico Medio fue, sin duda, la edificación de la Estructura PM3 en la Plaza $\mathrm{G}$ (tomando como base los resultados del TP6). El sondeo estratigráfico sugiere que el piso más antiguo (Piso 3) alcanzó $10 \mathrm{~m}$ de elevación desde la superficie de la Plaza E. Tres muestras de carbono 14 tomadas del relleno constructivo de la Plaza G lo datan entre el 196 y el 353 d.C. con $98.20 \%$ en rango de probabili- 
dad; entre el 421 y el 533 d.C. y entre el 425 y el 533 d.C. con $68.20 \%$ en rango de probabilidad. Estas últimas muestras, en conjunto con el análisis cerámico, revelan que la Plaza G fue construida entre los años 425 y 533 d.C.

Si bien la Plaza G fue el proyecto arquitectónico más voluminoso, la Gran Plaza (TP3 y TP9) fue diseñada con mayor extensión con el fin de acomodar a la mayor población en un evento público. En el relleno de la Gran Plaza no se encontraron materiales cerámicos diagnósticos del Clásico Medio, sino del Clásico Temprano (250-600 d.C.). Sin embargo, el análisis preliminar del estuco por medio de la catodoluminisencia realizado por Tatsuya Murakami indicó que el primer piso de la Gran Plaza fue construido durante el primer periodo mencionado, ya que la tecnología de los pisos más antiguos en ésta y en la Plaza G fue idéntica a la del Clásico Medio. Además se encontró un artefacto lítico del tipo "cepillo" (Domed Smoother) (figura 6) en el mismo relleno, que Rovner, Lewenstein y Nelson (1997) señalan como material diagnóstico del principio del Clásico Tardío. Es decir, se puede interpretar la emergencia de la mencionada plaza a partir del Clásico Medio. Con base en todos los resultados anteriores, sugerimos que la Gran Plaza, la Plaza G y probablemente la Plaza E fueron construidas durante el Clásico Medio.

En el caso de la Plaza K'awiil, el periodo constructivo tiene una fecha aún más exacta. Durante la excavación de prueba (TP5) se encontró un escondite (Escondite 3) o cache asociado al Altar 10, debajo del piso más antiguo de la plaza (figuras 7 y 8). Debido a la ausencia de una intrusión, creemos que el ente-
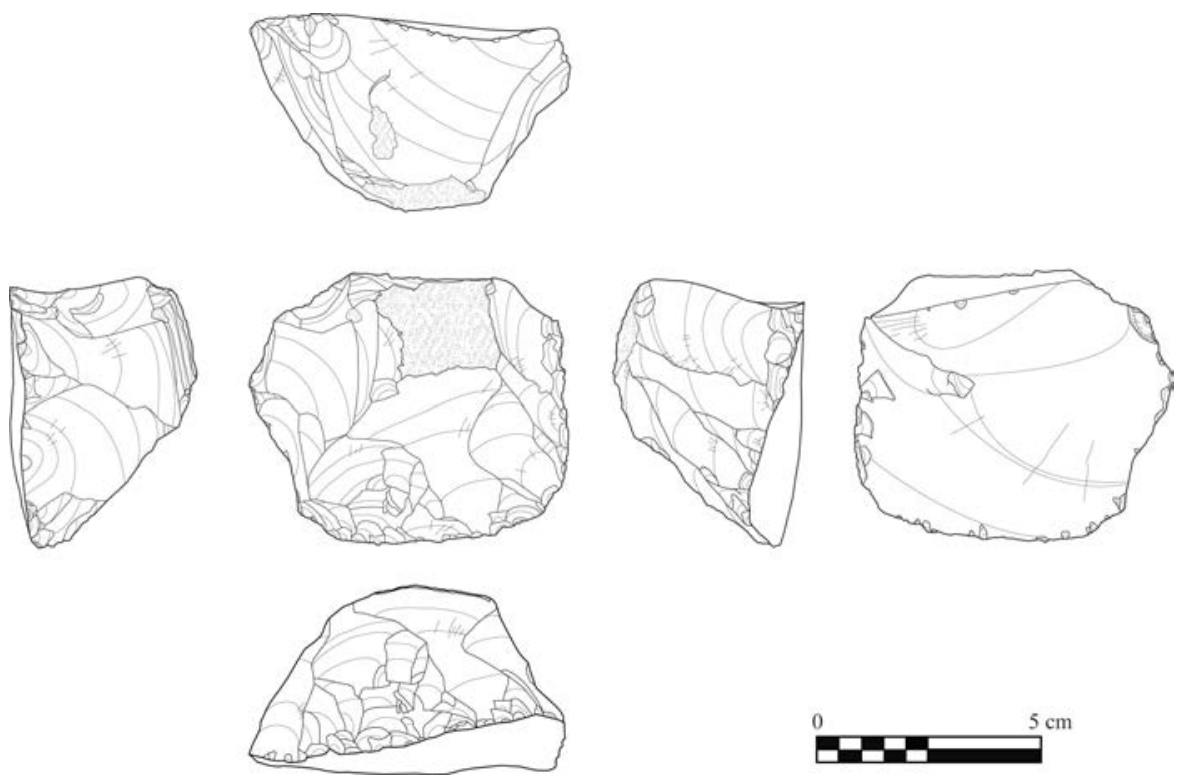

Figura 6. Herramienta lítica denominada "cepillo" (Domed Smoother), dibujado por Kenichiro Tsukamoto 
rramiento del Escondite 3 y la construcción de la plaza fueron contemporáneos. $\mathrm{Si}$ se considera que el Altar 10 contiene una Rueda Calendárica que registra la fecha del 20 de marzo del 554 d.C., la construcción de la Plaza K'awiil en el siglo sexto es contemporánea a la de las tres plazas anteriores.

El área total de las plazas se extendió $36571 \mathrm{~m}^{2}$, cifra cuatro veces más grande que la de los periodos anteriores (figura 4). Si una persona ocupa un metro cuadrado durante rituales públicos, las plazas pudieron haber acomodado más de 36000 participantes. Asimismo, la inversión de trabajo se incrementó de $9094.45 \mathrm{~m}^{3}$ a $22015.98 \mathrm{~m}^{3}$ en tan sólo 200 años (figura 5).

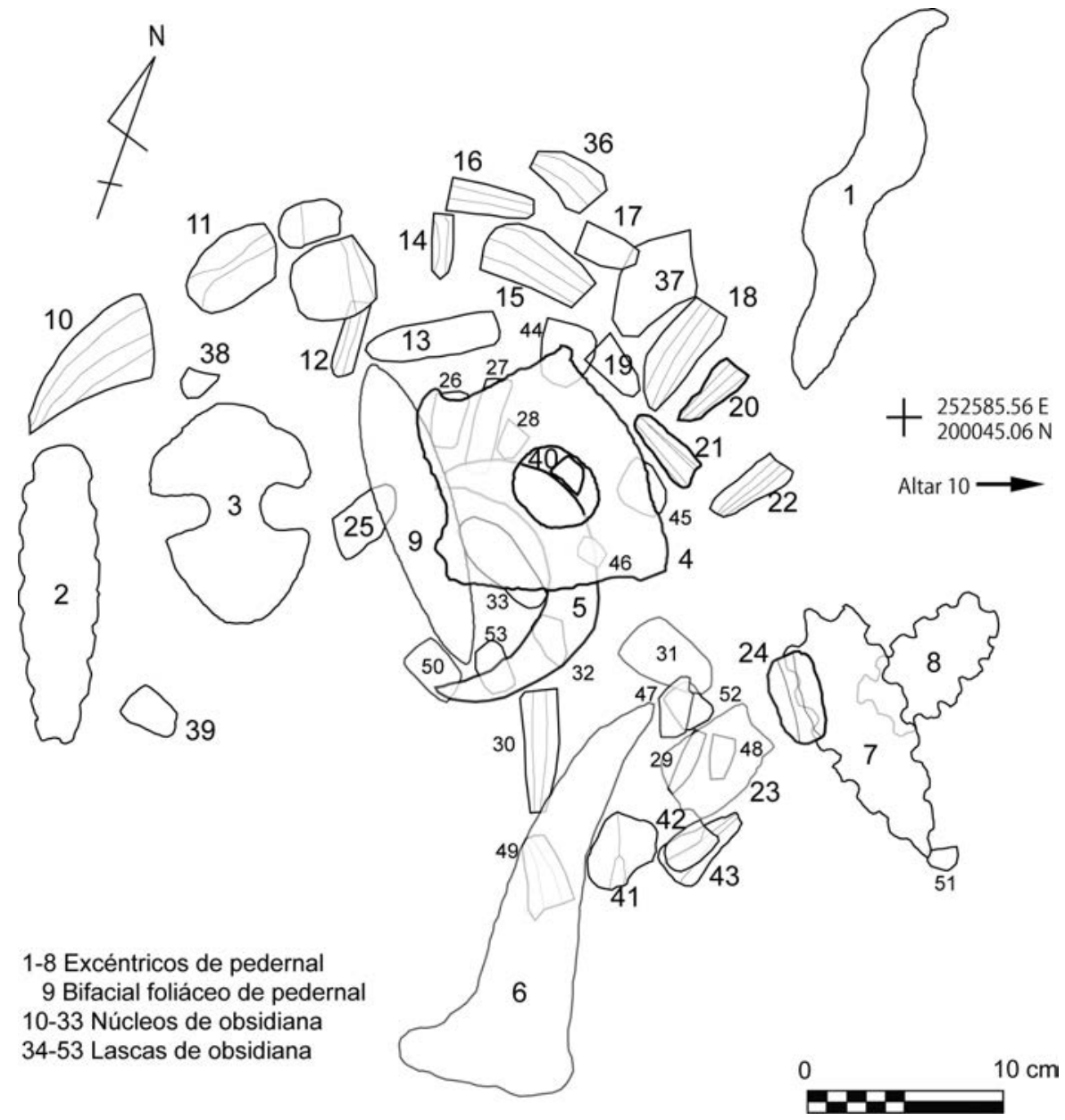

Figura 7. Plano del Escondite 3 descubierto en El Palmar, dibujado por Kenichiro Tsukamoto y Luz Evelia Campaña 


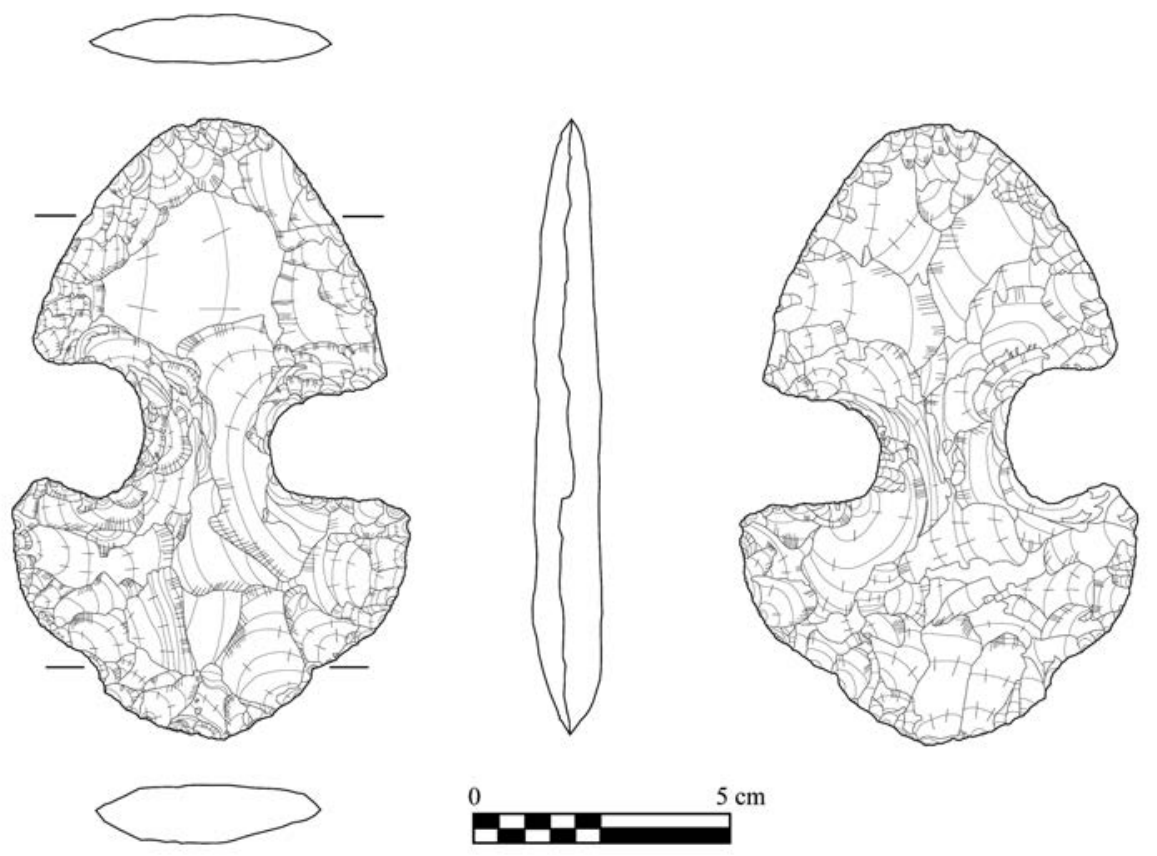

Figura 8. Excéntrico proveniente del Escondite 3 de El Palmar, dibujado por Kenichiro Tsukamoto

Clásico Tardío (600-800 d.C.)

Los mayas de El Palmar continuaron construyendo espacios abiertos, como la Plaza F (TP8) y la Plaza López (TP7) durante el Clásico Tardío (600-800 d.C.), además de remodelar las plazas anteriores. Sin embargo, la dimensión de estas nuevas plazas fue más pequeña. Al mismo tiempo, las élites gobernantes erigieron una gran cantidad de monumentos grabados en la Gran Plaza, la Plaza Central y la Plaza E. El área total de las plazas aumentó a $43595 \mathrm{~m}^{2}$ con la construcción de las Plazas F y López (figura 4), pero la inversión de trabajo disminuyó a 16133.5 $\mathrm{m}^{3}$ (figura 5).

Clásico Terminal (800-1000 d.C.)

La construcción o remodelación de plazas disminuyó de manera significativa durante el Clásico Terminal, aunque las estelas con inscripciones sugieren que la Gran Plaza, la Plaza E y la Plaza K'awiil siguieron funcionando para ceremonias conmemorativas en los años 800, 820 y 884 d.C., respectivamente. La Plaza H es 
la única que presenta evidencia de la remodelación, con una inversión laboral de $2685.05 \mathrm{~m}^{3}$ (figura 5).

\section{Construcciones y remodelaciones de plazas como una estrategia política}

Los resultados de las excavaciones de prueba y del análisis de los materiales señalan que las construcciones y remodelaciones de las plazas eran importantes para la sociedad de El Palmar. Nosotros creemos que la construcción intensiva de las plazas mayores refleja una estrategia de las élites gobernantes para organizar a la sociedad. En periodos premodernos, los espectáculos en un amplio espacio abierto, como la plaza, jugaban un papel preponderante para la organización política (Connerton, 1989; Foucault, 1984, 1995[1978]; Inomata, 2006; Joyce, 2004; Low, 1995; Moore, 1996). Es posible que la construcción y remodelación de las plazas públicas fueran proyectos importantes para las élites gobernantes de El Palmar, quienes requerían manifestar su conocimiento especial en la ejecución de los rituales para establecer contacto con los ancestros y las deidades. Investigaciones previas sugieren que, en Mesoamérica, ciertos saberes como la comunicación con los ancestros y la escritura jeroglífica eran exclusivos de las élites gobernantes, y mediante ellos reclamaban y sostenían su poder político con manipulaciones ideológicas y religiosas (Houston, Robertson y Stuart, 2000; Inomata, 2001; Joyce y Winter, 1996; McAnany, 1993, 1995).

Bajo esta condición, las plazas fueron los escenarios donde las élites gobernantes legitimaban su autoridad política a través de prácticas rituales. En este sentido, consideramos que el número de plazas en un sitio y su continua remodelación revela que las relaciones de poder entre las élites gobernantes y otros segmentos sociales fueron equilibradas por medio de rituales públicos celebrados en los espacios abiertos (Scott, 1998). Además, el súbito incremento de la capacidad para acomodar a los participantes en las plazas sugiere la transformación del sitio, de pueblo local a centro regional, ya que los espacios para la realización de espectáculos regularmente son diseñados en función del número de participantes. La construcción de nuevos espacios públicos, como la Gran Plaza y la Plaza E, indican que El Palmar se convirtió en un centro regional que albergaba a un gran auditorio que participaba del teatro político de las ceremonias conmemorativas.

Otros segmentos sociales no eran receptores pasivos de la ideología y dominación, sino sus evaluadores. Sus resultados (aceptación o rechazo) influían en su participación en otras construcciones (Geertz, 1980; Inomata, 2006), ya que los rituales públicos no funcionan con la ausencia del público: este y los protagonistas interactúan mutuamente para crear un ambiente de espectáculo.

Mientras las regiones colindantes se involucraron en las interacción política debido a la confrontación entre Tikal y Calakmul a partir del Clásico Medio 
(Adams, 1999; Martin, 2000; Stuart, 2000; Wright, 2005a y b), las remodelaciones de la Gran Plaza, la Plaza E y la Plaza G, así como las numerosas erecciones de las estelas y altares sugieren que los rituales-espectáculos públicos fueron exitosos y ayudaron a cimentar la identidad social. Particularmente, la edificación de la Plaza $\mathrm{G}$ como un espacio exclusivo de las élites revela que los otros grupos sociales consintieron su legitimación política y poder, y que aquellas consolidaban identidades distintas a las de los rituales públicos.

La construcción de plazas y de templos piramidales no sólo fue importante desde el punto de vista arquitectónico, sino también ideológico, pues convirtieron la ciudad en un lugar mitológico. Garza (2010: 43) sugiere que la plaza y la pirámide son símbolos de la tierra cuadrangular y de la montaña sagrada (véase también Ashmore, 1991, 2004; Brady y Ashmore, 1999; Schele y Freidel, 1990). Esta cosmovisión inscrita en el paisaje y las ceremonias conmemorativas repetitivas pudieron haber ayudado a producir y reproducir la memoria social (Connerton, 1989; Van Dyke y Alcock, 2003). Con base en el análisis de la sicología política, Caspary (1993) sugiere que la obediencia al poder ideológico con representaciones simbólicas tiende a desarrollarse durante periodos de crisis (véase también Joyce y Winter, 1996: 35; Volkan, 1985). Es decir, la intensa interacción política de las regiones cercanas pudo haber servido para cimentar la ideología política de El Palmar a partir del Clásico Medio, y la construcción y remodelación de las plazas grandes y privadas fue una respuesta de la solidaridad y la obediencia social.

\section{Conclusión}

La excavación y el análisis de los materiales evidencian que las grandes plazas, como la Gran Plaza y las Plazas E, G y K'awiil fueron construidas durante el periodo Clásico Medio (400-600 d.C.). Su construcción, junto con la de los templos piramidales monumentales, sugiere que la celebración de rituales públicos - como teatro político- era un elemento importante para las élites gobernantes, quienes legitimaban las autoridades políticas a través de los espectáculos y la materialización de ellos en los monumentos grabados. El fenómeno del proyecto arquitectónico en El Palmar es parecido al de Río Azul (Adams, 1999) y Uaxactún (Valdés y Fahsen, 1995). No obstante, por el momento la información limita la interpretación y aún no es posible revelar la relación de El Palmar con las superpotencias Tikal y Calakmul. Sólo podemos anotar que, al igual que esos sitios, el periodo Clásico Medio fue fundamental para su organización política y espacial. 


\section{BIBLIOGRAFÍA}

Adams, Richard E. W.

1999 Rio Azul: An Ancient Maya city. Norman: University of Oklahoma Press.

Adams, Richard E. W. y Richard C. Jones

1981 "Spatial Patterns and Regional Growth among Classic Maya Cities", American Antiquity, 46 (2): 301-322. Washington, D. C.: Society for American Archaeology.

Aimers, James J. y Prudence M. Rice

2006 "Astronomy, Ritual, and the Interpretation of Maya "E-Group" Architectural Assemblages”, Ancient Mesoamerica, 17: 79-96. Cambridge: Cambridge University Press.

Ashmore, Wendy

1991 "Site-planning principles and concepts of directionality among the ancient Maya”, Latin American Antiquity, 2 (3): 199-226. Washington, D. C.: Society for American Archaeology.

2004 "Ancient Maya Landscape", Continuities and Changes in Maya Archaeology: Perspectives at the Millennium. Charles W. Golden y Greg Borgstede (eds.). Nueva York: Routledge, 97-11.

Brady, James E. y Wendy Ashmore

1999 "Mountains, Caves, Water: Ideational Landscapes of the Ancient Maya", Archaeology of Landscape: Contemporary Persipective. Wendy Ashmore y Arthur B. Knapp (eds.). Malden [Estados Unidos]: Blackwell Publisher, 124-145.

Bueno, Ricardo

1999 Entre un río de robles: un acercamiento a la arqueología de la región Río Bec. México: Instituto Nacional de Antropología e Historia (Colección Científica, 411).

Campaña, Luz Evelia

2005 “Contribuciones a la historia de Becán”, Arqueología Mexicana, XIII (75): 4853. México: Raíces.

Caspary, William R.

1993 "New Psychoanalytic Perspectives on the Causes of War", Political Psychology, 14 (3): 417-446. Malden [Estados Unidos]: Wiley-Blackwell Publishers.

Clark, John E. y Richard D. Hansen

2001 The Architecture of Early Kingship: Comparative Perspectives on the Origins of the Maya Royal Court. Royal Courts of the Ancient Maya, Volume Two: Data and Case Studies. Colorado: Westview Press.

Connerton, Paul

1989 How Societies Remember. Nueva York: Cambridge University Press. 
Demarest, Arthur A.

1992 "The Dynamics of Galactic Polities", Ideology and Pre-Columbian Civilizations. Arthur A. Demarest y Geoffrey W. Conrad (eds.). Santa Fe: School of American Research Press, 135-157.

Foucault, Michel

1984 "Space, Knowledge, and Power", The Foucault Reader. Paul Rabinow (ed.). Nueva York: Pantheon Books, 239-256.

1995 Discipline and Punish: The Birth of the Prison. Nueva York: Vintage Books.

[1978]

Freidel, David A. y Linda Schele

1988 "Kingship in the Late Pre-Classic Maya Lowlands: The Instruments and Places of Ritual Power”, American Anthropologist, 90: 547-567. Arlington: American Anthropological Association

Garza, Mercedes de la

2010 "El universo temporal en el pensamiento maya”, Arqueología Mexicana 103: 38-44. México: Raíces.

Geertz, Clifford

$1980 \quad$ Negara: The Theatre State in Nineteenth-Century Bali. Princeton: Princeton University Press.

Grube, Nikolai

1992 "Classic May dance: Evidence from hieroglyphs and iconography", Ancient Mesoamerica, 3: 201-218. Cambridge: Cambridge University Press.

Houston, Stephen D.

1998 "Classic Maya Depictions of the Built Environment", Function and Meaning in Classic Maya Architecture: A Symposium at Dumbarton Oaks 7th and 8th October 1994. Stephen D. Houston (ed.). Washington, D. C.: Harvard University Press, 333-372.

Houston, Stephen, John Robertson y David Stuart

2000 "The Language of Classic Maya Inscriptions", Current Anthropology, 41 (3): 321-356. Chicago: Chicago University Press.

Inomata, Takeshi

2001 "Power and Ideology of Artistic Creation: Elite Craft Specialists in Classic Maya Society”, Current Anthropology, 42 (3): 321-349. Chicago: Chicago University Press.

2006 "Plazas, Performers, and Spectators: Political Theaters of the Classic Maya", Current Anthropology, 47 (5): 805-841. Chicago: Chicago University Press.

Joyce, Arthur A.

2004 "Sacred Space and Social Relations in Oaxaca", Mesoamerican Archaeology. Julia A. Hendon y Rosemary A. Joyce (eds.). Malden [Estados Unidos]: Blackwell Publishing, 192-216. 
Joyce, Arthur A. y Marcus Winter

1996 "Ideology, Power, and Urban Society in Pre-Hispanic Oaxaca", Current Anthropology, 37 (1): 33-47. Chicago: Chicago University Press.

Joyce, Rosemary A.

2001 "Planificación urbana y escala social: reflexiones sobre datos de comunidades clásicas en Honduras", Reconstruyendo la ciudad maya: el urbanismo en las sociedades antiguas. Andrés Ciudad, María Josefa Iglesias y María del Carmen Martínez (eds.). Madrid: Sociedad Española de Estudios Mayas (Publicación 6), 123-136.

Laporte, Juan Pedro y Vilma Fialko

1995 "Un reencuentro con Mundo Perdido, Tikal, Guatemala”, Ancient Mesoamerica, 6: 41-94. Cambridge: Cambridge University Press.

Low, Setha M.

1995 "Indigenous Architecture and the Spanish American Plaza in Mesoamerican and the Caribbean”, American Anthropologist, 97 (4): 748-762. Arlington: American Anthropological Association

Martin, Simon

2000 “Los Señores de Calakmul”, Arqueología Mexicana, VII (42): 40-45. México: Raíces.

McAnany, Patricia A.

1993 "The Economics of Wealth among Eighth-Century Maya Households", Lowland Maya Civilization in the Eight Century A.D.: A Symposium at Dumbarton Oaks 7th and 8thOctober 1989. Jeremy A. Sabloff y John S. Henderson (eds.). Washington, D. C.: Dumbarton Oaks Research Library and Collection, 6579.

1995 Living with Ancestors: Kingship and Kingship in Ancient Maya Society. Austin: University of Texas Press.

Moore, Jerry D.

1996 Architecture \& Power In the Ancient Andes: The Archaeology of Public Buildings. Cambridge: Cambridge University Press.

Restall, Matthew

2001 "The People of the Patio: Ethnohistorical Evidence of Yucatec Maya Royal Courts", Royal Courts of the Ancient Maya, Vol. 2. Takeshi Inomata y Stephen D. Houston (eds.). Boulder [Estados Unidos]: Westview Press, 335-377.

Ringle, William M. y George J. Bey III

2001 "Post-Classic and Terminal Classic Courts of the Northern Maya Lowlands", Royal Courts of the Ancient Maya, vol 2. Takeshi Inomata y Stephen D. Houston (eds.). Boulder [Estados Unidos]: Westview Press, 266-307. 
Rovner, Irwin, Suzanne M. Lewenstein y Fred W. Nelson

1997 Maya stone tools of Dzibilchaltún, Yucatán, and Becán and Chicanná, Campeche. Nueva Orleans: Tulane University, Middle American Research Institute.

Schechner, Richard

1985 Between Theater and Anthropology. Filadelfia. University of Pennsylvania Press.

Schele, Linda y David Freidel

1990 A Forest of Kings: The Untold Story of The Ancient Maya. Nueva York: Quill William Morrow.

Scott, James C.

1998 Seeing Like A State: How Certain Schemes To Improve the Human Condition Have Failed. New Haven / Londres: Yale University Press.

Sharer, Robert J. y Charles W. Golden

2004 "Kingship and Polity: Conceptualizing the Maya Body Politic", Continuities and Changes in Maya Archaeology: Perspectives at the Millennium. C. W. Golden y G. Borgstede (eds.). Nueva York: Routledge, 23-50.

Šprajc, Ivan

2008 Reconocimiento arqueológico en el sureste del estado de Campeche, México: 1996-2005. Ljubljana [Eslovenia]: Centro de Investigaciones Científicas de la Academia Eslovena de Ciencias y Artes (British Archaeological Reports, International Series 1742. Paris Monographs in America Archaeology, 19).

Stuart, David

2000 “' “The Arrival of Strangers': Teotihuacan and Tollan in Classic Maya History”, Mesoamerican's Classic Heritage: From Teotihuacan to the Aztecs. David Carrasco, Lindsay Jones y Scott Sessions (eds.). Niwot: Colorado University Press, 465-513.

Thompson, J. Eric S.

1936 "Exploration in Campeche and Quintana Roo and excavations at San José, British Honduras", Carnegie Institution of Washington Year Book 35. Washington, D. C.: Carnegie Institution, 125-128.

Tsukamoto, Kenichiro y Javier López Camacho

2007 "El Palmar: una ciudad ubicada en una antigua frontera maya", Antropología e Historia, por sus especialistas, vol. 1. Campeche: Consejo Nacional para la Cultura y las Artes / Instituto Nacional de Antropología e Historia, 20-21.

Tsukamoto, Kenichiro, Javier López Camacho y Octavio Q. Esparza Olguín 2010 "El Palmar, Campeche”, Arqueología Mexicana, 17(101): 72-77. México: Raíces.

Turner, Victor

1986 From Ritual to Theatre and Back. Nueva York: Performing Arts Journal Publications. 
Valdés, Juan Antonio y Federico Fahsen

1995 "The Reigning Dynasty of Uaxactun during the Early Classic: The Rulers and the Ruled", Ancient Mesoamerica, 6: 197-219. Cambridge: Cambridge University Press.

Van Dyke, Ruth M. y Susan E. Alcock

2003 "Archaeologies of Memory: An Introduction", Archaeologies of Memory, pp. 1-13; Ruth M. Van Dyke y Susan E. Alcock (eds.). Malden [Estados Unidos]: Blackwell Publishers.

Volkan, Vamik D.

1985 "The Need to Have Enemies and Allies: A Developmental Approach", Political Psychology, 6 (2): 219-247. Malden [Estados Unidos]: Wiley-Blackwell Publishers.

Wright, Lori E.

2005a "Identifying Immigrants to Tikal, Guatemala: Defining local variability in strontium isotope ratios of human tooth enamel", Journal of Archaeological Science, 32: 555-566. Londres: Elsevier.

2005b "In Search of Yax Nuun Ayiin", Ancient Mesoamerica, 16: 89-100. Cambridge: Cambridge University Press. 